\title{
FORAGING INTERFERENCE AND FRUIT PALATABILITY IN PTEROPUS SCAPULATUS (MEGACHIROPTERA: PTEROPODIDAE): \\ MANAGEMENT IMPLICATIONS
}

\author{
by
}

Sarah Jessie Robbins

\begin{abstract}
A thesis submitted to the Victoria University of Wellington in fulfillment of the requirements for the degree of Master of Conservation Science
\end{abstract}

Victoria University of Wellington

2004 


\section{ABSTRACT}

The "residents and raiders" theory emphasizes the importance of conspecific feeding interference in seed dispersal by frugivorous megachiropterans. Agonistic interactions at fruiting trees frequently result in the "ejection" of one bat, which has often first obtained some fruit. The ejected bat then flies to an unoccupied tree, thus dispersing nonconsumed seeds. For seeds too large to be swallowed this may be the sole method of dispersal. Raiding and subsequent seed spread only occur when bat populations are sufficiently large, relative to resources, to cause competition for food. If competition similarly affects nectarivorous bats and their floral resources, decline in a bat population could lead to reduced seed set and genetic diversity in their food-plant species. Pteropus scapulatus (Little Red Flying Fox) visit the flowers of dozens of Australian and New Guinean species and are believed to play an important role in the pollination of Eucalyptus and Melaleuca. Feeding-interference and raiding “success” by P. scapulatus eating fruit at Wellington Zoo (New Zealand) was studied to infer the importance of population size on cross-pollination. Decrease in population-to-resource ratio was correlated with decrease in raiding frequency, suggesting a decreased likelihood of cross pollination. These results highlight the value of management practices that promote the maintenance of large populations of nectarivorous megachiropterans. The effects of dominance and food preference on these behaviours were also evaluated. Dominance was inversely correlated to both dispersal and maturity. Contrary to many reports, females were not always subordinate to males. Fruit preference data may be useful for selecting “distracter” trees in orchards prone to damage by fruit bats and for ex situ husbandry concerns. Implications for population-, orchard-, and captive-management are discussed. 


\section{ACKNOWLEDGMENTS}

Completion of this study and programme would have been impossible without the time and technical, academic, emotional, and financial support of many people. I thank the Wellington Zoo staff, particularly Geert Van Eyken, Ian Butcher, and Mauritz Basson, for allowing me to perform (and complete) this project and for their cooperation and patience. The contributions of the ecology/biology graduate student seminar group, Mary McIntyre, Ben Bell, and, especially, Tim Markwell to the intellectual quality of this work are gratefully acknowledged. John Haywood is a statistical marathon man. I am also indebted to Hugh Spencer of the Australian Tropical Research Station for introducing me to flying foxes. I could not have completed this programme without the financial support of my father Joseph Robbins and the unwavering emotional support of my parents, brothers, grandparents, friends, and my partner Brian Meffle. Finally, I thank the bats, who were not always cooperative but always themselves. 
Table of Contents

Abstract ii

Acknowledgments iii

Chapter 1: GENERAL INTRODUCTION 1

Chapter 2: FOOD PREFERENCE OF PTEROPUS SCAPULATUS 10

Chapter 3: RESIDENTS VERSUS RAIDERS: THE ROLE OF FEEDING 25

INTERFERENCE IN POLLEN DISPERSAL BY PTEROPUS SCAPULATUS

Chapter 4: DOMINANCE RELATIONSHIPS IN PTEROPUS SCAPULATUS 40

Chapter 5: WELLINGTON ZOO MANAGEMENT RECOMMENDATIONS 49

Chapter 6: GENERAL CONCLUSION $\quad 69$

$\begin{array}{ll}\text { References } & 79\end{array}$

Appendix $\quad 84$

Diet species list 93

Recommended reading list for captive management 115 


\section{Chapter 1: GENERAL INTRODUCTION}

This thesis uses two captive Little Red Flying Fox (Pteropus scapulatus) populations at Wellington Zoo (New Zealand) to improve our understanding of fruit bat behaviour. This thesis aims to provide quantified behavioural and food-preference data with the objective of determining how these factors influence foraging behaviour. Fruit preference tests were performed using known diet species to provide a quantified index of palatability. This information can be used to facilitate husbandry training and to suggest appropriate pairings for distracter trees in orchards in its natural range, Australia and New Guinea. Feeding interference behaviours were recorded to explore the relationships among a bat's demographic characteristics, ecological role, and position in the social hierarchy. These relationships have important implications for management of both wild and captive flying fox populations.

\section{THE STATUS AND PROTECTION OF FLYING FOXES}

All extant Megachiroptera belong to the Pteropodidae Family (Jones et al. 2002). Some use insects but most rely on plants for food. Pteropus is the most speciose megachiropteran genus (Jones et al. 2002). This genus can be found from Madagascar to Fiji and southern Asia to southern Australia (Hall \& Richards 2000, p. 11). They and some other Pteropodidae are commonly referred to as flying foxes because of their long, dog-like faces. Many Pteropus are island endemics and often the only indigenous mammals or pollinators on an island (Cox et al. 1991; Meehan et al. 2002; Altringham 1996). Several species are extinct or endangered (Baillie \& Groombridge 1996; IUCN 2002; CITES 2003). 
Australia has thirteen Megachiroptera. Of the four extant Pteropus present on the mainland, two species, P. alecto (the Black Flying Fox) and P. poliocephalus (the Grey-headed Flying Fox), are dietary generalists. P. conspicillatus (the Spectacled Flying Fox) is primarily frugivorous and P. scapulatus (the Little Red Flying Fox) is considered nectarivorous (Richards 1995) but eats fruit in captivity and occasionally in the wild. Declines in Pteropus populations have been evident at least since the late 1920s (Ratcliffe 1932, p. 53-54). In addition to other factors, such as habitat loss and introduced pathogens, culling by orchardists has placed strong pressure on many Australian flying fox populations.

\section{FLYING FOXES AND AGRICULTURE}

To understand how flying fox foraging affects seed and pollen dispersal we must understand how the bats choose between the available diet options. As discussed below, the majority of the Australian Pteropus diet is composed of native species but cultivated fruit can be vital under some conditions.

Orchardists attribute enormous economic losses (AU\$20 million) to bat damage (Tidemann et al. 1997). Such figures must be viewed with scepticism: damage caused by other animals or even weather may be attributed to them and, in instances of actual flying fox attack, they may be blamed for a greater proportion of the damage than they performed (Fujita \& Tuttle 1991), the wrong Pteropus species may be blamed as orchardists often misidentify the raiding species (Richards 1991), estimates may be exaggerated or based on exceptional years, or, when given a dollar value, damage may be misrepresented by use of market-value figures that do not indicate lost income after processing and third-party costs (Pallin 1990; Jacobsen 1979 in Wahl 1994). 
Unfortunately, ecological value is not nearly so easy to establish as agricultural cost. Whilst the presence of flying foxes may be of concern to orchardists, their absence is of great concern to some economists and many ecologists. Many native Australian trees have developed flowering and fruiting characteristics specifically attractive to bats (Richards 1990). P. scapulatus is believed to be the pollinator for many commercially important timber trees (Hall 1990). In Southeast Asia, Megachiroptera pollinate or disperse the seeds of plants used to make nearly 450 products (Fujita \& Tuttle 1991). Durian (Durio zibethinus) is pollinated almost exclusively by them; the fruit of this one species is worth at least US\$120 million annually in Southeast Asia (Fujita \& Tuttle 1991). Pteropus are responsible for $80-100 \%$ of the seed rain in lowland Samoan rainforest, which can be up to 36 fruits $/ \mathrm{m}^{2}$ in non-roost areas (Cox et al. 1992).

Additionally, flying foxes perform a service that is far more valuable to orchardists than the fruit they ruin for market. The tiny population of the Endangered $P$. mariannus (IUCN 2002) is unable to prevent another source of crop damage: fruit flies and fungi breeding on fruit that would have been consumed by the bats have become so abundant that fresh fruit has to be imported to Guam (Anon. 1988). In Southeast Asia, but not Australia, many commercially important plants and their wild progenitors continue to be pollinated primarily by bats (Fujita \& Tuttle 1991).

Orchard raiding is closely tied to the abundance of native resources (Tidemann \& Nelson 1987). P. scapulatus is most likely to attack orchards following weather irregularities that affect native food availability. Heavy rains, which dilute nectar and can cause trees to divert energy to growth rather than blossom (Fleming \& Robinson 1987; Parry-Jones \& Martin 1987), and drought (Richards 1991; Ratcliffe 1931, p. 33, 
37) are often associated with $P$. scapulatus damage. The droughts that reduce the abundance of native foods also reduce orchard productivity so that damage by bats affects an already diminished crop (Nelson 1989). The low nutritive value of cultivated fruit necessitates even greater consumption (Fleming \& Robinson 1987; Nelson et al. 2000), which further compounds losses.

Owners of most small orchards can use exclusion netting to protect their trees from bats as well as from bird and hail damage. Some of those who have not enclosed their orchards use the traditional method of shooting bats as well as the more creative, but equally lethal, methods of attack by dogs and electrocution with the so called "Fire Fox” (Tudge 1994; see Fleming \& Robinson 1987, Hall \& Richards 1987, Loebel \& Sanewski 1987, Ratcliffe 1931, p. 67-76 and Vardon et al. 1997 for orchard deterrence and flying-fox removal reviews). Others have suggested the use of "distracter trees," plants that provide a food source favoured over nearby crops. This method requires synchrony of crop and "distracter" ripening and knowledge of the Pteropus "hierarchy of preference” (Parry-Jones \& Augee 2001, p. 54). Chapter 2 investigates the relative preference for seven cultivated fruits using captive-bred $P$. scapulatus. The influence of food preference on foraging behaviour and resultant seed/pollen dispersal is explored.

\section{CROSS POLLINATION BY NECTARIVOROUS BATS}

Seed and pollen distribution by flying foxes is linked to their foraging patterns. Megachiroptera visit (and potentially pollinate) the flowers of at least 75 genera belonging to 29 families (Marshall 1985). Although visitation does not necessarily lead to pollination, Australian Pteropus are likely to be vital to the transfer of pollen for outcrossing in eucalypt forests and woodlands (Hall \& Richards 2000, p. 79; Eby 1991). 
Support for cross pollination by pteropodid bats has been well demonstrated by several researchers, such as Altringham (1996, p. 178), Gould (1978), and Elmqvist et al. (1992). Flying foxes carry a greater pollen load than any other Australian vertebrate pollinator and have even greater pollen loads than those published for other bats (Hall \& Richards 2000, p. 79-80) so that even when a species is visited by other taxa, the number of species visited by pteropodids suggests that interrupting their services to floral reproduction could cause enormous disruption to an ecosystem.

Resource quantity and quality affect the probability of cross pollination. Nectar parceling (Gould 1978) and non-synchronous blooming encourage cross pollination at the expense of the pollinator's net energy gain (Heinrich \& Raven 1972). These "plant factors" interact with "bat factors," social and foraging behaviours, to determine how bats spread pollen and seed. The residents vs. raiders pattern is believed to underlie much of Pteropus cross-pollination and large-seed dispersal (Richards 1990). The pattern, which relates feeding interference and resource defence to pollen and seed spread, is discussed more thoroughly in Chapter 3.

\section{SOCIAL HIERARCHIES IN PTEROPUS POPULATIONS}

To understand how seed and pollen are distributed by certain foraging behaviours it is important to determine which bats are performing the distribution and what circumstances increase distribution. Several Pteropus species have been reported to establish and defend small territories at the day roost and/or feeding location (McWilliam 1985-1986; Brooke 2001; Elmqvist et al. 1992; Mickleburgh et al. 1992, p. 129; Nelson 1965a; Richards 1990; Gould 1978). In this paper, "dominance” is the ability to exclude other bats from roost or food resources that they desire. In small 
groups, such as most captive bat colonies, relative dominance may be recognized as a characteristic of each individual. However, in most wild colonies, which can include more than 1 million bats (Hall 1987), it is unlikely that any two bats would remember which was dominant. As physical encounters are unusual (Markus 2002; Trewhella et al. 2001), it would seem that certain characteristics (sex, size, maturity, behavioural display, etc.) cue potential combatants to the likely outcome of a fight, thus limiting the need for proof (or memory) of superior fighting skills. Species that use traits to indicate the probable outcome of an aggressive interaction benefit by avoiding the high energy cost and potential injury of combat. Changes in individual or group factors, such as maturation or the death of a dominant animal, may require physical conflict so that each individual can discern his or her own ability to maintain exclusive access to a resource. As with the establishment of a territory (Nelson 1965a), a high initial investment is needed to determine relative dominance but little energy is needed to maintain its "boundaries."

Relative dominance varies with maturity (Nelson 1965a), sex (Trewhella et al. 2001), possibly size (Law 1995) and harem size (Nelson 1965a), and, in interspecific conflicts, species (Trewhella et al. 2001). In the above studies, adults are dominant to juveniles, males are dominant to females, and larger animals may be dominant to smaller ones. Nelson (1965a) described the dominance hierarchy of male P. poliocephalus during the breeding season as determined by the number of mates. He considered polygamous males to be dominant to monogamous males and non-mated males to be subordinate to both polygamous and monogamous males. Exclusion from feeding and roosting areas can also extend to other species (Baker \& Harris 1957 in Gould 1978; 
Trewhella et al. 2001). Chapter 4 probes the patterns underlying the relationship between demographic characteristics of captive $P$. scapulatus and their ability to monopolize resources.

During this study, the bats were kept in two enclosures. They have since been moved into a single enclosure. Chapter 5 is a critical examination of this enclosure at Wellington Zoo and of published accounts of similar enclosures and the management policies of other institutions. This chapter aims to further the conservation of Pteropus species by improving the physiological and psychological well being of captive flying foxes and by increasing public awareness of their ecological importance. Physical conditions, enrichment, diet, and public education are among the areas explored.

\section{SUMMARY OF CHAPTER CONTENTS}

This paper reviews the feeding and feeding-interference patterns of megachiropterans with the objective of determining how these factors influence foraging behaviour and resultant seed and pollen dispersal. Chapter 2 expands our understanding of Pteropus scapulatus fruit preference through analysis of a three-choice test series of seven cultivated fruits commonly consumed by both wild and captive bats. The link between population size, territorial behaviours at feeding trees and seed dispersal is modelled in Chapter 3 using rates of food removal from the areas proximal to feeding stations under various group sizes. Data from the participants in these territorial interactions is used in Chapter 4 to show that dominance is closely related to maturity but is influenced less by sex than previously believed. Recommendations for changes to Little Red Flying Fox care specific to Wellington Zoo are based on a review of the literature and on the conclusions of the present study. They can be found in Chapter 5 . 
Additional resources for the management of captive Megachiroptera follow the Appendix.

\section{GENERAL METHODS}

\section{SUBJECTS}

Group 1 consisted of 6 adults ( 1 male: 5 females) and 1 juvenile (female, $>1$ year old); Group 2 had 8 adults (4:4) and 3 independent juveniles (2:1; all < 1 year old). All were captive bred: the male and one adult female in Group 1 were bred in Currumbin Sanctuary (Australia) and transferred to Wellington Zoo in 1991 (data were collected April - May 2003); the rest were bred at Wellington Zoo from Currumbin Sanctuary bats. Mating behaviour was not observed during the study period but adult females may have been in the early stages of pregnancy. Demographic and participation information can be found in Tables 1.1 and 1.2 in the Appendix.

Due to death and veterinary procedures, group size changed during the study. The juvenile female in Group 2 died (asphyxiation by soil) between Days 11 and 12; an adult female in Group 2 also died (cause unknown, not pregnant) and four bats from Group 1 and two bats from Group 2 were removed for veterinary care (tag-related injuries) after Day 12. For Days 14 and 15 Group 1 had 3 bats (ad. 1:1, juv. 0:1) and Group 2 had 7 bats (ad. 2:3, juv. 2:0). From Day 16 until the conclusion of the study five of the six injured bats were placed in Group 1 to make a total of eight bats (ad. 2:5, juv. 0:1); Group 2 remained as on Days 14 and 15 (i.e. $N=7$ ). This information is summarized in Table 1.3 in the Appendix. 


\section{HOUSING}

The bats were housed in two display exhibits. Enclosure 1 was $2.85 \mathrm{~m} \mathrm{x} 6.7 \mathrm{~m} \mathrm{x}$ $2 \mathrm{~m}$ (avg. height) with a sand substrate and faux rock, a small pond, and vine features. Enclosure 2 was $4.6 \mathrm{~m} \times 8.8 \mathrm{~m}$ x $2.5 \mathrm{~m}$ (avg. height) with a dirt and litter substrate and live plants, a small pond, and vine features. The live plants did not fruit or flower during the study. Both groups were maintained on a reversed 12:12 light cycle with lights turned off at $10.00 \mathrm{am}$. The light portion of their cycle was lit with fluorescent bulbs (“True Lights") and the dark portion with blue and orange spotlights. Sodium lights were present but rarely used. Temperature ranged from $18-22{ }^{\circ} \mathrm{C}$. Humidity was not monitored but seemed lower in Enclosure 1. Photographs of the enclosures and testing arrangements can be seen in Figures 1.1 - 1.4 in the Appendix. Feeding stations were spaced at $1 \mathrm{~m}$ intervals that correspond to areas labelled A, B, and C.

Food preference and feeding interference behaviours were assessed over 22 nonconsecutive test days spanning 38 days. The bats were maintained before the study and during non-test days on 1350 g (total for both groups) mixed chopped fruit. Each group was given 540 g "nectar."1 Bats were fed somewhat later $(11.30$ - 13.30) than maintenance schedules $(10.00$ - 11.00). Preference data were collected for all 22 study days with the exceptions of Day 13 for Group $1^{2}$ and Day 10 for both groups. ${ }^{3}$ Behavioural data were not collected for either group on Day 13.

\footnotetext{
1 “Nectar”: 11 Tbs honey, 1.5 Tbs vanilla Complan powder, 2 L water; 1/4 cup Sciencediet dog biscuits and bee pollen included on alternate days.

${ }^{2}$ Group 1 was considered to be too disturbed following removal of several bats on Day 13 to collect data: as they were always slower to approach food (up to half an hour after placement) it was decided that hours could pass before the bats calmed enough to eat.

${ }^{3}$ Planned test fruits were not available.
} 


\section{Chapter 2: FRUIT PREFERENCE OF PTEROPUS SCAPULATUS}

\section{INTRODUCTION}

Pteropus species use the fruit of at least 136 genera, the blossom of 97, the leaves

of 25, the bark and/or twigs of nine and the seed pods and sap of several others (Courts 1998). Although it has been said that they will eat "almost all fruit with a pretence to succulence” (Ratcliffe 1932, p. 11), their diet is not actually so undiscriminating. Both frugivorous and nectarivorous species consume a taxonomically non-random subset of available resources (Eby 1998; Banack 1998; Parry-Jones \& Augee 2001) and indicate a hierarchy of preference at the levels of morphology, nutrition, cultivation, species and variety. Unlike the plant-eating bats of the New World (Fleming 1986), Pteropus species are thought to have no core diet but to shift their usage as preferred foods ripen (Banack 1998). This “hierarchy of preference” (Parry-Jones \& Augee 2001, p. 54) means they are best described as "sequential specialists:" species "favouring at any one time one or a few plant species amongst the group of potential food plants available at that season” (Marshall 1983, p. 122). The scope of the present study is too limited to analyze the roles of all of these factors on fruit preference. They are briefly reviewed below to illustrate the variety of forces that have been determined to influence food preference.

\section{FACTORS THAT AFFECT PREFERENCE}

Some taxa are particularly common in the Pteropus diet. The Fabaceae, Moraceae, Myrtaceae, Proteaceae and Sapotaceae form large portions of many diet lists (Eby 1998; Banack 1998; Parry-Jones \& Augee 2001). The Lauraceae are usually avoided (Eby 1998). Preferred taxa often exhibit several physiological characteristics 
(Marshall 1983) that have come to be associated with chiropterochory and chiropterophily but Pteropus species do not limit their diet to those plants exhibiting "bat plant” characteristics. They feed on many with traits commonly ascribed to those used by birds (Meehan et al. 2002); their diet has been described as a subset of the avian diet (Eby 1998). Canopy, edge, and riparian trees (Eby 1998; Banack 1998) and those that display fruit or flowers at the periphery of the branch (Neuweiler 2000, p. 268) are particularly important. Some Pteropus species feed selectively on certain colours of fruit (P. conspicillatus: Hall \& Richards 2000, p. 76) but others do not ( $P$. poliocephalus: Hall \&Richards 2000, p. 76; Eby 1998).

Perhaps because of its implications for orchard management, the ripeness of flying fox foods has often been emphasised. Most authors agree that Pteropus species eat only ripe (Fujita 1988; Banack 1998) or over-ripe (Heaney \& Heideman 1987) fruit but that unripe fruit may be used if other sources of food become scarce (Tidemann \& Nelson 1987; Parry-Jones \& Augee 1991).

Preferences at and below the family level are based largely on chemical properties. Some have argued that fruit bats are energy restricted (Herbst 1986; Law \& Lean 1992) while others maintain that they are nitrogen (Thomas 1984; Fenton 1992) or calcium (Barclay 2002) restricted. Several studies (e.g. Wendeln et al. 2000; Nelson et al. 2000) of the nutritional composition of bat diets have concluded that only by consuming a variety of species can bats obtain the full complement of minerals, vitamins, and energy. Nutrient content can vary widely even within the same genus of fruit (Wendeln et al. 2000). Philippine fruit bats consume some Ficus species that produce only a small volume of fruit, possibly an indication that bats are sensitive 
enough to the nutritional quality of their food to select high-quality/low abundance fig species over those that merely produce in bulk (Utzurrum 1995).

Contrary to expectations, neither New World (Herrera 1999) nor Old World (Herrera et al. 2000) fruit bats prefer sugars (sucrose, fructose, glucose) in the order of their average composition in either the bats' wild (Baker et al. 1998) or captive diets. Megachiroptera selected sucrose over fructose and glucose, and fructose over glucose. Another study found that a nectarivorous megachiropteran showed equal preference for sucrose, glucose, and sucrose-glucose-fructose solutions but avoided fructose (Law 1993). High sugar concentration is also important (Law 1993; McWilliam 1985-1986; Cox 1984).

A variety of other food composition factors, such as steroidal content (Wickler \& Seibt 1976 in Fleming 1982) and high pulp-water content (Hall \& Richards 2000, p. 76; McWilliam 1985-1986), influence foraging. Philippine fruit bats appear to prefer fruit of certain colours but may actually be using colour as a signal of nutritional content rather than selecting on the basis of colour per se (Utzurrum 1995).

Physiology and metabolism influence diet. Reproductive female bats may require or resort to other food resources to compensate for the high energetic (Racey \& Speakman 1987) and calcium (Barclay 1995) cost of pregnancy and lactation. Animals at Jersey Zoo prefer protein-rich foods during pregnancy (Courts 1999). Ruby et al. (2000) predict that folivory increases during pregnancy to provide higher protein and calcium levels. The fruit preference of the New World bat Carollia perspicillata was not correlated with energy content or energy : handling-cost ratio but with spatio- 
temporal predictability, suggesting that ecological factors may be more important in food preference than nutrition (Lockwood et al. 1982 in Fleming 1982).

Pteropus species are known to favour some native resources over others. For instance $P$. poliocephalus consumes poplar leaves at high rates only when pollen and fig availability is low (Parry-Jones \& Augee 2001) and prefer Myrtaceae and Banksia pollen (Parry-Jones \& Augee 1991). Similarly, P. tonganus and P. samoensis eat Inocarpus fagifer only when favoured foods, such as Planchonella samoensis, P. garberi, and Terminalia catappa are not available (Banack 1998). Flying foxes in the Philippines prefer Ficus chrysolepis, F. pubinervis, and F. cf. variegata var. sycomoroides over F. crassiramea and F. sumatrana (Utzurrum 1995). Preferences for some blossom species may be related to the volume and odour-strength of their nectar (Ratcliffe 1931, p. 40).

\section{CULTIVATED FRUIT VERSUS NATIVE RESOURCES}

Although Ratcliffe (1931, p. 42) believed that individual bats would "acquir(e) the fruit-eating habit" and become "inveterate orchard robbers," most authors have concluded that most Pteropus prefer native fruit and blossom but that cultivated fruit can be an important resource if native foods fail (Banack 1998; Parry-Jones \& Augee 1991). Some captive bats have even refused to consume cultivated fruit (Cox 1984). Local flying fox populations increased with the prominence of native figs in their diet but not with their use of cultivated fruits (Parry-Jones \& Augee 2001) and have dispersed despite the availability of orchard fruit when native blossom became locally scarce (Parry-Jones \& Augee 1991). Although some provide the same energy content (Nelson et al. 2000), native fruits often provide nutrition superior to that of orchard fruit (Steller 1986). Inferior nutritional quality leads bats to consume a much greater volume than 
they would when feeding on non-cultivated fruit; this puts disproportional pressure on orchards (which increases public sentiment against flying foxes) and requires them to invest more energy to reach orchards distant from native-forest roosts (Nelson et al. 2000). Cultivated fruits also have lower variation in their nutritional content (Nelson et al. 2000); exclusive reliance on these would restrict a bat's ability to adjust nutrient intake.

\section{ORCHARD MANAGEMENT}

Fruit bats are considered agricultural pests in many of the regions they occupy (but see Korine et al. 1999) including Australia (Wahl 1994). A few authors (Mickleburgh et al. 1992 , p. 9; Hall \& Richards 1987) have commented on the potential of “decoy” or "distraction” crops. These crops, planted on the periphery of the orchard, are "sacrificed" to the bats in the hope that they will be sated and therefore not damage the for-sale crop. For this technique to work, the "distracter" would have to be preferred over the commercial crop, synchronously available, and could not be so desirable that the local bat population grew too large to be maintained by the distracter alone. Additionally, the orchardist would have to acknowledge that the distracter fruit itself was not a potential source of income. With these (admittedly severe) limitations in mind, any application of distraction crops could only be performed if it were known which fruits were preferred over others.

Damage to crops has given researchers and orchardists varied hierarchies of cultivated-fruit preference. Stonefruit (peaches, apricots, etc.) are usually thought to be preferred over pomefruit (apples, pears, etc.) (Hall \& Richards 2000, p. 109). Among specific cultivated fruits, Pteropus species have been said to favour peaches, figs, 
persimmons, mangoes (Ratcliffe 1931 p. 54), pears, rockmelon, grapes (Hall \& Richards 2000, p. 109), and bananas (Hall \& Richards 2000, p. 109; Richards 1990) and to avoid apples and citrus (Hall \& Richards 2000, p. 109). Papaya has been said to be favoured by some (Hall \& Richards 2000, p. 109; Richards 1990) but avoided by others (Banack 1998). Use of some fruits, such as oranges and mandarins, varies by species (Ratcliffe 1931, p. 41). Pteropus species also favour certain varieties of some orchard fruits (Ratcliffe 1931, p. 47, 48, 55). A preference hierarchy based on damage does not necessarily represent what a bat would choose to eat if given a selection as some fruits may not be damaged because they do not mature at a time when bats are in the area or may be better protected.

\section{CAPTIVE MANAGEMENT}

Information on cultivated-fruit preference is also useful for ex-situ management. Environmental enrichment and training for husbandry-related procedures or educational programmes are facilitated with use of favoured foods. Although several flying fox researchers (see above) have related that banana is the favourite food of Australian Pteropus, this apparent partiality has not been methodically evaluated. This study analyses the relative preference of seven cultivated fruits consumed by wild Little Red Flying Foxes (Pteropus scapulatus) and other Australian Pteropus species by using captive P. scapulatus. Trialled fruits (apple, banana, grape, fig, mandarin, mango, and nectarine) are known to be consumed by P. scapulatus and/or other Australian Pteropus (Hall \& Richards 2000, p. 109; Parry-Jones \& Augee 1991; Wahl 1994). 


\section{METHODS}

Food was assessed by presenting three of seven test foods (apple, banana, fig, grape, mandarin, mango, and nectarine) to Little Red Flying Foxes in two enclosures at the Wellington Zoo (Wellington, New Zealand) nocturnal house over 22 nonconsecutive days in April and May (autumn) 2003. Fruits were assessed in trios to reduce the number of presentations relative to assessment in pairs. Space in the enclosures was inadequate for testing more than three fruits per presentation.

Portions $(\text { Mean }=194.4 \mathrm{~g} \pm 37.8 \mathrm{~g}(S D) \text {, range }=115-320 \mathrm{~g})^{4}$ of each test fruit (apple, banana, fig, grape, mandarin, mango, nectarine - see Fruit Composition in Appendix for details) were placed individually in one of three pottles (feeding dishes) presented to each group. Feeding stations were fixed but the location of any particular fruit was determined by a balanced design. Pteropus can distinguish ripe from unripe fruits and empty from full dishes from at least $1.5 \mathrm{~m}$ (Luft et al. 2003) so it is not unreasonable to assume that the bats in this study would be able to identify fruits by smell and would be able to do so from $2 \mathrm{~m}$, the maximum distance (approx.) between two pottles. Therefore, consumption at one pottle is assumed to be based on a "fully informed" choice of the available fruits.

Because study time was limited it was not possible for all fruits to appear an equal number of times in all positions without compromising the presentation of an equal number of pairings of any one fruit with any other fruit. Because data from Group 1 were not collected on Day 13, pairings for banana-grape-mango are fewer than all other pairings. As originally designed no particular fruit was tested within 2 days of

\footnotetext{
${ }^{4}$ Larger portions of fruits known to be favoured were given to prevent pottles from being emptied within the test period. Difference in portion size has no effect on volume consumed (Steller 1986, pers. ob.).
} 
previous presentation to circumvent preference for novel (i.e. not recently consumed) foods. However, due to unavailability of some fruits, one set had to be moved to an alternate day (Table 2.1). This resulted in presentations of apple, fig, and mandarin on consecutive days. Canned nectarine, canned mango, and dried figs were substituted when their fresh counterparts became unavailable.

Preference was calculated by comparing the masses ${ }^{5}$ consumed of each fruit tested that day. Each fruit was compared individually to each other fruit in the trio to create three pairings for each presentation. Pairings were treated as the outcomes of games: the winner of each pairing was given a score of 1 and the loser a score of 0 , tied fruits each received 0.5 . Fruits with consumed masses that differed by $10 \%$ or less were treated as equally preferred. A win/lose matrix was created using the summed scores of all pairings from all trials. For example, if fruits D, E, and F were tested and $115 \mathrm{~g}$ of D, $180 \mathrm{~g}$ of $\mathrm{E}$, and $110 \mathrm{~g}$ of $\mathrm{F}$ were consumed then $\mathrm{D}=0$ and $\mathrm{E}=1$ for pairing $\mathrm{DE}, \mathrm{D}=0.5$ and $\mathrm{F}=0.5$ for pairing $\mathrm{DF}$, and $\mathrm{E}=1$ and $\mathrm{F}=0$ for pairing $\mathrm{EF}$. On another occasion if E, F, and $\mathrm{G}$ were compared and they were preferred in this order then $\mathrm{E}=1$ and $\mathrm{F}=0$ for $\mathrm{EF}, \mathrm{E}=1$ and $\mathrm{G}=0$ for $\mathrm{EG}$, and $\mathrm{F}=1$ and $\mathrm{G}=0$ for $\mathrm{FG}$. The preference matrix would then appear as in Table 2.2. If one or more dishes was empty, note was made of which had been emptied first and that dish was scored as "most preferred." Preference hierarchies were calculated with a hierarchy matrix Java applet (Huber 2001) based on the Batchelder-Bershad-Simpson (BBS) model.

Results may not indicate actual preference due to interactions among bats and among fruits. Banack (1998) speculated that under high population densities, weaker

\footnotetext{
${ }^{5}$ Mass is calculated from wet-weight. The brief exposure duration and gross approximation of mass made controlling for evaporative weight-loss unnecessary.
} 
animals may be forced to feed on a subset of less-favoured resources, thus diminishing apparent preference. Conversely, consumption of a food varies with the desirability of the alternatives (Courts 1999), thus exaggerating apparent preference. By ranking each set of three fruits, as described above, rather than directly using the consumed mass in BBS calculations, reduction or exaggeration of apparent preference should be limited.

Table 2.2. Hypothetical preference table for fruits D, E, F, and G. Scores are calculated from data in the text. Results of individual trials appear in parentheses.

\begin{tabular}{|c|c|c|c|c|c|}
\hline \multirow{2}{*}{ Winner } & \multicolumn{4}{|c|}{ Loser } & \\
\hline & $\mathrm{D}$ & $E$ & $F$ & G & Total wins \\
\hline $\mathrm{D}$ & - & 0 & $0.5(0.5)$ & & 0.5 \\
\hline$E$ & $1(1)$ & - & $2(1+1)$ & $1(1)$ & 4 \\
\hline $\mathrm{F}$ & $0.5(0.5)$ & $0(0+0)$ & - & $1(1)$ & 1.5 \\
\hline G & & $0(0)$ & 0 & - & 0 \\
\hline Total losses & 1.5 & 0 & 2.5 & 2 & \\
\hline
\end{tabular}

\section{RESULTS}

When fresh and processed fruits are combined, both groups showed a clear preference for banana and avoidance of apple (Fig. 2.1). All other fruits preferred (positive scores) by one were avoided (negative scores) by the other except mandarin, which was relatively disliked by both. When fresh and processed versions are considered the same fruit, all fruits appeared in nearly equal numbers at each feeding station and nearly all were compared with each other fruit three times.

Although much predictive power is lost, fresh and processed fruit must be considered separately. Preference scores for fresh fruits were not similar to their processed equivalents: there was a significant negative relationship between fresh and processed fruit scores $(r=-0.60)$. Therefore, fresh and processed versions of a fruit can not be considered equally favoured and can not be analyzed as a single fruit. When versions are separated, banana is still favoured and apple avoided but scores for the others are 
more evenly distributed (Fig. 2.2). Although relative preference differed between the Groups, there was a strong correlation $(r=0.44)$ between scores of individual fruits across Groups (Table 2.3 in Appendix). Consumption from each feeding station was not evenly distributed in either Group but was most clearly exhibited by Group 1, which avoided Station B, possibly due to its relatively exposed location. Not all processed and fresh fruits appeared an equal number of times at each station, therefore the effect of feeding station on apparent preference can not be ignored but, because of inadequate pairings, can not be statistically evaluated.

\section{DISCUSSION}

It can be stated with confidence that the bats prefer banana and fresh nectarine to apple and fresh fig. The more similar the BBS scores of a fruit between the Groups and the more distant scores are from another fruit the more definitively it can be said that these rankings reflect a hypothetical true desirability relationship between each fruit. Fresh and processed versions of a fruit received very different BBS scores. Therefore, processed versions must be considered separate fruits, effectively increasing the number of tested fruits to ten. Because the testing schedule had been designed to evaluate only the seven fresh fruits, there were an inadequate number of comparisons and balanced placement of each fruit at each feeding station was impossible. In effect, apparent preference due to a feeding-station effect can no longer be separated from a fruit effect. For these reasons only the most extreme examples of partiality can be considered reliable. 


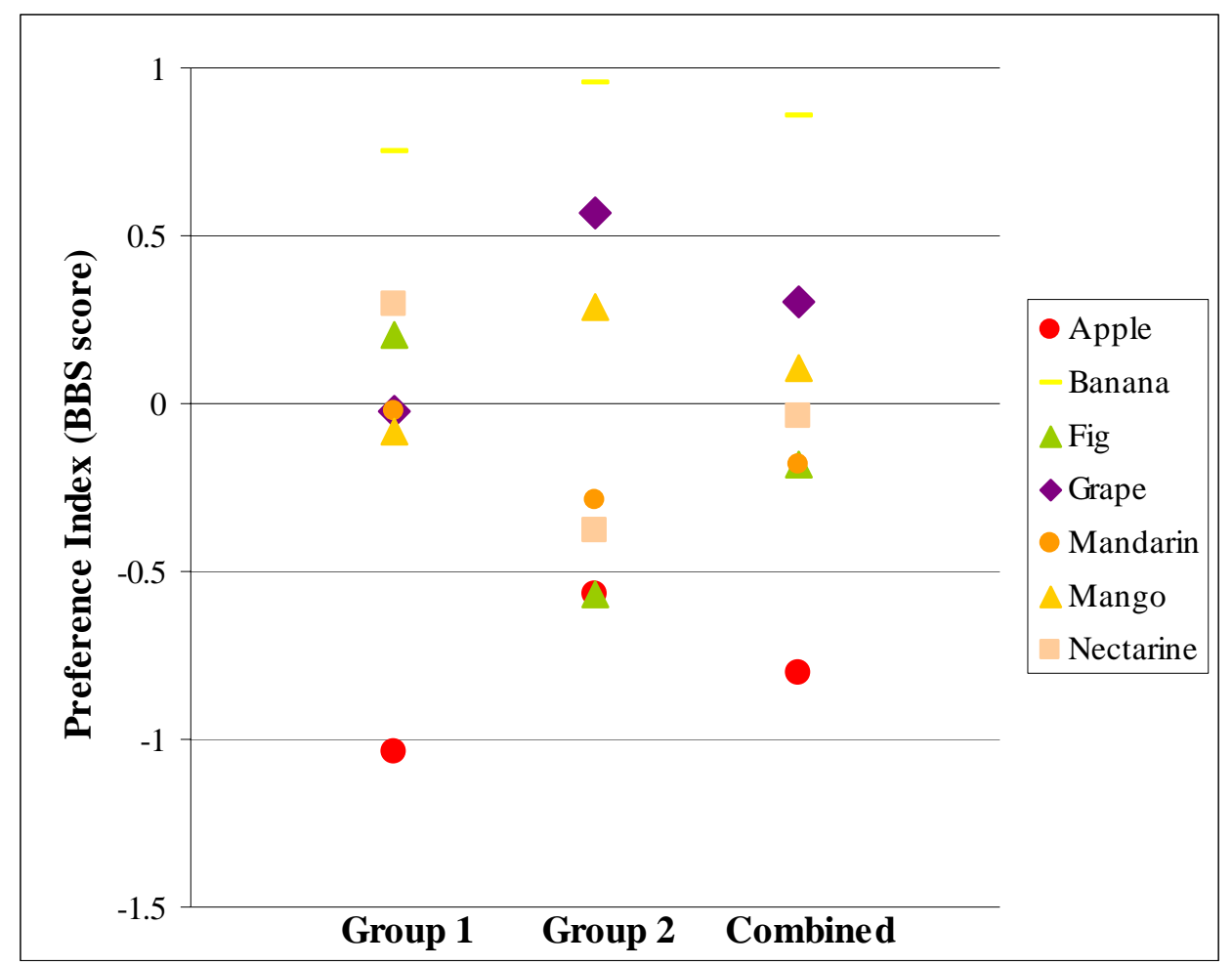

Fig. 2.1. Relative preference for fruits (combined canned and fresh) based on BBS scaling.

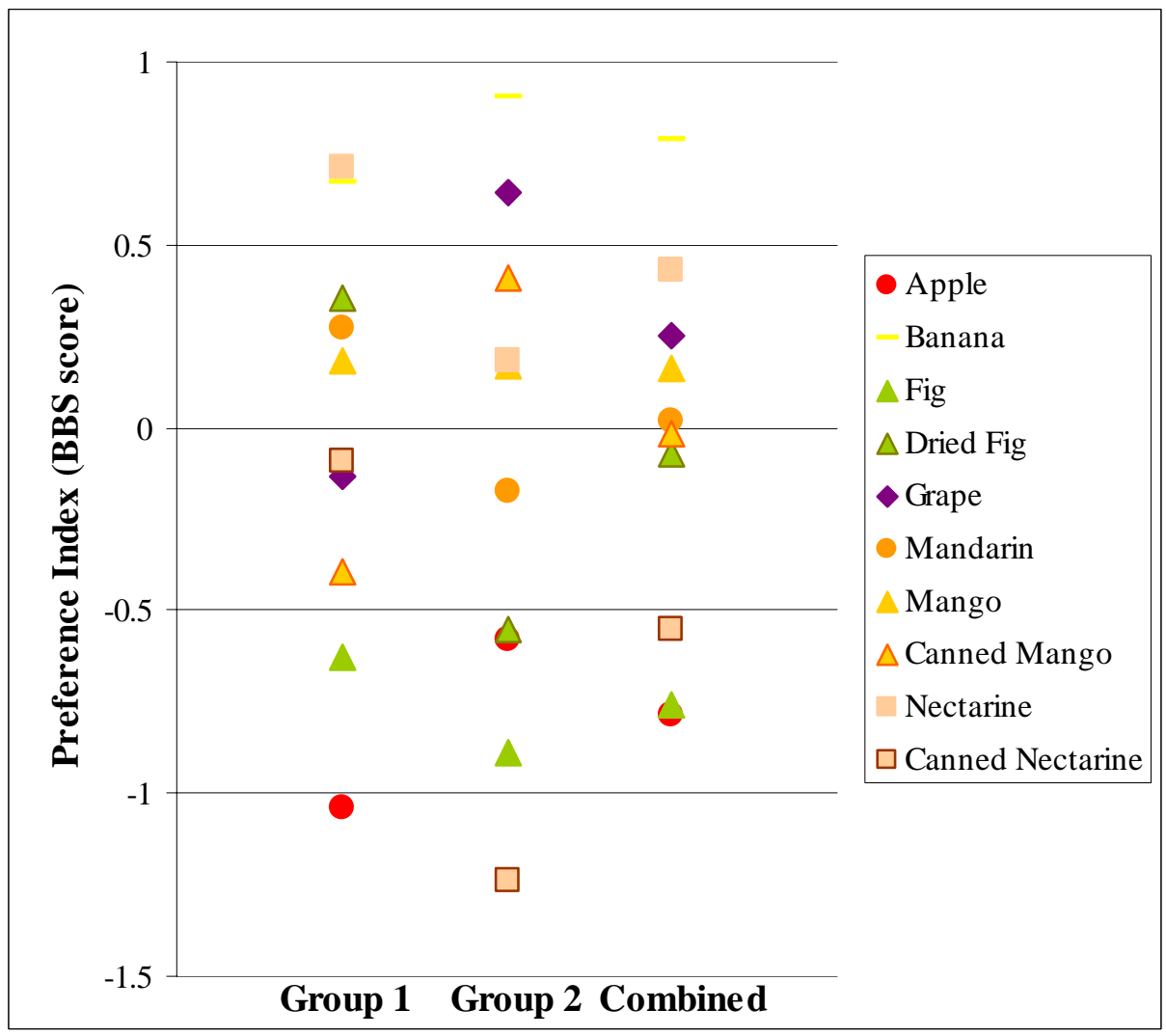

Fig. 2.2. Relative preference for fresh and packaged fruits based on BBS scaling. 
It is interesting to note that both groups preferred dried fig to fresh fig. This may be due to a variety difference between the figs but is more likely to be due to their moisture content. Although a preference for fresh fig might be expected, given the bats' liquid-extraction feeding, there are at least two (non-statistical) reasons that dried may have been preferred: dried figs may have had a more concentrated, stronger taste that appealed to the bats or the bats may not have been able to obtain as much juice from the firmer pulp of the dried fig so consumed a greater volume of fruit to extract an equal volume of juice, thus increasing their apparent preference for dried fig.

The use of several fruits on consecutive days due to the movement of one set to an alternate day did not appear to affect preference. None of these was the least preferred fruit on the second of the too-proximate presentations. Their reduced novelty seems to have had no meaningful influence so the effect of the set's changed day is ignored. Additionally, keepers responsible for non-test day feedings supplied apple and banana on some days that they were to be excluded. These fruits were common in the maintenance diet so it is unlikely that extra presentations affected preference.

Preference scores reflect similar relationships to other evaluations of Pteropus feeding. Like P. livingstonii (Courts 1999), P. scapulatus prefer banana over apple and favour grape and mango but do not avoid citrus. If the percentage of crops lost when flying foxes attack orchards can be considered an estimate of preference then nectarine (representing stone fruit) should have been most favoured, followed by mango, then banana, and finally apple (representing pomefruit) (Tidemann et al. 1997). Only the relative dislike of apple is reflected in the data from the current study, indicating that crop damage is not a valid approximation of preference and vice versa. This may be due 
to differences in orchard protection and/or harvesting or an abundance of preferred native food when banana matures. Based on these studies, $P$. scapulatus are likely to favour papaya and litchi and dislike kiwifruit and pineapple (Tidemann et al. 1997; Courts 1999).

Application of these findings to other Pteropus species or populations is hindered by diet variation between the diets of sympatric species and among camps of the same species (Eby 1991; Entwistle \& Corp 1997; Parry-Jones 1987). P. scapulatus and $P$. alecto have an $85 \%$ overlap in species visited for flowers (Richards 1995) but there is little overlap in resources used by $P$. livingstonii and $P$. seychellensis comorensis (Trewhella et al. 2001). Sympatrics $P$. tonganus and $P$. samoensis have a dietary overlap of about 50-66\% (Banack 1998). In a captive trial $P$. samoensis would eat Freycinetia reineckei inflorescences but $P$. tonganus refused them (Cox 1984). Preference also varies when cultivated fruits are compared: P. poliocephalus are said to be less "fond" of mangos than P. alecto and P. conspicillatus (Ratcliffe 1931, p. 40), P. alecto has been said to readily attack citrus orchards but $P$. poliocephalus does so only under food shortage (ibid., p. 41). P. tonganus forages more frequently in agroforest and consumes a greater variety of cultivated fruits than P. samoensis (Banack 1998). Despite such seemingly rigid resource partitioning, species not historically part of the native diet of any flying fox can be important and favoured resources (Banack 1998; Parry-Jones \& Augee 2001; Tidemann 1987). Overlapping range may not be the best indicator of dietary congruence because sympatric species are not always the closest taxonomic relative: three of the four Australian flying fox species are more closely related to species found outside of Australia than to each other (Jones et al. 2002). 
An additional concern for application to other Pteropus species is that $P$. scapulatus has taste buds at the base of its tongue whereas $P$. alecto and $P$. poliocephalus, also Australian species, have theirs at the tip (Birt et al. 1997). This anatomical difference, believed to indicate obligate nectarivory in $P$. scapulatus, may make the Little Red Flying Fox less discerning in its fruit selection (Hall \& Richards 2000, p. 68). P. conspicillatus is thought to compensate for its relatively few taste buds with its larger olfactory bulb (Birt et al. 1997), indicating that preference may occur using a different sensory system than other Australian Pteropus species use.

Problems can develop when captive studies are applied in the wild and vice versa. The use of cut fruit in this study does not simulate wild conditions, in which $P$. scapulatus teeth may not be strong enough to break the peels of some fruits (Ratcliffe 1931, p. 41). In the wild, figs may be preferred because of their high calcium content (O’Brien et al. 1998 in Barclay 2002) but calcium supplements provided at Wellington Zoo may influence food preference so would not reflect the choices of wild animals. Finally, higher temperatures increase the perception of sweetness (Cameron 1947). If fruits are favoured for their relative sweetness then variations in sugar composition could cause differences in perceived intensity at testing and wild-foraging temperatures.

Despite these caveats, knowledge of Pteropus food preferences can be vital to their management, particularly in orchards. Approximately 1500 orchards in New South Wales and a similar number in Queensland grow fruit attractive to flying foxes (Richards \& Hall 2000). Distracter trees, which provide food for the bats to prevent them from attacking a cash crop, are one potential application of food preference research. To be effective, distracter trees should be those with the highest preference scores that are 
suitable to the protected crop and should not provide more than minimum dietary requirements (Sullivan \& Sullivan 1988). As indicated by its unanimously high ranking in this study, banana should not be used: non-banana orchards that have used this crop as windbreaks have attracted additional bats (Palmer 1987). Mangos have been used successfully to protect other varieties of the same fruit. One mango grower protected an expensive variety of mango by interspersing an inexpensive variety, which he allowed to ripen on the trees in order to distract the bats from his more valuable crop (Ratcliffe 1931, p. 54-55). It has been suggested that oranges are spared greater loss because flying foxes prefer mandarins, which often are planted in the same areas in Australia (Ratcliffe 1931, p. 48)

Humans have both destroyed and created Pteropus food opportunities. In Australia, much of the post-European forest clearing has been on fertile tracts of land that would have provided more consistent, abundant, and high-quality resources than those of remaining patches (Hall \& Richards 2000, p. 92) but human migrants also have brought new flowering and fruiting species and extended the ranges of those already in Australia (Parry-Jones \& Augee 2001). Many of the Ficus found around Sydney, which have been planted at artificially high densities, came from other regions or countries; they provide a year-round resource for flying foxes (Parry-Jones \& Augee 2001). "Backyard" and orchard fruit are also used (Nelson 1965b). The availability of some species has decreased but it is clear that the variety of foods used by Australian Pteropus has greatly increased since the arrival of Europeans. A summary of species used by megachiroptera is available after the Appendix. 


\section{Chapter 3: RESIDENTS VERSUS RAIDERS: THE ROLE OF FEEDING INTERFERENCE IN POLLEN DISPERSAL BY PTEROPUS SCAPULATUS}

"While morphological and physiological responses to plant characteristics have increased the potential of bats to exploit fruits, pollen, and nectar, the behavior of bats determines the benefits received by both groups. What bats eat, how they treat their food and where they go with it are the critical components to the interactions between bats and plants.” Heithaus (1982)

\section{INTRODUCTION}

Neuweiler (2000) estimated that 750 plant species (160 in the Old World) rely in part on bats for pollination and seed dispersal. There is suggestive evidence that batdigested seeds have higher frequencies of germination (Entwistle \& Corp 1997) and germinate at a faster rate than seeds that have not been digested (Bollen \& Van Elsacker 2002). The ecological relationships between Old World bat species and their food plants have largely focused on seed dispersal (e.g. Eby 1991). Much of this research has attempted to link dispersal to local population density and resource defence.

It had been thought, based on studies of Neotropical species, that nectarivorous and frugivorous bats do not defend food resources (Fleming 1982). Some authors (e.g. Howell 1979 in Elmqvist et al. 1992) had even shown evidence that some Neotropical species feed cooperatively. However, since Fleming's publication, even Neotropical species (Glossophaga soricina: Lemke 1985 in Elmqvist et al. 1992) have been found to defend resources. Feeding interference, behaviour that disrupts the foraging of another bat, has been reported in a number of Old World bat species. Pteropus poliocephalus (Eby 1991), P. conspicillatus (Richards 1990), P. alecto (McWilliam 1985-1986), P. samoensis (Brooke 2001), and African megachiropterans (Ayensu 1974 and Kingdon 1974 in Fleming 1982) have been observed fighting over fruit resources. Noisy 
vocalizations by other Pteropus species (Mickleburgh et al. 1992, p. 142; Wilson \& Engbring 1992) suggest fruit defence is even more common.

Feeding interference may result in foraging further from the day roost (Walton \& Trowbridge 1983) or the use of a feeding roost away from the source tree (Marshall 1983) to avoid competition. Quarrelling can lead bats to drop or dislodge fruits before they can effectively be dispersed. Rousettus aegyptiacus drops $25 \%$ of its food as a result of fighting with conspecifics (Jacobsen \& Du Plessis 1976 in Marshall 1983). It is likely that the noisy squabbling associated with feeding interference attracts more bats to the food source, thus escalating disputes (Hall \& Richards 2000, p. 65).

In some species, the number of bats per tree appears to be determined spatially (Richards 1987) while in others it varies with flowering intensity (Trewhella et al. 2001; Brooke 2001) or fruit abundance (Brooke 2001). P. samoensis uses feeding roosts unless the fruit is too large to be removed or the tree has abundant small fruits and flowers (Brooke 2001). If the fruit is too large then the entire tree will be defended; only the immediate area around small fruits and flowers is defended. Roosting territory size (sensitivity to intruders) varies by individual (5-22 ft radius: Markus 2002).

Feeding interference can potentially be vital to seed dispersal. The "residents and raiders” model of the relationship between feeding interference and seed dispersal was described and named by Richards (1987) following observations of Pteropus conspicillatus. The model has strong implications for seed dispersal under varying population density. A foraging megachiropteran establishes a territory in a fruiting tree and defends it from conspecifics (details in Chapter 4). A bat with a territory is called a “resident.” A bat without a territory, a "raider," attempting to feed in one of these 
locations is either ejected or ejects the resident. The fleeing bat often obtains fruit before leaving and will take it elsewhere to consume it. By removing the intact fruit from the source tree the ejected bat disperses seeds too large to be swallowed or that are destroyed by digestion. The noisy territorial disputes alert nearby bats that a food source has been found. This "inadvertent recruitment of competitors" (Elmqvist et al. 1992, p. 21) causes further antagonistic interactions with the ultimate result that a large volume of fruit is moved away from the source tree. A key point in this phenomenon is that dispersal only occurs on a large scale when feeding locations are limited relative to the number of bats.

The resident-and-raider pattern of feeding interference has been recorded in several Pteropus species and agonistic interactions at fruiting trees by many other species suggest that it may be a more common occurrence than previously recognized. Authors frequently comment on the noisy squabbling of foraging Pteropus (Mickleburgh et al. 1992, p. 142; Wilson \& Engbring 1992, p. 45) or their general silence with the occasional quiet vocalizations (Mickleburgh et al. 1992, p. 125), which are consistent with reinforcement of established feeding territories. Other species, such as $P$. seychellensis (Mickleburgh et al. 1992, p. 134) have been described carrying fruit away from the source tree with no comment on any preceding agonistic interactions. NonPteropus megachiropterans in Africa have been reported to "jostle and knock fruits away from one another” (Ayensu 1974 and Kingdon 1974 in Fleming 1982).

Like Richards (1987), most publications of megachiropteran feeding interference have been on the subject of frugivorous species. With the notable exceptions of $P$. vampyrus (Gould 1978) and P. tonganus (Elmqvist et al. 1992) feeding interference at 
floral resources has rarely been documented and only McWilliam (1985-1986) seems to have suggested that a primarily nectarivorous species defends blossoms. A resident-andraider pattern exhibited by nectarivores would result in pollen dispersal away from the source tree, increasing the probability of cross pollination. A successful raider would brush against the blossom with his scaly, pollen-collecting fur (Altringham 1996, p. 178) while obtaining nectar. When ejected, the raider would expose the next flower to viable pollen attached to his muzzle, chest and back (Hall \& Richards 2000, p. 79-80). Unlike seed dispersal, the distance that pollen can be transported from the source is not limited by gut retention time. Pollen dispersal is also not limited by the flying fox's small oesophagus (Tedman \& Hall 1985) or load-bearing capacity (Richards 1990). Because not all pollen will be lost at the next flower, flying foxes are able to visit multiple species for nectar without ruining their effectiveness as pollinators.

This study attempts to illustrate that this phenomenon occurs in the nectarivore Pteropus scapulatus, albeit under artificial conditions that use fruit. Behaviours observed at the three feeding stations described in the previous chapter are analysed. As not all bats in group sizes that exceed three animals can have exclusive access to a feeding station it is hypothesized that when $N>3$, "extra” bats potentially will be unable to feed without risk of ejection. If the resident-and-raider model applies to nectar- and pollen-feeding bats then its implications for population decline on cross pollination must also be considered.

\section{METHODS}

Data were collected concurrently with that of fruit preference and dominance (Chapters 2 and 4). As most incidences of dispersing food from the station are 
performed by raiders, for simplicity this section of the analysis will refer to those bats that moved food away from the station as raiders even though, in some cases, they were actually displaced residents. As described in Chapter 2, population sizes of both groups were non-experimentally changed during the study. The number of days that data were collected at these group sizes differed from that of the fruit preference data. A summary of the number of days at a particular group size is found in Table 3.1 in the Appendix.

Baseline: For Days 1-12 groups consisted of 7 bats (adults 1:5, juveniles 0:1) in Group 1 and 11 bats (adults 4:4, juveniles 2:1) in Group 2. The juvenile female in Group 2 (Juv. Gold) died between Days 11 and 12 but, as she contributed little to raiding intensity (see below), data from Day 12 are included in analyses of $N=11$. During this period bats were individually identified.

Reduced: Raiding data were not collected on Day 13 as four bats from Group 1 and an additional three bats from Group 2 required veterinary care and remaining bats were judged to be too agitated from inspection to behave as typical. Following this non-experimental removal, bats were no longer individually identified. For Days 14 and 15 Group 1 had the three remaining bats (adults 1:1, juveniles 0:1). Group 2 had the seven remaining bats (adults 2:3, juveniles 2:0) from Day 14 until the end of the study.

Augmented (Group 1 only): Five of the six injured bats (all injured Group 1 bats and one of those originally in Group 2) were placed in Group 1 for the remainder of the study (Days 16-22) to form a group size of eight (adults 2:5, juveniles 0:1).

Interactions at feeding stations are categorised (as below) and recorded as having occurred or not occurred at one minute intervals, as preliminary observation agreed with reports that disputes resolve in less than 1 minute (Markus 2002). Behaviours repeated in the same minute by the same bat at the same location with the same outcome (e.g. three unsuccessful raid attempts by Juv. Silver at Station A defended by Purple and Green) are recorded as having occurred only once. Similarly, if a successful raid and unsuccessful raid (Juv. Silver at Station A defended by Purple is ejected four times: with food, without food, without food, with food) occur under these conditions, a single 
Ejected (food) is recorded. Such repeated occurrences are rare enough that underestimation of raiding frequency and success are not of serious concern. Steal, Ejected (food), Resident Ejected (by raider), Resident Ejected (by resident), and Mobbing are considered "successful" dispersal events. ${ }^{6}$ They appear below in both italics (attempted) and bold (successful). Ejected (no food) and Distant Display are "unsuccessful” attempts. They appear below in italics (attempted).

\section{Behaviour Categories:}

No Bat: unattended station

Resident Only: attended only by bats who have fed from or defended station (i.e., residents)

Near: number of non-residents within $1 \mathrm{~m}$ of station that are not included in other behaviour categories

Steal: number of non-residents able to remove food and leave station without apparent notice of resident(s)

Ejected (no food): number of non-residents ejected by resident(s) that were unable to obtain food

Ejected (food): number of non-residents ejected by resident(s) that were able to obtain food

Resident Ejected (by raider): number of residents ejected by raider(s)

Resident Ejected (by resident): number of residents ejected by another resident(s)

Distant Display: number of bats further than $1 \mathrm{~m}$ from station seen to deviate from approach after resident(s)'(s) territorial display

Mobbing: three or more bats simultaneously raiding a station

The number of bats in each category (except No Bat, Resident Only, and Near) and twice the number of Mobbing events are summed to determine the number and rate of attempted dispersal events per session. Mobbing counts are doubled to give a conservative estimate of the number of bats that successfully obtain fruit during that minute.

\footnotetext{
${ }^{6}$ NB: "Success" refers to movement of the food away from the source does not necessarily mean that the bat performing the dispersal would have wanted that outcome of the interaction.
} 
Territorial invasions, in which a bat enters a resident’s territory (1 m radius from feeding station) without apparent tolerance by the resident, are analyzed to determine how often potentially agonistic encounters are resolved without any prompting from the resident and how often raiders defeat residents. Invasions are composed of Steal, Ejection (with food), Ejection (without food), and Resident ejected (by raider) behaviours. Bats that are Near but leave without food and without prompting are not considered.

It was expected that favoured foods would inspire the most vigorous raiding and defence. The relationship between food preference and aggression was determined using the BBS scores for fruit from each group (Chapter 2) and the average raid attempts/h/extra bat (i.e. $N$ - 3) that occurred at a station where that fruit was tested. Other raiding reports are not standardized by the number of "extra" bats unless indicated.

\section{RESULTS}

Breakdowns of behaviours performed by individual bats can be found in Tables 3.2 and 3.3 in the Appendix. In both groups, individual bats raided at different rates (Fig. 3.1 - 3.2; Tables 3.4 - 3.5 in Appendix for details). Juv. Silver performed more than $30 \%$ of all raid attempts in Group 2. As would be expected, the most dominant bat, Purple, almost never acted as a disperser because he could control access to the feeding station. Bats of greater dominance were more likely to have successful raids than those low in the hierarchy. The relationship between dominance and raiding is discussed in Chapter 4 . 
Because raiding was only measured for two days in the reduced condition for Group 1, even the absolute absence of raiding on those days did not allow $t$ tests to detect a significant difference in raiding attempts when Reduced was compared with Baseline and Augmented. Although raiding attempts in Group 1 were lower when $N=8$ than when $N=7$, this difference also was not significant. A tabular comparison of raiding attempt rates in Group 1 can be found in Table 3.6 in the Appendix. Raiding attempts/h decreased in Group 2 when four bats were removed (Fig. 3.3) but the difference was not great enough to be significant $(t(19)=0.50, p>0.05)$. At equal group size $(N=7)$ Group 1 raided at a significantly lower rate than Group $2(t(19)=$ 5.36, $p<0.01$ ). Raids were more likely to be successful in Group 2 with a smaller group size ( $N=11: 29.3 \% ; N=7: 33.3 \%)$ but this was not significant $(t(19)=0.69, p>0.05)$. Proportional success when Groups were of equal size approached significance (Gr. 1: 52.8\%; Gr. 2: 33.3\%; $t(19)=1.84, p=0.081)$. Details of behaviours at each feeding station at different population densities can be found in Tables 3.7-3.11 in the Appendix.

As would be expected, attempted raids/h were generally greater when a Group had more bats but attempted raids/h per extra bat also varied with group size. As above, rates in Group 1 were not significantly different. Results of these comparisons also appear in Table 3.6 in the Appendix. In Group 2, raids/h/extra bat was significantly greater in the reduced condition than at baseline $(t(19)=4.08, p<0.01)$. Again, rates were not equal when size in both groups was equal: Group 2 had a significantly higher rate of raids/h/extra bat compared to Group $1(t(19)=5.94, p<0.01)$.

In Group 1, 13.8\% of territorial invasions were resolved when the raider left without any prompting (steals) (Fig. 3.4). In Group 2, only 4.0\% were resolved in this 
way, probably due to greater resident vigilance in reaction to the much higher raidingattempt rate. Raiders defeated residents in $8.4 \%$ of Group 1 invasions and $5.6 \%$ of Group 2 invasions.

There was a low correlation $(r=0.38)$ between fruit preference and raiding in Group 1; there was no correlation ( $r=0.17$ ) in Group 2. Data from the two days when Group 1 was reduced was not included in the analysis of the relationship between food preference and raiding because the number of bats was equal to the number of feeding stations, eliminating the potential need for raiding.

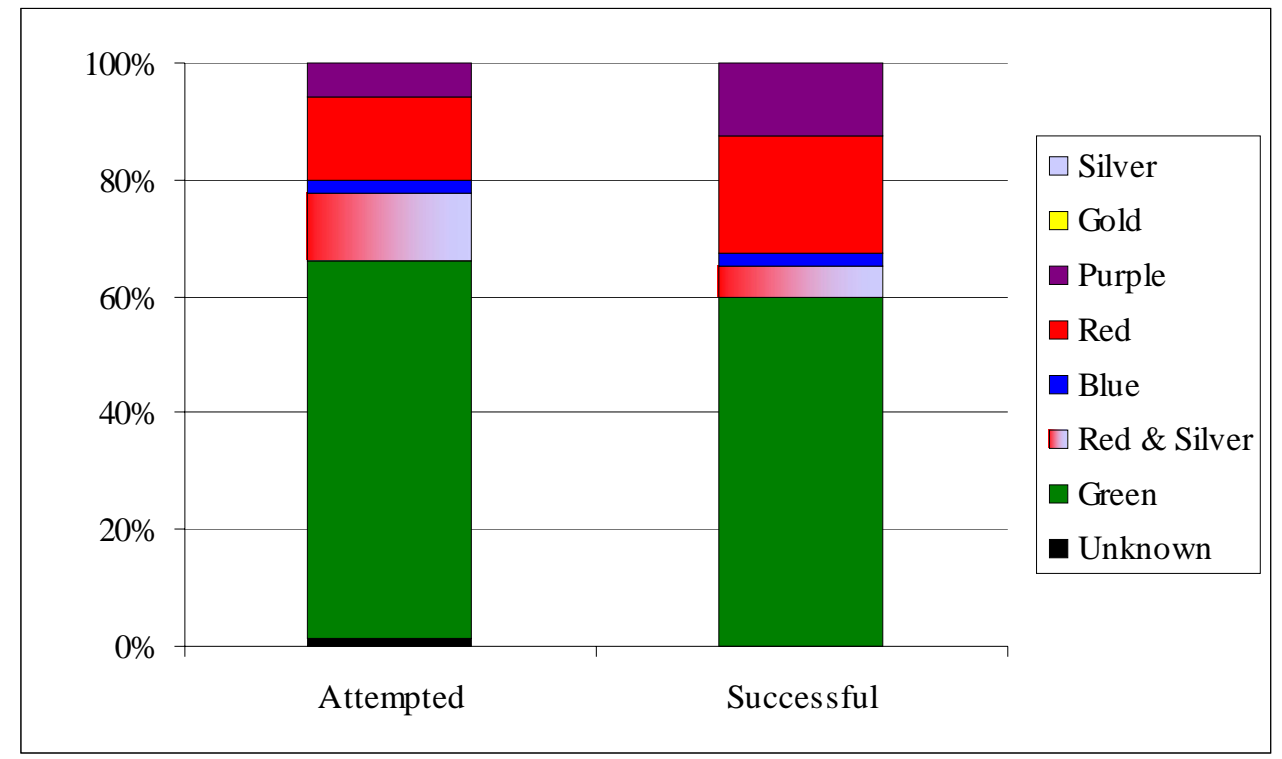

Fig. 3.1. Percent of raiding attempts and successes performed by individual Group 1 bats. Shown in order of dominance (see Ch. 4). 


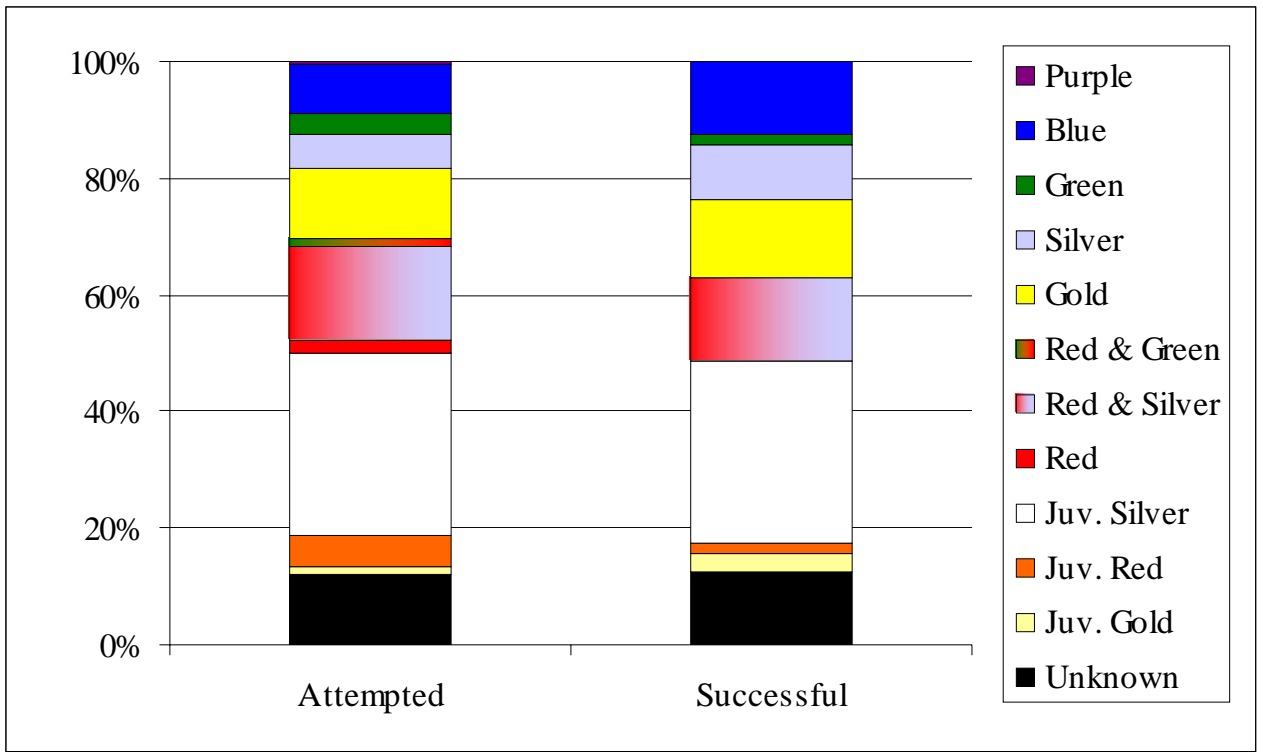

Fig. 3.2. Percentage of raiding attempts and successes performed by individual Group 2 bats in order of dominance (see Ch. 4).

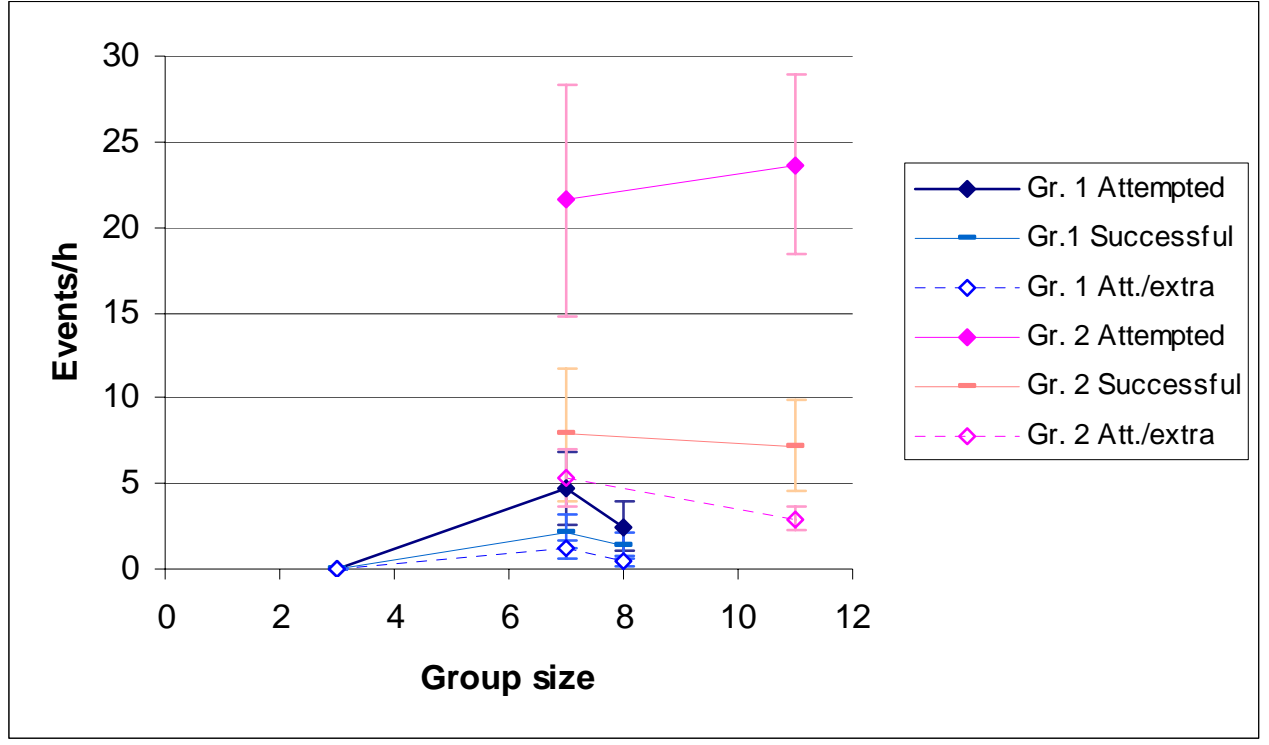

Fig. 3.3. Rates of attempted and successful (food dispersal) raids. Rates represent the mean $( \pm 2 S E)$ number of raids/station/hour of each session at a particular group size. Attempted raids per extra bat $(N-3)$ are also shown. 


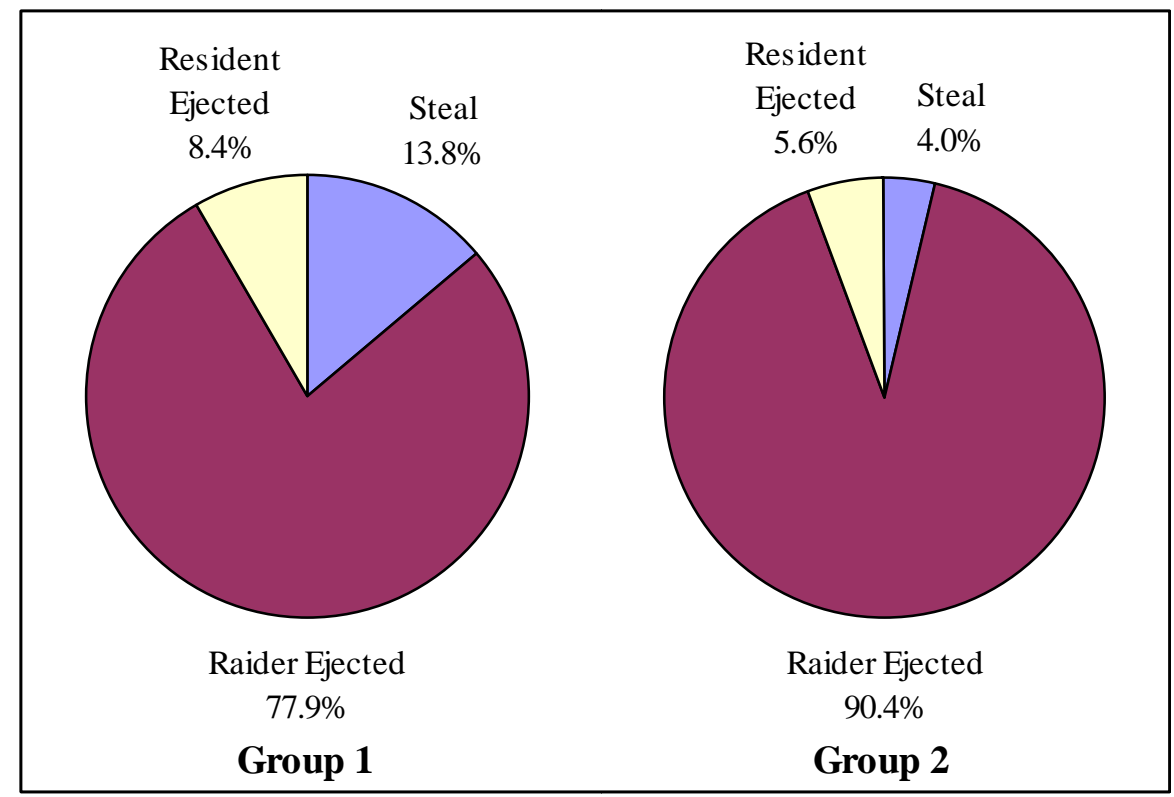

Fig. 3.4. Resolution of territorial invasions.

\section{DISCUSSION}

It is no great surprise that fewer bats leads to less fighting. What is notable is its quantification. Group size and composition were not experimentally determined therefore all conclusions drawn from this study must be tentative. The relationship between raiding frequency and population was obscured by a strong Group effect and, more specifically, by the behaviour of certain individuals. However, it is clear that reduced competition for food leads to a lower incidence of food removal from its source and that some bats remove more food than others. This finding also has important ecological ramifications.

\section{RAIDING FREQUENCY}

Although the difference in raiding frequency between baseline and augmented conditions in Group 1 was not significant, the decrease in raiding with a greater number of bats was not the predicted outcome. It is possible that if Group 1 had begun the study in the augmented condition and then been reduced to the baseline condition that raiding 
intensity would still have been greater at baseline: the bat that would have been removed, Group 2 Gold, could have had an inhibitory effect on territoriality. However, if the hypothesis, that raiding rates are positively related to population : resource ratios, is in fact accurate there are several factors that may have exerted a stronger force in the opposite direction following the reconstitution of Group 1. The augmented condition occurred in the two weeks following the thumb-amputations of five of the eight group members; the recovering bats may not have defended or raided as aggressively as they had previously done or would do once fully recovered. Missing thumbs may decrease a bat's propensity for raiding, although this seems unlikely: presumably, a bat missing one or both thumbs would have difficulty dominating a feeding station so would be more likely to resort to fly-by raids. Another factor may be the characteristics of the bat moved from Group 2 to Group 1. While in Group 2, the Gold bat was low ranking (see Chapter 4) and responsible for about 10\% of all attempted raids but in Group 1 he may have had a much higher rank and been able to obtain food without raiding. If he was particularly tolerant of others at "his" station then the other bats may have had no need to raid either. He also may have been less hesitant to use all three stations, effectively increasing the available resources so that less raiding was necessary.

\section{EFFECTIVE GROUP SIZE}

Although raiding frequency was high relative to Group 1, rate and change in raiding rate in Group 2 could have been greater than what were observed had the effective group size been equal to the actual size. The effective population size of Group 2 under the baseline condition was much lower than 11 bats. Three bats depended on fallen food for the majority of their diet and one, Juv. Red, was able to rely on his high- 
ranking mother for access to food. Although these bats may have contributed to a subjective sense of resource limitation or, in the case of Juv. Red, actually contributed to reducing those resources, in terms of feeding interference they do not represent "whole” bats. The population size of Group 2 would be better described as effectively 7 - 8 bats. Similarly, in the reduced condition only five of the remaining seven bats made large and independent contributions to either raiding or resource defence; Juv. Red and one of the scavenging bats did not. Of the bats that were removed, none of them were dominant (resource controlling) and only two of them performed many raids (the others scavenged) so that the population was effectively reduced by two bats rather than four. Therefore, the actual population may have been reduced from 11 to 7 but the effective population decreased from 7 - 8 to 5 - 6. Thus, insignificant change in raiding intensity between these two conditions is less surprising. This is illustrated as "Gr. 2 Att./extra" in Fig. 3.3. Attempted raids/h/extra bat was greater at $N=7$ (7.19 att. raids/h/extra bat) than at $N=11$ (2.96 att. raids/h/extra bat). The apparent increase in raids/bat is probably due to the removal of non-raiding bats that had depressed the average. Using the above approximations of the effective population there was a much smaller difference but still an increase in raids in the reduced condition relative to baseline: there were $3.60-4.32$ att. raids/h/extra bat in the reduced condition and $2.96-3.38$ att. raids/h/extra bat at baseline.

In addition, raiding rates in the reduced condition for Group 2 may have been artificially inflated by a change in data recording method. Because identification tags had to be removed concurrently with the reduction in group sizes, it was often impossible to determine if the same bat performed more than one raid in a one-minute 
interval. For instance, if the Gold bat made two unsuccessful raids and one successful raid at the same Station in the same minute, this would have been recorded as "Gold Ejected (food).” If the same behaviours were performed by a non-tagged bat, it would have been recorded as "Raider Ejected (no food)," "Raider Ejected (no food)," and "Raider Ejected (food)." Although, as previously mentioned, such occurrences were unusual, both successful and unsuccessful raids may have been recorded as having occurred at greater rates in the reduced (Group 2) and augmented (Group 1) conditions than if they had been performed at Baseline, when individuals were identifiable.

\section{PREFERENCE AND FEEDING INTERFERENCE}

Two factors, success rate and fruit preference, are believed to have had little or no effect on raiding rate. When group size was equal the number of successes in Groups 1 and 2 were not equal, indicating that raiding rate is not determined by the number of successful raids per bat. Aggression, as inferred from raiding frequency, did not greatly increase in the presence of favoured foods. This is contrary to the conclusions of other studies. Masefield (1999) found that $P$. livingstonii were more aggressive on days when preferred forage was supplied. Patrolling, repeated flight through a foraging area with aggressive behaviour toward approaching conspecifics, almost exclusively occurred when availability of favoured fruits peaked and Syzygium inophylloides flowers were abundant (Brooke 2001).

A Steal, a successful raid that does not appear to evoke notice from the resident, is similar in concept to departure from a day-roost perch by a non-resident without prompting from the resident. Markus (2002) found that $4.8 \%$ of intruding bats left without active encouragement from the resident. The similarity between this figure and 
the $4.0 \%$ of territorial invasions that resolved as Steals in Group 2 may indicate that similar vigilance and/or tolerance of non-resident bats apply to roosting and feeding territories. The higher rate of $13.8 \%$ in Group 1 may be due to its relatively low conflict rate in general and low ejection rate in particular. Trewhella et al. (2001) determined that about $13.5 \%$ of displacements from Pteropus day roost territories were due to the ejection of the resident by a same-species non-resident. This figure is not unlike the 8.4\% and 5.6\% of conflicts in Groups 1 and 2, respectively, that were similarly resolved.

\section{CONCLUSION}

Several factors appear to be important in feeding-interference rates. Contrary to the findings of Brooke (2001) ${ }^{7}$, the present study found that reduction of population density depresses raiding frequency. Raiding rates are not absolutely determined by the population : resource ratio, as illustrated by the very different rates performed by the two groups at an equal group size. However, rates appear to be positively linked to population : resource ratio for a particular combination of individuals. In small groups, such as those found in most captive environments, these individuals are believed to create a dynamic that may not characterize other combinations of animals. This dynamic could be determined by the behaviours of certain individuals or the interaction of several particular individuals, demographic factors (e.g. sex ratio or age distribution), enclosure differences, or any number of social, physical, or environmental variations. Addition of new animals to a group may alter this dynamic in a less predictable way than subtraction of group members. Experimental manipulation of group composition and size is needed to further explore these factors.

\footnotetext{
${ }^{7}$ Brooke (2001) found no correlation between rates of chasing (a feeding-roost defence behaviour) and the estimated size of local populations of $P$. samoensis.
} 


\section{Chapter 4: DOMINANCE RELATIONSHIPS IN PTEROPUS SCAPULATUS}

\section{INTRODUCTION}

Pteropus species defend feeding and roosting areas with vocalizations, "wing clapping” and spread-wing displays, by chasing and sometimes by biting or thumb-claw fighting intruders (McWilliam 1985-1986; Brooke 2001; Elmqvist et al. 1992; Mickleburgh et al. 1992, p. 129; Nelson 1965a; Richards 1990; Gould 1978). Encounters are resolved when one or both bats leave the immediate area (Elmqvist et al. 1992). Except for P. samoensis (Brooke 2001), most disputes are settled without physical contact (Markus 2002; Nelson 1965a) or even proximity: P. vampyrus have changed direction at a distance of $30 \mathrm{~m}$ when the bat they were approaching spread its wings in warning (Gould 1978). Ritualized combat is believed to reduce the energy cost to both bats and to minimize the risk of injury (Markus 2002; Nelson 1965a). The noisy squabbles that result from these disputes may alert nearby residents who rush to the edges of their territories, driving the intruder from one territory to the next (Nelson 1965a). Once feeding and roosting territories are created they remain quiet except when boundaries are reinforced (Richards 1990). Although rarely reported explicitly, individuals do sometimes tolerate the presence of conspecifics while feeding ( $P$. rodricensis: Mickleburgh et al. 1992, p. 204; P. scapulatus: pers. obs.). These “tolerant” bats act much like roosting pairs, defending their feeding territory from others (Mickleburgh et al. 1992, p. 129).

I define "dominance” as the ability to exclude other bats from resources that they desire. A bat is said to be dominant to another if, in its pattern of interactions, it is more likely to control resource access. A dominant bat need not exhibit control in all 
interactions (for instance, it may allow another to feed in its territory) but must be capable of excluding the other animal. Most analyses of bat dominance (e.g. Neuweiler 1969 in Pierson \& Rainey 1992) have assumed linearity (if Bat A is dominant to Bat B and Bat $\mathrm{B}$ is dominant to Bat $\mathrm{C}$ then Bat $\mathrm{A}$ is dominant to Bat $\mathrm{C}$ ) but not all mammal hierarchies are linear (Jameson et al. 1999). This may reflect actual dominance patterns but may also be due to limited numbers of observations (Jameson et al. 1999). It is possible that a subordinate will exclude a dominant animal but this is unusual, by definition, except in the case of circular triads. In a circular triad Bat A is dominant to Bat $\mathrm{B}$, Bat B is dominant to Bat $\mathrm{C}$, but Bat $\mathrm{C}$ is dominant to Bat A. Such an intransitivity is likely to occur when bats are of a similar ranking within the group and when relatedness influences dominance, as will be discussed later.

Relative dominance varies with maturity (Nelson 1965a) and sex (Trewhella et al. 2001) and may also vary with body (Law 1995) and harem size (Nelson 1965a). In interspecific conflicts, dominance varies with species (Trewhella et al. 2001). Residents are more likely to eject raiders than vice versa (Markus 2002) but Trewhella et al. (2001) found that this pattern was not maintained when the resident was female and the intruder was male nor when, among Pteropus, the raider's species was dominant to the resident's species. Causality of "resident dominance" can not be determined from these reports nor from the data collected in the present study. It is unclear whether dominant bats are more likely to have territories so are more likely to win disputes or whether having a territory increases a bat's position in the hierarchy, as suggested by Nelson (1965a).

Investigations of dominance patterns typically have focused on males: male hierarchies (Neuweiler 1969 in Pierson \& Rainey 1992) and breeding status (i.e. 
monogamous, polygamous: Nelson 1965a). Apart from noting that females are subordinate to males (Nelson 1965a; Trewhella et al. 2001) or that males will fight over them (Wiles 1987a in Pierson \& Rainey 1992), agonistic interactions involving females are rarely mentioned. The most notable exception is displacement of some males by a captive female $P$. livingstonii (Masefield 1999). Others have observed females defending feeding or day roosts (Brooke 2001; Nelson 1965a; Mickleburgh et al. 1992, p. 204), exemption from feeding- or day-roost eviction by males during (Wiles 1987a in Pierson \& Rainey 1992) or outside of the mating season (Markus 2002; Mickleburgh et al. 1992, p. 204). In most of the above interactions it is evident that males do not consider females a dominance threat. Even territory defence is not always a clear example of female dominance: $P$. poliocephalus females will defend a roosting territory until their mates waken and conclude the dispute (Nelson 1965a).

This study investigates the linearity of dominance hierarchies in the two small $P$. scapulatus groups used for taste preference trials (Chapter 2). Linearity would be most evident in smaller groups because individuals can be consistently identified (by researchers as well as other bats) and a larger number of interactions between any two animals is likely to be observed. The influences of sex and age on dominance are also examined.

\section{METHODS}

Data were collected on the same schedule as that described in Chapter 3 but only for the period that bats were tagged. The participants and outcomes of interactions at feeding stations were recorded. Behaviours follow Chapter 3 definitions except that identity was recorded rather than the number of bats performing the behaviour. A bat 
was said to have "won" the interaction if it ejected another (regardless of whether that bat or the other was a resident or raider) or was a resident when a co-resident ejected either a raider or another resident because it was often not clear which resident's behaviour was responsible for the outcome. "Distant displays" were considered "wins" if the approaching bat was deterred. Unlike in Chapter 3, “steals” and “mobbing” were not counted. Outcomes were scored as with fruit-preference pairings in Chapter 2 except that no ties were allowed. Choice of model has a strong effect on dominance rankings (Tufto et al. 1998); the Batchelder-Bershad-Simpson (BBS) model was used for reasons described by Jameson et al. (1999). As in Chapter 2, BBS scores were calculated with a hierarchy matrix Java applet (Huber 2001). Separate hierarchies were created for each group. Juv. Red and Juv. Gold were assigned equal scores to that of Juv. Silver, the lowest-ranking Group-2 bat, due to confounding behaviours (see below) but the juvenile in Group 1 was included in that analysis.

\section{RESULTS}

Two Group 2 juveniles are ignored in this analysis because they exhibited behaviour that confounded interactions. Juv. Gold foraged mainly on the ground so had very few interactions ( $N=7$ ) (Table 4.1 in Appendix), all were defeats and the majority of them ( $n=5)$ were with Purple, the most dominant bat, so offer little information about relative dominance. Juv. Red foraged almost exclusively with the bat assumed to be his mother (Green), a high ranking individual. Due to his association with her during many interactions he had a higher calculated position in the hierarchy than his few independent interactions would suggest. It is interesting to note that Juv. Red was observed ejecting Juv. Silver, a larger individual. Juv. Silver and the juvenile in Group 1, Green, are 
included in their respective hierarchies because their behaviour did not appear confounded by atypical foraging strategy or association with other bats.

The hierarchy applet reached congruence for BBS scores after 16 iterations for Group 1 and fourteen iterations for Group 2. Scores can be found in Tables 3.2 and 3.3 in the Appendix. Relative-dominance is illustrated in Fig. 4.1 and 4.2. High, positive scores indicate high rank. Group 1 had four circular triads as a result of two interactions (Table 4.2 in Appendix) that did not follow the pattern predicted by BBS scores. Group 2 had four circular triads from fourteen dominance reversals (Table 4.1 in Appendix). Eight of these reversals were between closely-ranked Blue and Green.

The three juveniles in Group 2 each displayed a different foraging technique that, with varying success, counteracted their dominance disadvantage. As previously mentioned, Juv. Red fed with the adult female Green and gained by her ability to eject the raiders of her feeding station or the residents of a station she approached. The second juvenile male, Juv. Silver, perched on a branch between Stations B and C before making fly-by raids. The third, the female Juv. Gold, scavenged on the ground for dropped pieces. Neither of the latter two young was associated with any particular adult female. 


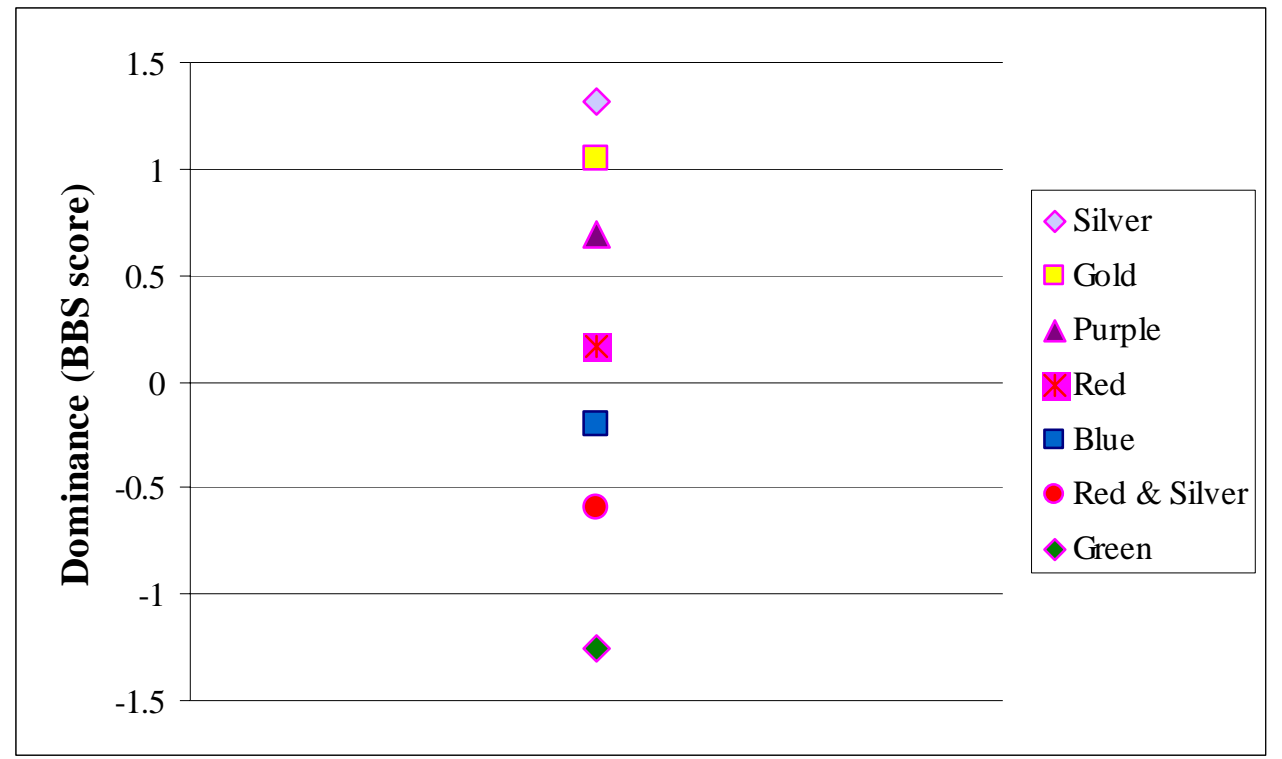

Fig. 4.1. Relative dominance of Group 1 bats when dominance is the ability to control access to food. Marker border indicates sex (blue = male, pink = female).

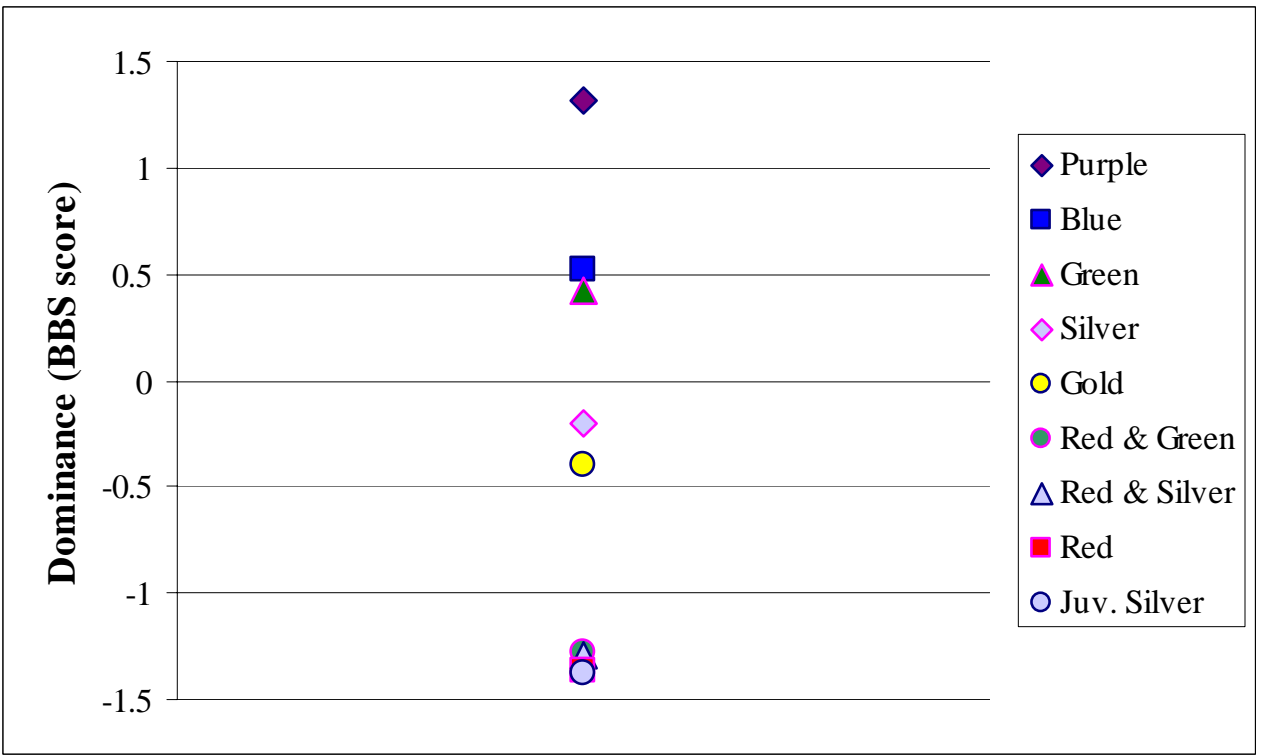

Fig. 4.2. Relative dominance of Group 2 bats when dominance is the ability to control access to food. Marker border indicates sex (blue = male, pink = female).

\section{DISCUSSION}

As shown by the circular triads found in this study, dominance is generally but not strictly linear. As with other data analysed with the BBS model (Jameson et al. 1999), most instances in which the winner was inaccurately predicted by BBS scores 
were between animals in the middle of the hierarchy and those with very similar scores. Some circular triads and intransitivities may be the result of considering all residents to have "won" an interaction with an ejected raider. Co-residency between particular adults was not common enough to have significantly altered relative dominance. The effect of alliances between low-ranking individuals on their interactions with highranking individuals warrants further investigation.

Contrary to other accounts of flying fox hierarchies, females were not universally subordinate to males. The only male in Group 1, Blue, was placed in the middle of the hierarchy. In his nine agonistic encounters with other bats the only five that he won were against the lowest ranked bat, Green. His ranking may have more to do with his individual characteristics than his sex: he rarely came to the feeding stations during the observation period and did not have the aggressive guarding behaviour seen in several of the Group 2 bats. In Group 2, a female bat, Green was ranked above two adult males and near the top of the hierarchy. If wild P. scapulatus or other Pteropus species exhibit male-over-female dominance, as suggested by some researchers (see above), the entire group may benefit. Nelson (1965a) proposed that dominance by sex allows males to “stabilize” monogamous and polygamous groups during the breeding season and, in polygamous groups, to interrupt fights between females. It is unclear what Nelson meant by "stable" but if this is taken to mean that the group exhibits a consistent dominance hierarchy then the present study indicates that small groups of captive $P$. scapulatus (observed outside of the mating season) do not require male dominance to create a "stable" group nor to resolve female-female conflicts. 
There was a negative correlation between dispersal frequency ("raiding" as defined in Chapter 3) and dominance ${ }^{8}$. Although the data used to calculate dispersal frequency and dominance are related, an inverse relationship between them does not necessarily follow. For instance, in Group 2 Red, Red \& Green, and Juv. Gold were the bats observed in 16 of the 17 instances $^{9}$ of bats seen on the ground. Due to their foraging method, these bats were responsible for little dispersal (Fig. 3.2) yet none won any encounters (Table 3.3 in Appendix). In the wild, flying foxes have a strong aversion to foraging on the ground (Ratcliffe 1931, p. 50; Courts 1996) so this behaviour would not be such a viable option. The inverse correlation between dispersal and dominance by Group 2 bats $(r=-0.19)$ was strengthened $(r=-0.55)$ when those bats that scavenged for fallen food were discounted. The relationship was more immediately evident in Group $1(r=-0.78)$ in which the least dominant bat, Green, had the highest raiding frequency (Fig. 3.1). In this group, no bat regularly scavenged on the ground but many retrieved pieces that fell on a stump just below Station A. These results suggest that in the wild seed and pollen dispersal are performed most frequently by low ranking individuals. Age was closely related to BBS score. Most of those born in 1999 or later (Tables 2.1 and 2.2 in the Appendix) are low-ranking/dispersers. Data were collected in 2003.

The interactions between Juv. Red and Green exhibit the potential importance of maternal ranking. Juv. Red obtained the greatest amount of fruit for the least effort by foraging with his mother. If a wild mother is able to maintain her own feeding territory,

\footnotetext{
${ }^{8}$ Juv. Red and Juv. Gold were assigned the BBS score of Juv. Silver because their foraging behaviours confounded dominance estimates.

${ }^{9}$ Juv. Red was the bat in the remaining incident; he was believed to have fallen in a dispute so this instance is ignored.
} 
then her juvenile would obtain a greater volume of food than if foraging independently and would be able to observe effective territorial behaviours. Relatedness between mothers and offspring can have a strong effect on dominance-structure estimates that are based on feeding behaviours by creating intransitivities where juveniles dominate their mothers (Tufto et al. 1998). In a study of caribou hierarchies, relatedness had a stronger effect on the dominance structure than sex, age, or antler size (Tufto et al. 1998). There was no evidence in the present study to indicate that offspring were dominant to their mothers but similar studies carried out intermittently over several years could further investigate whether tolerance for another mature bat increases with relatedness and how dominance of the mother affects dominance of independent offspring.

In conclusion, demographic factors affect the outcome of feeding-interference interactions. Contrary to published observations of most Pteropus species, P. scapulatus females are not universally subordinate to males. It may be that the larger size of the average adult male Pteropus has confounded previous studies of male-female dominance. Age also affects position in the hierarchy. Although P. scapulatus are considered sexually mature at age three, bats younger than four years old tend to be subordinate to and perform more dispersal than older bats. Due to the near-adult size of sub-adult bats and the physical limitations of banding, it would be nearly impossible to confirm the correlation of dominance with age in a wild population. Relatedness may allow the semi-dependent juveniles of high-ranking females to obtain better food resources than those with low-ranking mothers. The mother's rank in the hierarchy thus affects the probability of both her physical and genetic survival. 


\section{Chapter 5: WELLINGTON ZOO MANAGEMENT RECOMMENDATIONS}

\section{INTRODUCTION}

Fruit bat exhibits have become popular attractions at zoos (Vaughn 1989; Fascione 1996). Their success has led not only to increasing public appreciation of these often-feared animals but to increased populations of captive bats as well. Zoos have been pivotal in protecting several species, such as the Rodriguez fruit bat (Pteropus rodricensis) (Fascione 1996). Folsom Children's Zoo (Lincoln, NB), Brookfield Zoo (Chicago, IL), Philadelphia Zoo (PA), Metro Washington Park Zoo (Portland, OR) and the Wildlife Conservation Park/Bronx Zoo (New York City, NY) all display this species (Fascione 1996). As attention to bats and to their declining populations have grown, it is likely that public interest in the quality of their captive environments has also increased.

Analyses of Pteropus scapulatus food preferences and dominance patterns (Chapters 2 and 4) at Wellington Zoo have important implications for their management. Chiroptera-enclosure literature and personal observations of the zoo's visitors provide additional support for changes to the exhibit's design and operation. Recommendations focus on feeding but encompass enclosure design, public education, and individual identification. Some early suggestions, such as a more engaging information display, are already being implemented. Wellington Zoo should continue to improve the experiences of their flying foxes and of those who observe them. Although sometimes difficult, ${ }^{10}$ changes should always be made with consent of veterinarians, keepers, and managers.

\footnotetext{
10 "Sometimes we have all finally laughingly agreed that the designer's dream may be one in which natural materials, including decomposed fecal matter, are present as they might be in the wild while the veterinarian's dream is of a tiled set of walls, floor, and ceiling that are automatically sprayed hundreds of times per day to eliminate all potentially deleterious microorganisms. It has sometimes surprised me that people of good will can finally come to mutually acceptable agreement when they are working from such diametrically opposed biases.” Markowitz 1982, p. 170
} 


\section{PHYSICAL STRUCTURE}

\section{Signage}

Many visitors may be unclear about what is and is not on display in the Wellington flying fox exhibit. Visitors frequently expressed that they could not find the kiwi (Apteryx sp.) (a former occupant of this enclosure) but were also heard to comment that they could see a morepork (Ninox novaeseelandiae) flying even though no

morepork was present. Visitors also mistook the flying foxes for a species of native New Zealand bat. Clearer, eye-height signage (as well as the display on flying foxes currently being constructed) would better inform the public.

\section{Lighting}

The dim lighting conditions pose an additional problem. While it is recognised that nocturnal houses are designed to reflect night conditions during open hours, the current display is too dark to allow vision to adjust within the time most visitors spend in the area, especially as bats usually roost in the darkest, farthest (therefore the most difficult to observe) area of their enclosures (Pate 1996). The Metro Washington Park Zoo in Portland, Oregon (USA) has developed a Pteropus exhibit that uses lighting and backgrounds to suggest a mountain scene at sunset (Pate 1996). This design allows a plausible justification (from the visitor's perspective) to increase the brightness of the exhibit by allowing the last 'rays' of the ‘sun' (directional lighting) to be projected from the floor of the enclosure to the ceiling or upper branches where the bats roost. It uses yellow-red lights, which would emphasize the red-brown colouring of $P$. scapulatus, and allows the less-obtrusive incorporation of a basking lamp, which could replace the Wellington exhibit's orange spotlight. 


\section{Temperature}

Markowitz (1982, p. 197-198) stressed that captive animals should make as many decisions about their environment as possible. Increasing the variety of temperature and lighting conditions in the Wellington Zoo enclosure would give the bats more control over their immediate environment by providing them a range of conditions. In the wild P. scapulatus roost in non-shaded areas even in temperatures most humans find uncomfortable. They most efficiently regulate body temperature at ambient temperatures of $24-35{ }^{\circ} \mathrm{C}$ but will allow core body temperature to reach $41{ }^{\circ} \mathrm{C}$ before making an earnest attempt to cool (Bartholomew et al. 1964). The exhibit temperature, currently kept at $18-22{ }^{\circ} \mathrm{C}$, should be increased to $24-35{ }^{\circ} \mathrm{C}$ or basking lamps ${ }^{11}$ should be added. Basking lamps would encourage them to use more-visible areas of the exhibit particularly if the rest of the exhibit is kept at its current temperature range. They would also provide a way for the bats to dry their wings in Wellington's damp winters. It should be noted that shivering does not necessarily indicate that a bat feels cold: nervous flying foxes shiver regardless of ambient temperature (Bartholomew et al. 1964).

\section{Future enclosures}

Other features of the Portland enclosure (Pate 1996) should be considered for future changes to the Wellington Zoo nocturnal house. The enclosure is horseshoe shaped, allowing visitors a nearly 360 degree view while also increasing the complexity and flight-distance available to the bats. The termini of the 'horseshoe' are wider than the middle to provide adequate turning space in flight. The enclosure floor is sunk about

\footnotetext{
${ }^{11}$ Lamps must be covered with weld-mesh to prevent bats from having direct contact with the hot surface Courts, S.E. 1996. An ethogram of captive Livingstone's fruit bats Pteropus livingstonii in a new enclosure at Jersey Wildlife Preservation Trust. Dodo 32: 15-37..
} 
one metre below the visitors' floor, thereby increasing the perception of viewing the bats in their natural canopy roost and bringing bat-flight closer to eye-level.

Another option would be a free-flight enclosure which visitors would be able to enter, much like the new 'Twilight,' the second nocturnal house at Wellington Zoo. The Henry Doorly Zoo (Omaha, NB) houses P. giganteus and the Egyptian fruit bat Rousettus aegyptiacus, as well as other animals, in a free-flight enclosure, which can also be viewed by diners at a zoo restaurant (Fascione 1996). Although some of Wellington Zoo's visitors appeared reluctant to enter the current viewing area, which has a glass separation between the bats and viewers, ninety percent of visitors to the Brookfield Zoo chose to enter the free-flight bat exhibit after learning that there would be no barriers between them and P. rodricensis (Fascione 1996). An exhibit that allowed visitor entry but also contained an enclosed viewing room would accommodate both the apprehensive and those desiring a more immersed experience.

The floor of the Wellington enclosure is comprised of dirt. If it were instead covered in a substrate of "deep shavings" that are not cleaned of fallen food, as at the Jersey Wildlife Preservation Trust, UK (Courts 1999), keepers would need to spend less time cleaning and may be able to use the area for composting other food scraps. The Egyptian fruit bat Rousettus aegyptiacus will develop symptomatic $\mathrm{B}_{12}$ deficiency if given washed fruit (Prociv \& Tracey 1986) and P. poliocephalus is believed to consume old faeces to obtain $\mathrm{B}_{12}$ synthesized by bacteria (Prociv \& Tracey 1986) so care must be taken to ensure that sanitation does not compromise the animals' health. 


\section{Weather}

Wellington Zoo should continue its practice of shifting the bats from an exposed exhibit to an indoor enclosure (the original nocturnal house) during the winter because cold, wet weather can increase mortality rates, especially among one- and two-year old juveniles (Hall \& Richards 2000) and damage cold-susceptible wing membranes even at non-lethal temperatures (Bartholomew et al. 1964). Unlike some other bat species, $P$. scapulatus does not enter torpor and rarely, if ever, experiences freezing conditions in its natural range (Bartholomew et al. 1964).

\section{$\underline{\text { Short-term }}$}

- Eye-height signage

- Bat information display

- Brighter ambient light inside exhibit (possibly with a 'sunset' theme)

- Basking lamps covered in weld-mesh.

- Lower enclosure floor height relative to visitor floor

- Wood shaving substrate

- Leave dropped food on substrate

- Continue shifting bats to indoor enclosure in winter

\section{Long-term}

- Horseshoe-shaped enclosure and/or

- Visitor entry

\section{FEEDING}

The majority of data collected for this study were related to what and how the Little Red Flying Foxes ate. Several changes to food presentation and composition are recommended. Some suggestions also pertain to the physical design of the exhibit. More information on the nutritional requirements of bats can be found in articles listed in the appended "Recommended reading list for captive management." 


\section{Water}

Fruit bats should have ad libitum access to fresh water (Dierenfeld et al. no date). Although the current enclosure allows bats to obtain water ad lib. from a shallow pool, the pool is too small and surrounded by too much vegetation to allow them to skim the surface then lick the water from their fur (Jones 2001). The bats should not be required to crawl down to the ground to obtain water as, in the wild, flying foxes have a strong aversion to going to the ground and only do so in extreme circumstances (Ratcliffe 1931, p. 50; Courts 1996). Only neonates would have a significant risk of drowning; bats swim surprisingly well (Dillon 1960 in Mickleburgh et al. 1992, p. 188; H. Spencer, pers. com.). Branch-height stations containing drinking water should be added to the exhibit. They should be of a sufficient size or volume that the bats do not empty them between keeper visits. A saline solution (half the concentration of sea water) is preferred (Nelson 1989; Hall \& Richards 2000, p. 109) but should be offered in addition to (not instead of) plain water.

\section{Diet presentation and volume}

The increase in fighting that occurs at high bat : feeding station ratios (Chapter 3), combined with the deaths of two non-dominant bats during this study, suggest that subordinate bats may not have adequate access to food when few feeding stations are provided. Despite presentation of equal total volumes of food it is believed that individual flying foxes did not obtain equal volumes at different bat : pottle ratios. It is suspected that under test conditions dominant bats obtained more food (and subordinate bats less food) than under baseline (i.e. zoo standard) procedures. It is therefore 
recommended that, until this inequality can be verified or refuted, keepers use one feeding station for every two bats or (at minimum) three bats.

Wellington $P$. scapulatus currently each receive just under $100 \mathrm{~g}$ of fruit daily, $26-33 \%$ of their mass (Nelson 1965b). Each P. livingstonii, a larger species than $P$. scapulatus, receives about $360 \mathrm{~g}$ of fresh fruit and vegetables plus $20 \mathrm{~g}$ of soaked Old World Monkey pellets each day at the Jersey Wildlife Preservation Trust (Courts 1996). Other captive Pteropus species have been reported to consume $28 \%$ of their body weight in food (wet weight; 7\% dry weight) each day (Dierenfeld \& Seyjagat 2000). Dempsey \& Crissey (1995) proposed that adult bats be offered 50 - 120\% of their body weight in food (10-15\% of body weight on dry matter basis). Shilton (1999) found that captive Cynopterus sphinx, a frugivorous megachiropteran, maintained wild-caught weight when provided twice their body weight in fruit. Wellington Zoo's practice of providing food based on a visual approximation of fruit volume should be re-examined to ensure that this method provides adequate food. There is some evidence that blossom bats may rapidly increase body mass when food is abundant beyond maintenance requirements, such as when offered ad libitum (Law 1993). However, it has been recommended that nectarivorous bats, such as $P$. scapulatus, have ad libitum access to homogenously mixed diets, which should be given at least twice each day (Dierenfeld et al. no date). Juveniles and pregnant females are differentially affected by food shortage (Collins 2000) so should be used if dietary sufficiency is to be evaluated by bat weight.

\section{Nutrition}

Wild fruits contain different levels of some nutrients than cultivated varieties do so that particular care must be taken to ensure that the diet is nutritionally complete 
(Dierenfeld et al. no date). Some diseases in fruit bats have been related to over- or under-dietary provision (see review in Dierenfeld et al. no date; Hall \& Richards 2000, p. 49). Vitamin E deficiency has been a problem for some captive Pteropus species; it can be prevented by including kale leaves in the diet (Stone 2002-2003). Bats will consume more of a preferred food when paired with less-preferred food (Courts 1999). Less-preferred fruits (Chapter 2) that are nutritionally important should be presented before or exclusive of preferred fruits. Provision of extra protein (e.g. double the ration of milk powder) (Hall \& Richards 2000, p. 109) and extra food in general (50\% more than usual) (Dempsey \& Crissey 1995) are recommended for pregnant and lactating bats. Flying foxes have a maintenance nitrogen requirement of about $457 \mathrm{mg} / \mathrm{kg}^{0.75}$-day (Steller 1986). Fruit-bat diets have also been supplemented with vionate and calcium carbonate (Herrera et al. 2000), vitamin and mineral-enriched molasses blocks (Martin et al. 1995), and, during cold weather, avocado, butter or olive oil (Luckhoff 1987). Dempsey \& Crissey (1995) provide three examples of nutritionally complete diets that vary widely in the proportions composed by fruit, illustrating the flexibility of nutrient provision when the diet includes various types of vegetables, nectar, nutritionally complete products, and vitamin supplements. Diet evaluations should include the nutritional content of food in enrichment activities as well as that provided in meals.

Obesity has been reported among some captive $P$. rodricensis and P. livingstonii but the excess weight has been attributed to food presentation and composition rather than volume (Courts 1999). Courts found that high dietary diversity (mean $=13$ fruits/vegetables) each day allowed younger/captive-born P. livingstonii (which began feeding earlier than older/wild-born individuals) and dominant bats to select preferred 
fruits from the mixed-fruit feeding troughs, thus avoiding less-preferred but nutritionally-important foods. ${ }^{12}$ The older and subordinate bats that consumed what remained also did not obtain a nutritionally balanced diet. Courts emphasizes that problems associated with selective consumption from high-diversity provisions are exacerbated by the bat dominance hierarchy that gives some animals the opportunity to consume preferred food from several feeding stations. If food is provided in superabundance to ensure that subordinate animals obtain adequate food then dominant animals will be able to consume even more than their required intake and may develop weight problems. He recommends that the number of stations (one for each weaned bat) be further increased, that stations be widely distributed to avoid confining all of the food in a single bat's territory, that banana and avocado be given only occasionally instead of daily (to assist in weight loss), and that nutrients be balanced over a week rather than a day so that only 4-5 types of fruit or vegetable (in addition to pellets) be given on any one day. He further recommends that foraging stations be moved regularly to encourage foraging behaviour. Although Courts maintains that a single site could not be dominated by a single bat, it seems unlikely that all bats would have equal access to the site and the increase in aggressive interactions may lead to greater incidence of injury.

\section{Short term}

- Enlarge the pool in the exhibit and clear surrounding vegetation

- Branch-height water stations, available ad lib.

- One feeding station for every 2-3 bats

- Re-evaluate food weight provided

- Provide 'nectar' twice daily

- Re-evaluate nutrition

- Provide only 4-5 types of fresh food daily

- Balance nutrients over a week

\footnotetext{
${ }^{12}$ Courts' observations directly contradict Erkert (1982) who found that captive lower-ranking mega- and microchiropterans approach feeding stations earlier (often before dark) than high-ranking individuals.
} 


\section{ENRICHMENT}

The monotonous feeding schedules (same content, time, and location) for most zoo animals are efficient and usually designed for easy cleaning but do not reflect the variety and novelty inherent to natural foraging situations (LeBlanc, no date). Enrichment can be used to stimulate foraging and social behaviours and may even prevent undesirable, boredom-related activities. Masefield (1999, p. 49) reports that enrichment of adult male $P$. livingstonii has prevented them from "engaging in more deleterious occupations,” such as injuring juveniles. Although some or all animals may clearly benefit from enrichment activities, their participation should always be voluntary (Markowitz 1982, p. 198-199). As feeding behaviours were the focus of this study, enrichment suggestions below are primarily related to foraging. An extensive review of fruit-bat enrichment ideas can be found in (LeBlanc, no date).

\section{Intact fruit}

Natural foraging behaviour could be encouraged by loose or hung intact fruits (kebabs) (Dierenfeld et al., no date). Size must be considered for some loose fruits: despite the variety of handling behaviours available to flying foxes that permit them to manipulate very large fruits (Eby 1998), P. scapulatus may have difficulty handling large intact round fruits such as apples and peaches (Ratcliffe 1931, p. 45). These should not be left loose (as they will fall to the ground) but can be used if hung securely as kebabs. Fruits that are difficult for P. scapulatus to consume intact due to their rind, such as oranges, can be included chopped but unpeeled in pottles. Rather than being consumed in their entirety, these unpeeled oranges are held and licked (Courts 1996). 


\section{Forage}

Forage has been described as the most effective enrichment for some groups of bats (Masefield 1999). Vegetable and tree leaves can be important sources of protein (Kunz \& Ingalls 1994) and can increase the variety and complexity of fruit bat enclosures. Masefield (1999), using ash (Fraxinus excelsior), bamboo (Phyllostachys/ Arundinaria sp.), bramble (Rubus fruticosus agg.), and willow (Salix sp.), found that aggressive and non-aggressive social interactions and general activity increased in the presence of forage but were positively correlated with palatability. Aggressive social interaction was not greatly increased by forage presence but may not be completely undesirable as it establishes and maintains the dominance hierarchy (Masefield 1999). Dominant and subordinate bats were equally likely to use the many foraging stations (nearly one per bat) that were arranged so as not to be confined to the territory of a single bat, thus minimising conflict. He found that willow was the most popular forage species, followed by bamboo. Ash became more popular as the study continued. Bramble was popular with only a few bats. These species are also likely to be readily available for use by Wellington Zoo. Unlike some forms of enrichment, popularity of each forage and forage in general did not wane with exposure (it even improved for ash), suggesting that familiarity may increase use of new enrichment and food items.

\section{Nectar}

The wild diet of $P$. scapulatus is approximately 90\% nectar (Richards 1995). Natural nectar-foraging behaviours can be encouraged by using feeding tubes and bowls and by the provision of fresh flowers (Dierenfeld et al., no date). 'Nectar' can be made by adding sugar and honey to water (with or without the inclusion of dog biscuits, 
vitamins, and bee pollen currently included in Wellington Zoo's bat 'nectar'). Presentation of 'nectar' at nocturnal-house equivalents of dawn and dusk would mimic the peaks in nectar secretion by an Australian Banksia species (Paton \& Turner 1985). The concentration of sucrose found naturally in the nectar of B. integrifolia, a known diet species for Australian Pteropus, is $24 \% \mathrm{wt} / \mathrm{wt}$ (Law 1993) but blossom bats accept 'nectar' concentrations from table sugar of $40 \% \mathrm{wt} / \mathrm{wt}$, the highest concentration offered (Law 1995). 'Nectar' of varying concentrations could be presented simultaneously to simulate the inconsistent nectar rewards of natural foraging and to encourage movement between feeding stations (Paton \& Turner 1985). If bees became a problem in an outdoor enclosure the solution could be sprayed onto flowers or given in buckets within two hours of sunset when bees are no longer active (Law 1995).

\section{Short term}

- Increase frequency and variety of enrichment activities

- Intact-fruit kabobs and loose intact fruit

- Forage (leaf) enrichment

- Feeding tubes and flowers

- Simulate nectar availability of wild foraging

\section{TRAINING}

Training has many benefits: it can reduce capture- and handling-stress (experienced by keepers as well as the bats), facilitate oral medicating (LeBlanc, no date), and allow participation in free-flight shows or school visits. Flying foxes soon recognise when a stimulus is not a danger (Markus 2002) and have habituated to many methods designed to frighten but not to injure them (Ratcliffe 1931, p. 16; Vardon et al. 1997). Non-captive flying foxes have been notably tolerant of tourist attention to their roosts in Tonga (Grant 1996). Even the loud noises, such as slamming car doors, and 
many people associated with 10 to 15 daily tours do not seem to disturb them. Wildcaught $P$. poliocephalus and $P$. scapulatus have readily adapted to captivity and handling (Bartholomew et al. 1964).

\section{Overcoming fearfulness}

Although $P$. scapulatus may be less wary in the wild, it is apparent that Wellington's captive colony fears humans even under conditions (such as darkness) in which the bats are not normally caught. Perhaps avoidance despite non-handling conditions is due to this species’ purported lack of intelligence (Ratcliffe 1931, p. 16). Habituation and conditioning can be used to make them accept human contact enough to facilitate husbandry-related procedures (LeBlanc no date), or even free-flight education performances. Juveniles (especially those that are hand reared) will be most readily trained but it is possible that by focusing on dominant adult animals the other bats will more readily accept training: if the most submissive bats are trained first then moredominant bats are less likely to "follow the leader" and must, more or less, be started from scratch. If feasible, training should initially be done in a smaller area than the nocturnal-house enclosure until the bat reliably approaches the handler, at which point the animal can be returned to the group to act as an example (and competition for rewards). The first or first few animals should be housed away from the main group to avoid the stressful identification and capture of bats for training. Training should use operant conditioning with favoured foods (Chapter 2) as rewards. These favoured foods should not be included in the regular diet. This will require a significant investment of time that may be best allocated to volunteers rather than staff. 


\section{Short term}

- Select individuals; use juveniles and dominant animals

- Selected animals in smaller enclosure until approach trainer

- Habituation and positive reinforcement training

- Food rewards

\section{Long term}

- Free-flight shows

- Off-site public education

\section{PUBLIC EDUCATION}

Little Red Flying Foxes can contribute much more to Wellington Zoo’s three themes: Islands in Isolation, Forests Will Flourish, and Wildlife for Sale. Many Pteropus species are endemic to islands. They have representatives in Australia $(P$. scapulatus, $P$. poliocephalus, $P$. conspicillatus, $P$. alecto) and Madagascar ( $P$. voeltzkowi), two of the nations the zoo has chosen to illustrate the effects of isolation on wildlife. The relationship between Australian eucalypt and rain forests and flying foxes (Chapter 3) is an excellent example of the interdependence of plants and animals. Extinctions of several island Pteropus species have been attributed to over-exploitation for food (Wiles 1990; Lemke 1986) and traditional medicines (Heinrichs \& Zahnke 1997). Photos are available of flying foxes intact in a bowl of soup (Lemke 1986) and shrink-wrapped for sale in a grocery store (Wiles 1990).

Like many of the visitor comments observed during this study, initial reactions to bats at the Metro Washington Zoo (Portland, OR) are typically negative, especially among adults, which (according to Pate (1996)) encourages their children to investigate. Despite this initial (proclaimed) aversion an exit survey revealed that the bat exhibit was the visitors' favourite of the rainforest exhibits (surpassing those of monkeys, otters, and crocodiles) and that many came to the zoo specifically to see the bats (Fascione 1996). 
Other reports are even less ambiguous: a keeper at the Wildlife Conservation/Bronx Zoo (New York City, NY) said he had never heard negative comments about the $P$. giganteus that are included in the large walk-through enclosure (Fascione 1996). The trained $P$. giganteus used in the Marine World (Vallejo, CA) wildlife show is considered one of its most popular animals (Vaughn 1989). This bat visits over 10,000 children at schools each year. Public interest is already so great that more than $60 \%$ of North American zoos responding to a survey indicated that they have bat education programmes, even though some of those institutions did not actually house any bat species (Fascione 1996).

Wellington Zoo could exploit this enthusiasm by including a trained flying fox in its planned free-flight avian show (Ian Butcher, pers. comm.) and by incorporating regular keeper talks at their enclosure. Public fear could be reduced by encouraging several individuals to enter the enclosure with the keeper to re-stock fresh food or, after bats have been trained to approach the keeper, to offer food by hand.

Short term

- Daily keeper talks

Long term

- Free-flight shows

- Hand feeding by visitors

\section{OTHER RECOMMENDATIONS}

\section{Banding}

Thumb bands used to identify individual bats can restrict blood flow to the digit if even marginally snug, which can rapidly lead to severe tissue damage (pers. obs.). Future banding exercises should use the aluminium thumb bands used by the Australasian Bird and Bat Banding Scheme or the plastic rings used by other institutions 
(Masefield 1999; Morrison 1978). If greater visibility is required, gift-wrap ribbon (which is reflective, comes in multiple colours, and is more colour-fast than cotton string) can be looped through the band instead of directly around the thumb. The consistent size of the metal (or plastic) bands will reduce the chance of restricted blood flow yet allow adequate space for additional identification ribbons.

\section{Sex ratio}

Wild $P$. scapulatus may segregate by sex during parts of the breeding cycle but their overall populations do not seem differ from parity (McIlwee \& Martin 2002). Problems, such as continual harassment of females, have occurred in Pteropus enclosures with many more males than females (Hugh Spencer, pers. comm.; pers. obs.). The current enclosure at Wellington Zoo allows adequate space for sex-based segregation so efforts should be made to keep an equal number of male and female animals. Other institutions house males and females separately (Herrera et al. 2000).

\section{Exhibiting more species}

The exhibit would benefit from the addition of another Pteropus species. A thematically consistent choice would be another Australian species ( $P$. conspicillatus, $P$. poliocephalus, ${ }^{13}$ P. alecto). The addition in itself is unlikely to negatively affect the current bats as wild P. scapulatus roost with other Pteropus species (Nelson 1965a). They all have similar dietary requirements and a high degree of diet-species overlap (Fujita \& Tuttle 1991). Alternatively, a diurnal species (P. melanotus natalis, P. niger, P. molossinus, $P$. insularis, $P$. seychellensis, $P$. hypomelanus maria, $P$. samoensis samoensis: Pierson \& Rainey 1992; P. livingstonii: Trewhella et al. 2001) would be

\footnotetext{
${ }^{13}$ Unlike $P$. scapulatus, $P$. poliocephalus testicular growth is sensitive to changes in photoperiod so, if kept with artificial lighting, light:dark cycles must be carefully manipulated (Martin 1999).
} 
more suitable to an exhibit that did not use a reversed light cycle, although even reputedly diurnal species may actually be more active at night (Brooke 2001). Care must be taken to ensure adequate roosting area as it has been suggested that if roosting habitat becomes limited, Pteropus may be less tolerant of other species (Markus 2002).

The other Pteropus species would be better candidates for training for a freeflight show or other public education programme. P. poliocephalus, the Grey-Headed Flying Fox, and P. alecto, the Black Flying Fox, are the most likely contenders as their Vulnerable status in New South Wales (NSW National Parks and Wildlife Service 2002, p. 1) lends greater urgency to captive breeding. Information on minimum enclosure size and standards of care can be found in the Fruit Bat Husbandry Manual (Fascione 1996).

Non-Pteropus species could also be added. The Metro Washington Park Zoo Pteropus enclosure includes other bat species, birds and reptiles (Pate 1996). $P$. scapulatus inhabits several habitat types, including eucalypt forest, mangroves, and heathlands (McWilliam 1985-1986) permitting significant flexibility in selecting other species to be displayed. Although they would contribute to a naturalistic design and would be educational and perhaps enjoyable to the public, known predators, such as crocodiles, white-bellied sea eagles (Haliaeetus leucogaster), Brahminy kites (Haliastur indus), powerful owls (Ninox strenua), and large pythons (Hall \& Richards 2000, p. 53), should not be included.

\section{Short term}

- Metal or plastic thumb bands for visual identification

\section{Long term}

- Approximately equal male : female population

- Another Pteropus species

- More Australian species 


\section{CONCLUSION}

The maintenance of animals in captivity provides many opportunities that would otherwise be impractical or impossible, such as controlled research on their biology and ethology, breeding of species no longer able to survive in the wild, and the ability of the public to appreciate them in person. However, these opportunities are not free from obligations. In addition to the obligation to provide for the physical health of captive animals, which has historically been the emphasis of care, most institutions now recognize that they also have a responsibility for the psychological and social health of their animals (Markowitz 1982, p. 197-198). While display of nocturnal animals, such as most bat species, in a nocturnal house allows visitors to view them when most active, the darkness can obscure the exhibit's features. Not only can the public less-well appreciate the habitat considerations but they can not see the exhibit well enough to critique design elements, such as enrichment activities, that modern visitors have come to expect.

The Wellington Zoo Little Red Flying Fox enclosure could be improved by changes to the physical structure and care structure. It is obvious that the physical and psychological welfare of their charges are of paramount importance to the zoo's keepers. The necessity of working overtime and on days off to finish feeding or repair enclosures or cover for co-workers at a conference would make any change to exhibit management all the more daunting. Increasing the number of staff and making greater use of volunteers would alleviate both time pressure and (potential) employee exhaustion. In the past decade Wellington Zoo has made significant improvements to the designs of many of its enclosures. The new walk-through nocturnal house, for example, is 
evidence that increasing the quality of animal welfare and of visitor experience remain priorities. Implementation of the design and management recommendations described above will continue this transformation.

\section{SUMMARY OF RECOMMENDATIONS}

\section{Physical Structure}

Short-term

- Eye-height signage

- Bat information display

- Brighter ambient light (inside exhibit) (possibly with a 'sunset' theme)

- Basking lamps covered in weld-mesh.

- Lower enclosure floor height relative to visitor floor

- Wood shaving substrate

- Leave dropped food on substrate

- Continue shifting bats to indoor enclosure in winter

Long-term

- Horseshoe-shaped enclosure and/or

- Visitor entry of free-flight enclosure

\section{Feeding}

\section{Short term}

- Enlarge the pool in the exhibit and clear surrounding vegetation

- Branch-height water stations, available ad lib.

- One feeding station for every 2-3 bats

- Re-evaluate food weight provided

- Provide 'nectar' twice daily

- Re-evaluate nutrition

- Provide only 4-5 types of fresh food daily

- Balance nutrients over a week

\section{Enrichment}

Short term

- Increase frequency and variety of enrichment activities

- Intact-fruit kabobs and loose intact fruit

- Forage (leaf) enrichment

- Feeding tubes and flowers

- Simulate nectar availability of wild foraging 


\section{Training}

Short term

- Select individuals; use juveniles and dominant animals

- Selected animals in smaller enclosure until approach trainer

- Habituation and positive reinforcement training

- Food rewards

\section{Long term}

- Free-flight shows

- Off-site public education

\section{Public Education}

Short term

- Daily keeper talks

\section{Long term}

- Free-flight shows

- Hand feeding by visitors

\section{Other}

\section{$\underline{\text { Short term }}$}

- Plastic or metal thumb bands for visual identification

\section{Long term}

- Approximately equal male: female population

- Another Pteropus species

- More Australian species 


\section{Chapter 6: GENERAL CONCLUSION}

Flying fox management encompasses several distinct areas but, as this study illustrates, research can have overlapping applications. Food preferences impact orchard-raiding deterrence and zoo management. Raiding patterns relate to captive health and seed and pollen dispersal. Dominance hierarchies influence the demographics of raiders with implications for wild-population and zoo management. Exhibit design affects animal welfare as well as public education. Although flying-fox research has become much more abundant since the 1980s, our understanding of flying fox biology, ecology, and behaviour remains sketchy, at best. Their migratory habits and, until recently, use of non-urban habitats as well as the number of endemics on remote islands made this research prohibitively difficult. Further development in our knowledge of flying-fox relationships with each other, their environment, and with humans is vital if cohesive species- or land-management plans are to be created for Pteropus and the flora and fauna with which they interact. Additional applications of the present study to flying fox management and more considerations of the above relationships as well as a general summary of its findings are below.

\section{Chapter 2: FOOD PREFERENCE OF PTEROPUS SCAPULATUS}

Flying foxes consume such a taxonomically diverse variety of fruit and blossom that a comprehensive investigation of food palatability would be impossible. Evaluating just the cultivated fruits that are included in Pteropus diets would be a prohibitively large undertaking. As illustrated by this study, the conclusions reached by such research may not accurately reflect the preferences of another group of the same species. Even 
wider variation would be expected for cross-species applications. Nonetheless, this study established that some fruits are distinctly more appealing than others. Bananas and nectarines are desired; apples are avoided. Fresh and processed versions of the same fruit are not equally favoured. Further exploration may reveal what factors determine these preferences. Energy content, fibre content, sugar composition, mineral content, familiarity or novelty, taxonomic similarity to wild resources, odour composition or strength, and handling cost are just a few possibilities. Understanding the reasons underlying Pteropus preference would allow more rapid determination of which cultivated and native fruits and other foods are most effective for behavioural enrichment or husbandry training for captive animals and may give new insight to wildanimal patterns of migration.

Both cultivated fruits and native diet-species produce large, synchronously ripening or blossoming crops (Fenton 1992), a factor known to be attractive to flying foxes (Banack 1998). This makes use of a single native species as an orchard distracter a good possibility. Studies designed to further evaluate the potential of certain tree species for use as distracters should focus on the crop to be protected: when does it need protection (blossoming or ripening), is it preferred to native resources, is exclusion fencing impossible, etc. Known or suspected Pteropus diet species that blossom or ripen simultaneously with the target crop should be presented in pairs (with each other and/or the target crop) for statistical simplicity. Tested foods can be presented in individual bowls or combined as in Courts' (1999) investigation. Studies that are not concurrently investigating feeding interference should use a large number of feeding stations, perhaps as many stations as bats if performed with captive animals or as many stations as 
required to minimize feeding interference if performed with free-range animals. If the consumed proportion of each tested food is used to measure preference, then the higher competition would result in greater diversity of food plants used by flying foxes as a group due to competitive exclusion (Banack 1998) and would reduce the apparent preference for favoured foods. Similarly, estimations of preference based on apparent preferences of individual bats would be skewed and result in lower estimation of individual dietary diversity (Banack 1998). Distracter research should be performed during the period of the breeding cycle in which crop protection would occur in order to simulate preferences that would change with social or physiological seasonal variation.

Distracter trees would have to be located within a few kilometres of the target crop. The trees would have to be watered during drought and otherwise tended to ensure sufficient crops, particularly during years when native flower or fruit would otherwise fail and precipitate heavy orchard raiding (Tidemann \& Nelson 1987; Parry-Jones \& Martin 1987; Fleming \& Robinson 1987). Alternatively, preference information could be used to increase the native food supply on public land through plantings and extra care during periods of potentially poor production. Orchardists would have to be willing to forego income that would be generated from the market sale of distracter fruit but some additional returns could be gained by selling or donating for tax-deduction the fallen or damaged fruit to groups such as zoos or livestock farmers or bat rehabilitators that do not require unblemished fruit or by using damaged fruit for compost to improve the soil of their commercial crops. Use of non-commercial native plants for distracters would eliminate the temptation to profit directly. 


\section{Chapter 3: RESIDENTS VERSUS RAIDERS: THE ROLE OF FEEDING}

\section{INTERFERENCE IN POLLEN DISPERSAL BY PTEROPUS SCAPULATUS}

It is clear that a diminished population raids with reduced frequency. The decrease in raiding with reduced bat : resource density found in this study can not be used directly to predict how a particular population decline will affect cross pollination or seed dispersal in the wild. Diminished dispersal reflects conditions at particular trees or patches rather than in regions. Local population and food abundance would produce consistent levels of feeding interference only if all bats knew the locations of all resources, required minimal energy to shift between locations, considered all resources to be equally desirable. Although tree- and patch-scale interactions will most directly reflect the relationship between feeding interference and dispersal, the ramifications of changes in the frequency of these interactions will be seen at all spatial scales. Reduced populations are predicted to lead to shifts in forest composition away from batdependent plants, decreased local genetic diversity, reduced fruit set, slower regeneration of cleared tracts, possibly increased losses to orchardists (see below) and a cascade of changes to local flora and fauna.

Plants influence pollinator/disperser behaviour by controlling resource quantity and quality. Blossom abundance has been proposed to directly promote feeding territoriality among Pteropus (Gould 1978) but may also indirectly increase aggressive behaviour by causing larger bats to expand their typical feeding ranges thereby evicting smaller neighbours (Syconycteris australis: Law 1995). Pollinators with high energy requirements, such as bats, rely on plants that provide a large volume of nectar (Heinrich \& Raven 1972) so that those species providing a relatively abundant resource are more 
likely to be worth the cost of defence. Similarly, some species provide more concentrated nectar than others (Gould 1978) making them a more valuable resource.

Characteristics of the bats themselves affect the probability of feeding interference. Some species appear more "tolerant” of neighbours than others: up to three P. vampyrus have been observed foraging in a large flowering Durio zibethinus (Gould 1978) but at least 30 P. poliocephalus have been reported in a single fruiting Ficus (Eby 1991). Although more bats will forage simultaneously in larger canopies (Gould 1978) it is unlikely that this difference could be explained by canopy size alone. Markus (2002) has warned that increased competition for roost sites could lead to greater incidence of interspecies conflict. Sensitivity to intruders also varies by individual (this study).

Feeding interference only contributes to cross pollination if the ejected bat leaves the tree or at least the branch (geitonogamous pollination). Pteropus species readily meet this criterion. Nearly all P. scapulatus movements between flowering trees are greater than 10 metres in distance (Hall \& Richards 2000, p. 79). P. tonganus departing from a flowering Ceiba pentandra returned to the same tree but at a different location in only $7 \%$ of departures (Elmqvist et al. 1992). In 38\% of the departures the bats flew to another $C$. pentandra, an appropriate target for out-crossing. The destination of the remaining 55\% could not be ascertained but could have also been $C$. pentandra

Feeding interference does not uniformly benefit plants and may not always be necessary for large-seed dispersal. $P$. tonganus destroys about half of $C$. pentandra flowers and developing fruits during foraging activity, including agonistic encounters (Elmqvist et al. 1992). However, damage does not always detract from flying fox 
pollination: Freycinetia reineckei are successfully pollinated by $P$. samoensis despite considerable damage to the inflorescences (Cox 1984). Not all Pteropus species require "raiding" for large-seed dispersal. Maximum width for swallowed seeds is usually around 3.5 mm (Bollen \& Van Elsacker 2002; Richards 1987). Although rare, ingestion (and subsequent dispersal) of seeds up to $10 \mathrm{~mm}$ in diameter has been reported (Bollen \& Van Elsacker 2002). Species that use feeding roosts away from the source tree, such as P. samoensis (Banack 1998; Brooke 2001) and P. rufus (Bollen \& Van Elsacker 2002), disperse large seeds regardless of population density. These species also may not exhibit territoriality when foraging. Carried-seed dispersal is not limited to a feeding roost close to the source tree, mango seeds have been found at day roosts which are often located several kilometres from foraging areas (P. voeltzkowi: Entwistle \& Corp 1997).

Long-distance pollinators are not equally important for all plant populations or circumstances. They increase the effective breeding size of their food species, a service most needed by those species that occur in low densities and are randomly spaced (Heithaus 1982). Because most trees used as a nectar and pollen resource by Australian flying foxes grow in multi-species communities, they depend on these long-distance pollinators for out-crossing (Hall \& Richards 2000, p. 79). Also, species that are not normally affected by insufficient pollination may have reduced fruit production due to limited pollinators or levels of cross pollination during peak flowering (Copland \& Whelan 1989) so that feeding interference may only benefit these plants when blossom is most abundant. 


\section{Chapter 4: DOMINANCE RELATIONSHIPS IN PTEROPUS SCAPULATUS}

If bat populations are limited by resource availability, juvenile mortality may be disproportionately high, leading to rapid population decline. In the wild, immature but independent young are likely to comprise the bulk of "disperser" bats. As in this study, wild residents, the “dispersal enforcers,” are probably older, dominant male or female animals. This partitioning highlights the importance of maintaining age stratification in wild populations. It also suggests that populations limited by food availability will disproportionately lose young bats to starvation. ${ }^{14}$ This conclusion is supported by the relatively high occurrence of juveniles and sub-adults in animal-care-group admissions following localised food shortages but increased representation of adults and adult males during a widespread shortage (Collins 2000). High juvenile mortality has a significant impact on population growth and can lead a faster rate of population decline than similar mortality rates for older animals (McIlwee \& Martin 2002) so programmes that increase juvenile survivorship, such as the fostering and release of orphaned young, are particularly important.

Separate analysis of interactions at day and feeding roosts may yield dissimilar calculated-dominance hierarchies. Species or individuals that have non-territorial roosting, such as non-breeding $P$. tonganus, do necessarily tolerate conspecifics while feeding (Elmqvist et al. 1992). Similarly, bats that roost as a group do not necessarily feed communally: Elmqvist et al. (1992) found no evidence for cooperative foraging despite mass departure from the day roost and concluded that each bat acts opportunistically. Although day and feeding roosts have some characteristics in

\footnotetext{
${ }^{14}$ Others have suggested juvenile mortality is decreased by increasing the number of feeding stations so that females obtain greater access (Brambell pers. comm. in Mickleburgh et al. 1992, p. 204).
} 
common, such as the way in which they are defended, some aspects markedly differ. Feeding territories typically extend in a 1.5 - 3 m radius (Mickleburgh et al. 1992, p. 129; Elmqvist et al. 1992; Richards 1990) but can vary with the number of bats in the tree (Markus 2002). Day-roost territories during the mating season are somewhat smaller (Nelson 1965a; Mickleburgh et al. 1992, p. 134), although a territory as large as $6.6 \mathrm{~m}$ radius has been reported (Markus 2002). Day roosts are often marked with scapular-gland secretions (Nelson 1965a; Markus 2002) but this behaviour during foraging is unreported suggesting longer-term residency at day roost territories. Neuweiler (1969 in Pierson \& Rainey 1992) reported that male P. giganteus maintain a vertical hierarchy which is manifested by the height of the bat's territory at the day roost, with more dominant bats located higher in the tree. ${ }^{15}$ Such an arrangement in a food tree would probably not allow the most dominant bat to control the most food-productive branches. If day-roost height is truly an indication of dominance, the agonistic interactions used to calculate dominance at foraging sites may not create a hierarchy that accurately predicts the outcomes of interactions at day roost sites.

\section{Chapter 5: WELLINGTON ZOO MANAGEMENT RECOMMENDATIONS}

Wellington Zoo has devoted the interest, knowledge, money, and commitment needed to improve its exhibits to meet the criteria for a "quality” zoo that have changed so much since the zoo was established. I believe that shifting Group 1 into Enclosure 2 made the most profound improvement to their bats' welfare for the least cost that would be possible. If the $P$. scapulatus are to continue to occupy their current enclosure a number of changes should be made to the physical environment and management that will benefit both the animals and the visitors who come to see them. Improvements to

\footnotetext{
${ }^{15}$ This may have some practical purpose: higher branches would be more conducive to a long pre-flight drop, described by several authors (e.g. Dillon 1960 in Mickleburgh et al. 1992, p. 118; Pierson \& Rainey 1992), and would be more exposed to flight-assisting breezes.
} 
lighting and enrichment activities for the bats and information for the visitors are necessary. Incorporating $P$. scapulatus or another Pteropus species in a free flight show and the construction of a walk-through exhibit should be considered in long-term planning. The Fruit Bat Husbandry Manual (Fascione 1995) and other publications from the Lubee Foundation in Florida would be valuable additions to the zoo library.

\section{GENERAL}

The attitudes of Australians are changing. The images of flying foxes in children's literature reflect an improved appreciation and general awareness of the bats (Bernhardt 1995). More people care for orphaned and injured flying foxes than any other native animal (Hall \& Richards 2000, p. 108). Television news presenter Richard Morecroft raised the profile of flying foxes with his book documenting his experience fostering Archie, an orphaned P. poliocephalus (Bernhardt 1995).

P. scapulatus numbers are not low enough or believed to be declining fast enough to warrant protection (Hall \& Richards 2000, p. 96). However, this does not exclude the possibility of a significant decline. Obtaining a reliable population estimate for any bat species is difficult but it is especially challenging for this species. Unlike some other Australian Pteropus (e.g. P. poliocephalus: Parry-Jones 1987), P. scapulatus does not establish year-round camps (Hall 1987) or roost in urban areas (Parry-Jones 2000) so that declines in population may be less apparent. Additionally, their migration patterns are irregular (Hall \& Richards 2000, p. 95) and their range is larger than the combined ranges of the other three mainland species (Hall \& Richards 2000, p. 11) making location and simultaneous census of all camps nearly impossible. Without basic population information, well-considered management plans can not be developed. 
This study has implications for in-situ and ex-situ management and has affected the way we understand Pteropus social interactions. It has given a sketch of their cultivated-fruit preferences that will be useful for managing the nutrition and behaviour management of captive populations as well as for improving orchard-protection strategies. It has established that seed and pollen dispersal, mediated by antagonistic interactions, are greatly affected by resource availability and group composition. It has also demonstrated that female Pteropus can dominate male conspecifics and explored the possibility of the benefit to juveniles of high maternal dominance. Most importantly, this study has provided a foundation for further exploration of these issues. 


\section{REFERENCES}

Allen, G.M. 1939. Bats. Cambridge: Harvard University Press.

Altringham, J.D. 1996. Bats: Biology and Behaviour. Oxford: Oxford University Press.

Anon. 1988. Putting CITES to work for flying foxes. BATS Magazine 6(1): 10-11.

Baillie, J. \& Groombridge, B. (Eds.). 1996. IUCN Red List of threatened animals. Gland, Switzerland.: IUCN.

Baker, H.G., Baker, I. \& Hodges, S.A. 1998. Sugar composition of nectars and fruits consumed by birds and bats in the tropics and subtropics. Biotropica 30(4): 559-586.

Banack, S.A. 1998. Diet selection and resource use by flying foxes (genus Pteropus). Ecology 79(6): 1949-1968.

Barclay, R.M.R. 1995. Constraints on reproduction in bats: energy or calcium? Symposium of the Zoological of Society of London 67: 245-258.

Barclay, R.M.R. 2002. Do plants pollinated by flying fox bats (Megachiroptera) provide an extra calcium reward in their nectar? Biotropica 34(1): 168-171.

Bartholomew, G.A., Leitner, P. \& Nelson, J.E. 1964. Body temperature, oxygen consumption, and heart rate in three species of Australian flying foxes. Physiological Zoology 36(2): 179-198.

Bernhardt, P. 1995. The Bat in the Hat: Flying Foxes in Australia’s Children’s Literature. BATS Magazine 13(4): 15-17.

Birt, P. 2000. Summary information on the status of the Grey-headed (Pteropus poliocephalus) and Black (P. alecto) Flying-fox in New South Wales. Paper presented at a workshop to assess the status of the Grey-headed Flying-fox in New South Wales, University of Sydney, Australia, G. Richards (Ed.)

Birt, P., Hall, L.S. \& Smith, G.C. 1997. Ecomorphology of the tongues of Australian Megachiroptera (Chiroptera: Pteropodidae). Australian Journal of Zoology 45(4): 369-384.

Bollen, A. \& Van Elsacker, L. 2002. Feeding ecology of Pteropus rufus (Pteropodidae) in the littoral forest of Sainte Luce, S.E. Madagascar. Acta Chiropterologica 4(1): 33-47.

Brooke, A.P. 2001. Population status and behaviours of the Samoan flying fox (Pteropus samoensis) on Tutuila Island, American Samoa. Journal of the Zoological Society of London 254(3): 309-319.

Cameron, A.T. 1947. The Taste Sense and the Relative Sweetness of Sugars and Other Sweet Substances. New York: Sugar Research Foundation, Inc.

Carroll, N. 1990. The Philosophy of Horror or Paradoxes of the Heart. New York: Routledge.

CITES. 2003 (Last Updated Oct. 16, 2003). Appendices I, II, and III. Convention on International Trade in Endangered Species of Wild Fauna and Flora. Available: www.cites.org/eng/append/appendices.shtml [Nov. 2, 2003].

Collins, L. 2000, 29th April 2000. Impact of periods of food shortage on the body weight of Grey-headed Flying Foxes. Paper presented at a workshop to assess the status of the Grey-headed Flying-Fox in New South Wales, University of Sydney, G. Richards (Ed.)

Copland, B.J. \& Whelan, R.J. 1989. Seasonal variation in flowering intensity and pollination limitation of fruit set in four co-occurring Banksia species. Journal of Ecology 77: 509-523.

Courts, S.E. 1996. An ethogram of captive Livingstone's fruit bats Pteropus livingstonii in a new enclosure at Jersey Wildlife Preservation Trust. Dodo 32: 15-37.

Courts, S.E. 1998. Dietary strategies of Old World Fruit Bats (Megachiroptera, Pteropodidae): how do they obtain sufficient protein? Mammal Review 28(4): 185-193.

Courts, S.E. 1999. Dietary studies of Livingstone's fruit bat Pteropus livingstonii: feeding behaviour, diet evaluation and modification. Dodo 35: 26-47.

Cox, P.A. 1984. Chiropterophily and ornithophily in Freycinetia (Pandanaceae) in Samoa. Plant Evolution and Systematics 144: 277-290.

Cox, P.A., Elmqvist, T., Pierson, E.D. \& Rainey, W.E. 1991. Flying foxes as strong interactors in south Pacific island ecosystems: a conservation hypothesis. Conservation Biology 5: 448-454.

Cox, P.A., Elmqvist, T., Pierson, E.D. \& Rainey, W.E. 1992. Flying foxes as pollinators and seed dispersers in Pacific Island ecosystems. Paper presented at the an international conservation conference on Pacific Island flying foxes, D.E. Wilson \& G.L. Graham (Eds.). United States Fish and Wildlife Service: Biological Report 90(23). 
Crome, F.H.J. \& Irvine, A.K. 1986. Two bob each way: the pollination and breeding system of the Australian rain forest tree Syzygium cormiflorum (Myrtaceae). Biotropica 18: 115-125.

Dempsey, J.L. \& Crissey, S.D. 1995. Nutrition. In N. Fascione (Ed.), Fruit Bat Husbandry Manual. AZA Bat Taxon Advisory Group: The Lubee Foundation Inc.

Dierenfeld, E., Dempsey, J. \& Delorme, M. No date. Eclectic chiropteran cuisine: from fruits, fish \& flowers to blood \& bugs! Available: www.riverbanks.org/battag/LINKS/nutrition.html [Jan. 12, 2003].

Dierenfeld, E.S. \& Seyjagat, J. 2000. Plasma Fat-soluble vitamin and mineral concentrations in relation to diet in captive pteropodid bats. Journal of Zoo and Wildlife Medicine 31(3): 315-321.

Duncan, A., Baker, G.B. \& Montgomer, N. 1999. The Action Plan for Australian Bats. Canberra, Australia: Environment Australia.

Eby, P. 1991. Finger-winged night workers: managing forests to conserve the role of grey-headed flying foxes as pollinators and seed dispersers. In D. Lunney (Ed.), Conservation of Australia's Forest Fauna. (pp. 91-100). Mossman: Royal Zoological Society of New South Wales.

Eby, P. 1998. An analysis of diet specialization in frugivorous Pteropus poliocephalus (Megachiroptera) in Australian subtropical rainforest. Australian Journal of Ecology 23(5): 443-456.

Elmqvist, T., Cox, P.A., Rainey, W.E. \& Pierson, E.D. 1992. Restricted pollination on oceanic islands: pollination of Ceiba pentandra by flying foxes in Samoa. Biotropica 24(1): 15-23.

Entwistle, A.C. \& Corp, N. 1997. The diet of Pteropus voeltzkowi, an endangered fruit bat endemic to Pemba Island, Tanzania. African Journal of Ecology 35: 351-360.

Erkert, H.G. 1982. Ecological aspects of bat activity rhythms. In T.H. Kunz (Ed.), Ecology of Bats (pp. 201-242). New York: Plenum Press.

Fascione, N. 1995. Fruit Bat Husbandry Manual. The Lubee Foundation, Inc. and the American Zoo and Aquarium Association Bat Taxon Advisory Group.

Fascione, N. 1996. The evolving role of American zoos in bat conservation. BATS Magazine 14(1): 8-14.

Fenton, M.B. 1992. Bats. New York: Facts on File.

Fleming, P.J.S. \& Robinson, D. 1987. Flying fox (Chiroptera: Pteropodidae) on the north coast of New South Wales: damage to stone fruit crops and control methods. Australian Mammology 10(2): 143-145.

Fleming, T.H. 1982. Foraging strategies of plant-visiting bats. In T.H. Kunz (Ed.), The Ecology of Bats (pp. 287-325). New York: Plenum Press.

Fleming, T.H. 1986. Opportunism versus specialization: the evolution of feeding strategies in frugivorous bats. In A. Estrada \& T.H. Fleming (Eds.), Frugivores and seed dispersal (pp. 105-118). Dordrecht, the Netherlands.: Dr. W Junk.

Fujita, M. 1988. Flying foxes and economics. BATS Magazine 6(1): 4-9.

Fujita, M.S. \& Tuttle, M.D. 1991. Flying foxes (Chiroptera: Pteropodidae): threatened animals of key ecological and economic importance. Conservation Biology 5(4): 455-465.

Gould, E.H. 1978. Foraging behavior of Malaysian nectar-feeding bats. Biotropica 10(3): 184-193.

Grant, G.S. 1996. Kingdom of Tonga: safe haven for flying foxes. BATS Magazine 14(2): 16-17.

Hall, L. \& Richards, G. 2000. Flying Foxes: Fruit and Blossom bats of Australia. Sydney: University of New South Wales Press.

Hall, L.S. 1987. Identification, distribution and taxonomy of Australian flying-foxes (Chiroptera Pteropodidae). Australian Mammalogy 10(2): 75-79.

Hall, L.S. 1990. Bat conservation in Australia. Australian Zoologist 26(1): 1-3.

Hall, L.S. \& Richards, G.C. 1987. Crop protection and management of flying-foxes (Chiroptera Pteropodidae). Australian Mammalogy 10(2): 137-139.

Heaney, L.R. \& Heideman, P.D. 1987. Philippine fruit bats: endangered and extinct. BATS Magazine 5(1): 3-5.

Heinrich, B. \& Raven, P.H. 1972. Energetics and pollination. Science 176: 597-602.

Heinrichs, S. \& Zahnke, K. 1997. The fruit bats of Sulawesi. BATS Magazine 15(3): 11-15.

Heithaus, E.R. 1982. Coevolution between bats and plants. In T.H. Kunz (Ed.), The Ecology of Bats (pp. 327-367). New York: Plenum Press.

Herbst, L.H. 1986. The role of nitrogen from fruit pulp in the nutrition of the frugivorous bat Carollia perspicillata. Biotropica 18: 39-44.

Herrera, L.G., LeBlanc, D. \& Nassar, J. 2000. Sugar discrimination and gustatory thresholds in captiveborn frugivorous Old World Bats. Mammalia 64(2): 135-143. 
Herrera, L.G.M. 1999. Preferences for different sugars in neotropical nectarivorous and frugivorous bats. Journal of Mammalogy 80(2): 683-688

Huber, $\quad$ R. 2001. $\quad$ Hierarchy Matrix Applet (Version 2.1) [http://caspar.bgsu.edu/ software/Java/1Hierarchy.html].

IUCN. 2002. IUCN Red List of Threatened Species. Available: www.redlist.org.

Jameson, K.A., Appleby, M.C. \& Freeman, L.C. 1999. Finding an appropriate order for a hierarchy based on probabilistic dominance. Animal Behaviour 57: 991-998.

Jones, K.E., Purvis, A., MacLarnon, A., Bininda-Emonds, O.R.P. \& Simmons, N.B. 2002. A phylogenetic supertree of the bats (Mammalia: Chiroptera). Biological Reviews 77(2): 223-159.

Jones, V. 2001. Evening drinks for grey-headed flying foxes. The Australasian Bat Society Newsletter 17: 41-42.

Korine, C., Izhaki, I. \& Arad, Z. 1999. Is the Egyptian fruit-bat Rousettus aegyptiacus a pest in Israel? An analysis of the bat's diet and implications for its conservation. Biological Conservation 88(3): 301-306.

Kunz, T.H. \& Ingalls, K.A. 1994. Folivory in bats: an adaptation derived from frugivory. Functional Ecology 8: 665-668.

Law, B. \& Lean, M. 1992. An observation of little-red flying foxes (Pteropus scapulatus) feeding on lerps. Australian Mammalogy 15: 143-144.

Law, B.S. 1993. Sugar preferences of the Queensland Blossom Bat Syconycteris australis: a pilot study. Australian Mammalogy 16(1): 17-21.

Law, B.S. 1995. The effect of energy supplementation on the local abundance of the common blossom bat, Syconycteris australis, in southern-eastern Australia. Oikos 72: 42-50.

LeBlanc, D. No date. Ten enrichment priorities for bats in captivity. Available: www.riverbanks.org/battag/links/enrichment.html [Jan. 12, 2003].

Lemke, T.O. 1986. Marianas fruit bats near extinction. BATS Magazine 3(1): 1-2.

Loebel, R. \& Sanewski, G. 1987. Flying-foxes (Chiroptera - Pteropodidae) as orchard pests. Australian Mammalogy 10(2): 147-150.

Luckhoff, H. 1987. Rearing orphan Pteropus spp. (Chiroptera: Pteropodidae) for release in the wild. Australian Mammology 10(2): 127-128.

Luft, S., Curio, E. \& Tacud, B. 2003. The use of olfaction in the foraging behaviour of the golden-mantled flying fox, Pteropus pumilus, and the greater musky fruit bat, Ptenochirus jagori (Megachiroptera: Pteropodidae). Naturwissenschaften 90(2): 84-87.

Markowitz, H. 1982. Behavioral Enrichment in the Zoo. New York: Van Nostrand Reinhold Company.

Markus, N. 2002. Behaviour of the black flying fox Pteropus alecto: 2. Territoriality and courtship. Acta Chiropterologica 4(2): 153-166.

Marshall, A.G. 1983. Bats, flowers and fruit: evolutionary relationships in the Old World. Biological Journal of the Linnean Society 20: 115-135.

Marshall, A.G. 1985. Old world phytophagous bats (Megachiroptera) and their food plants: a survey. Zoological Journal of the Linnean Society 83(4): 351-369.

Martin, L. 1999. On seasonal breeding in Australian Flying-foxes, with August observations on a maternity camp of Pteropus scapulatus in northwest Queensland. The Australasian Bat Society Newsletter 12: 5-9

Martin, L. 2002. Another squawk from The Battered Old Bent Bat - a squawk that almost wasn't. The Australasian Bat Society Newsletter 19: 29-35.

Martin, L., Kennedy, J.H., Little, L., Luckoff, H.C., O’Brien, G.M., Pow, C.S.T., Towers, P.A., Waldon, A.K. \& Wang, D.Y. 1995. The reproductive biology of Australian flying-foxes (genus Pteropus). Symposia of the Zoological Society of London 67: 167-184.

Masefield, W. 1999. Forage preferences and enrichment in a group of captive Livingstone's fruit bats Pteropus livingstonii. Dodo 35: 48-56.

Mcllwee, A.P. \& Martin, I.L. 2002. On the intrinsic capacity for increase of Australian flying-foxes (Pteropus spp Megachiroptera). Australian Zoologist 32(1): 76-100.

McWilliam, A.N. 1985-1986. The ecology of Pteropus in north-eastern New South Wales. Myotis Mitteilungsblatt Fledermaus 23-24: 201-208.

Meehan, H.J., McConkey, K.R. \& Drake, D.R. 2002. Potential disruptions to seed dispersal mutualisms in Tonga, Western Polynesia. Journal of Biogeography 29: 695-712. 
Mickleburgh, S., Hutson, A. \& Racey, P. 1992. Old World Fruit Bats: An Action Plan for their Conservation. Gland, Switzerland: The World Conservation Union (IUCN).

Morrison, D.W. 1978. Foraging ecology and energetics of the frugivorous bat, Artibeus jamaicensis. Ecology 59: 716-723.

Nelson, J.E. 1965a. Behaviour of Australian Pteropodidae (Megachiroptera). Animal Behaviour 13: 544557.

Nelson, J.E. 1965b. Movements of Australian flying foxes (Pteropodidae: Megachiroptera). Australian Journal of Zoology 13: 53-73.

Nelson, J.E. 1989. Pteropodidae. In D.W. Walton \& G.J. Richardson (Eds.), Fauna of Australia: Mammalia (Vol. 1B, pp. 836-844). Canberra: Australian Government Publishing Service.

Nelson, S.L., Miller, M.A., Heske, E.J. \& Fahey, G.C., Jr. 2000. Nutritional consequences of a change in diet from native to agricultural fruits for the Samoan fruit bat. Ecography 23(4): 393-401.

Neuweiler, G. 2000. The Biology of Bats. Oxford: Oxford University Press.

NSW National Parks and Wildlife Service. 2002. Policy for the mitigation of damage to commercial fruit crops by flying-foxes. Hurstville, NSW: NPWS.

Pallin, N. 1990. The flying foxes of Ku-ring-gai. BATS Magazine 8(2): 12-16.

Palmer, R.H. 1987. Flying-foxes (Chiroptera: Pteropodidae) in the Coffs Harbour District of New South Wales. Australian Mammalogy 10(2): 141.

Parry-Jones, K. 1987. Pteropus poliocephalus (Chiroptera - Pteropodidae) in New South Wales. Australian Mammalogy 10(2): 81-85.

Parry-Jones, K. 2000. Historical declines since the early 1900s, and current mortality factors and abundance of the Grey-headed Flying-fox in NSW. Paper presented at a workshop to assess the status of the Grey-headed Flying-fox in New South Wales, University of Sydney, Australia, G. Richards (Ed.)

Parry-Jones, K. \& Augee, M.L. 1991. Food selection by grey-headed flying-foxes (Pteropus poliocephalus) occupying a summer colony site near Gosford, New South Wales. Australian Wildlife Research 18: 111-124.

Parry-Jones, K. \& Martin, L. 1987. Open forum on movements and feeding patterns in flying-foxes (Chiroptera - Pteropodidae). Australian Mammalogy 10(2): 129-132.

Parry-Jones, K.A. \& Augee, M.L. 2001. Factors affecting the occupation of a colony site in Sydney, New South Wales by the Grey-headed Flying-fox Pteropus poliocephalus (Pteropodidae). Austral Ecology 26: 47-55.

Pate, D. 1996. Behind the scenes of the Metro Washington Park Zoo's bat exhibit. BATS Magazine 14(1): 11.

Paton, D.C. \& Turner, V. 1985. Pollination of Banksia ericifolia Smith: birds, mammals, and insects as pollen vectors. Australian Journal of Botany 33: 271-86.

Payne, N. 1984. Fruit bat off the menu? BATS Magazine 1(1): 1-2.

Pierson, E.D. 1984. Can Australia's flying foxes survive? BATS Magazine 1(3): 1-3.

Pierson, E.D. \& Rainey, W.E. 1992. The biology of flying foxes of the genus Pteropus: a review. Paper presented at the an international conservation conference on Pacific Island flying foxes, D.E. Wilson \& G.L. Graham (Eds.). US Fish and Wildlife Service: Biological Report 19(23)

Prociv, P. 1984. A protest from Australia. BATS Magazine 1(3): 3-4.

Prociv, P. \& Tracey, R.A. 1986. Faecal synthesis of vitamin $B_{12}$ in Australian Pteropus species (Chiroptera: Pteropodidae). Australian Mammalogy 10: 5-9.

Racey, P.A. \& Speakman, J.R. 1987. The energy costs of pregnancy and lactation in heterothermic bats. Symposium of the Zoological Society of London 57: 107-125.

Ratcliffe, F.N. 1931. The flying fox (Pteropus) in Australia. Bulletin of the Council for Scientific and Industrial Research Australia 53: 1-80.

Ratcliffe, F.N. 1932. Notes on the fruit bats (Pteropus spp.) of Australia. Journal of Animal Ecology 1: 3257.

Ratcliffe, F.N. 1961. Flying foxes drinking sea water. Journal of Mammalogy 42(2): 252-253.

Richards, G. \& Hall, L.S. 2000. Australia’s flying foxes at a crossroad. BATS Magazine 18(2): 5-7.

Richards, G.C. 1987. Aspects of the ecology of Spectacled Flying-foxes, Pteropus conspicillatus (Chiroptera: Pteropodidae), in tropical Queensland. Australian Mammalogy 10(2): 87-88. 
Richards, G.C. 1990. The spectacled flying-fox, Pteropus conspicillatus (Chiroptera: Pteropodidae), in north Queensland. 2. Diet, seed dispersal, and feeding ecology. Australian Mammalogy 13: 2531.

Richards, G.C. 1991. The conservation of forest bats in Australia: do we really know the problems and solutions? In D. Lunney (Ed.), Conservation of Australia's Forest Fauna (pp. 81-90). Mossman: Royal Zoological Society of NSW.

Richards, G.C. 1995. A review of ecological interactions of fruit bats in Australian ecosystems. Symposia of the Zoological Society of London 67: 79-96.

Richardson, P. 2002. Bats. Washington DC: Smithsonian Institution Press.

Ruby, J., Nathan, P.T., Balasingh, J. \& Kunz, T.H. 2000. Chemical composition of fruits and leaves eaten by short-nosed fruit bat, Cynopterus sphinx. Journal of Chemical Ecology 26(12): 2825-2841.

Shilton, L.A., Altringham, J.D., Compton, S.G. \& Whittaker, R.J. 1999. Old World fruit bats can be longdistance seed dispersers through extended retention of viable seeds in the gut. Proceedings of the Royals Society of London Series B 266(219-223).

Steller, D.C. 1986. The dietary energy and nitrogen requirements of the grey-headed flying fox, Pteropus poliocephalus (Temminck) (Megachiroptera). Australian Journal of Zoology 34: 339-349.

Stone, C. 2002-2003. Tolga Bat Hospital. Tolga Bat Hospital. Available: www.athertontablelands.com/bats [Oct. 30, 2003].

Sullivan, T.P. \& Sullivan, D.S. 1988. Influence of alternative foods on vole populations and damage in apple orchards. Wildlife Society Bulletin 16: 170-175.

Tedman, R.A. \& Hall, L.S. 1985. The morphology of the gastrointestingal tract and food transit time in the fruit bats Pteropus alecto and P. poliocephalus (Megachiroptera). Australian Journal of Zoology 33: 625-640.

Thomas, D.W. 1984. Fruit intake and energy budgets of frugivorous bats. Physiological Zoology 57(4): 457-467.

Tidemann, C.R. 1987. Notes on the flying-fox, Pteropus melanotus (Chiroptera: Pteropodidae), on Christmas Island, Indian Ocean. Australian Mammalogy 10(2): 89-91.

Tidemann, C.R., Kelson, S. \& Jamieson, G. 1997. Flying-fox damage to orchard fruit in Australia incidence, extent and economic impact. Australian Biologist 10(4): 177-184.

Tidemann, C.R. \& Nelson, J.E. 1987. Flying foxes (Chiroptera: Pteropodidae) and bananas: some interactions. Australian Mammology 10(2): 133-135.

Tidemann, C.R. \& Vardon, M.J. 1997. Pests, pestilence, pollen and protein: the need for community-based management of flying-foxes in Australia. Australian Biologist 10: 77-83.

Trewhella, W.J., Rodriguez-Clark, K.M., Davies, J.G., Reason, P.F. \& Wray, S. 2001. Sympatric fruit bat species (Chiroptera: Pteropodidae) in the Comoro Islands (Western Indian Ocean): diurnality, feeding interactions and their conservation implications. Acta Chiropterologica 3(2): 135-147.

Tudge, C. 1994. Going bats over conservation. New Scientist 1916: 27-31.

Tufto, J., Solberg, E.J. \& Ringsby, T.-H. 1998. Statistical models of transitive and intransitive dominance structures. Animal Behaviour 55: 1489-1498.

Utzurrum, R.C.B. 1995. Feeding ecology of Philippine fruit bats: patterns of resource use and seed dispersal. Symposia of the Zoological Society of London 67: 63-77.

Vardon, M.J., Simpson, B.K., Sherwell, D. \& Tidemann, C.R. 1997. Flying-foxes and tourists: a conservation dilemma in the Northern Territory. Australian Zoologist 30: 310-315.

Vaughn, T. 1989. Marine World Africa USA gets involved with bats. BATS Magazine 7(3): 14.

Wahl, D.E. 1994. The management of flying foxes (Pteropus spp.) in New South Wales. Unpublished Masters Thesis, University of Canberra, Australia.

Walton, R. \& Trowbridge, B.J. 1983. The use of radio-tracking in the studying of foraging behaviour of the Indian Flying fox (Pteropus giganteus). Journal of Zoology 201(4): 575-579.

Wendeln, M.C., Runkle, J.R. \& Kalko, E.K.V. 2000. Nutritional values of 14 fig species and bat feeding preferences in Panama. Biotropica 32(3): 489-501.

Wiles, G.J. 1990. Giving flying foxes a second chance. BATS Magazine 8(3): 3-4.

Wilson, D.E. \& Engbring, J. 1992. The flying foxes Pteropus samoensis and Pteropus tonganus: status in Fiji and Samoa. Paper presented at the an international conservation conference on Pacific Island flying foxes, D.E. Wilson \& G.L. Graham (Eds.). United States Fish and Wildlife Service: Biological Report 90(23) 


\section{APPENDIX}

Table 1.1. Demographic information on bats in Group 1.

\begin{tabular}{|l|c|l|l|}
\hline \hline Tag Colour & Sex & DOB & Participation \\
\hline Blue & M & 1989 (arr. 1991) & All \\
\hline Gold & F & 1989 (arr. 1991) & Days 1-12, 16-22 \\
\hline Green & F & Early 2002 & All \\
\hline Purple & F & 1993 & Days 1-12, 16-22 \\
\hline Red & F & 2000 & All \\
\hline Red \& Silver & F & 1998 & Days 1-12, 16-22 \\
\hline Silver & F & 1999 & Days 1-12, 16-22 \\
\hline
\end{tabular}

Table 1.2. Demographic information on bats in Group 2.

\begin{tabular}{|l|c|l|l|}
\hline \hline Tag Colour & Sex & DOB & Participation \\
\hline Blue & M & 1994 & All \\
\hline Gold & M & 1994 & $\begin{array}{l}\text { Days 1-12, Days 16- } \\
\text { 22 in Group 1 }\end{array}$ \\
\hline Green & F & 1998 & All \\
\hline Purple & M & 1992 & All \\
\hline Red & F & 1999 & Days 1-12 \\
\hline Red \& Green & F & 1993 & All \\
\hline Red \& Silver & M & 1998 & Days 1-12 \\
\hline Silver & F & 1999 & All \\
\hline Juv. Gold & F & Late 2002 & Days 1-11 \\
\hline Juv. Red & M & Late 2002 & All \\
\hline Juv. Silver & M & Late 2002 & All \\
\hline
\end{tabular}

Table 1.3. Summary of group composition and food-preference data days.

\begin{tabular}{|c|c|c|c|}
\hline \hline \multirow{2}{*}{$\begin{array}{c}\text { Group } \\
1\end{array}$} & $\begin{array}{c}\text { Number } \\
\text { (Adult [M:F]; Juvenile [M,F]) }\end{array}$ & Days & $\begin{array}{c}\text { Total } \\
\text { Days }\end{array}$ \\
\cline { 2 - 4 } & $7(6[1: 5] ; 1[0: 1])$ & $1-9,11,12$ & 11 \\
\cline { 2 - 4 } & $3(2[1: 1] ; 1[0: 1])$ & $14-15$ & 2 \\
\hline \multirow{2}{*}{$\begin{array}{c}\text { Group } \\
2\end{array}$} & $8(7[2: 5] ; 1[0: 1])$ & $16-22$ & 7 \\
\cline { 2 - 4 } & $7(5[2: 3] ; 3[2: 1])$ & $1-9,11,12$ & 11 \\
\hline
\end{tabular}

Fruit Composition:

Apples: assorted red, usually “Orchard Crisp” Sunrise \#3607

Bananas: cultivated

Figs: organic from NZ and from local yard

Grapes: "Dole” purple grapes from Chile \#4056

Mandarins: "First" Fresh New Zealand

Mangoes: "Del Monte" Philippine

Canned nectarines: "Wattie's" Nectarine Slices in Fruit Juice. Fruit was drained of juice and rinsed before being cut. No added sugar or preservatives. Fruit juice: apple or grape plus nectarine puree.

Canned mangoes: "Wattie’s" Mango Slices Lightly Sweetened in Syrup. Fruit was drained of syrup and rinsed before being cut. Syrup: water, sugar. No preservatives.

Dried figs: "Dessert Maid” Dried Figs (Tenderised). Fruit was rinsed and briefly soaked (5-20 minutes) in water before being cut. No added sugar. Preservative (202). 


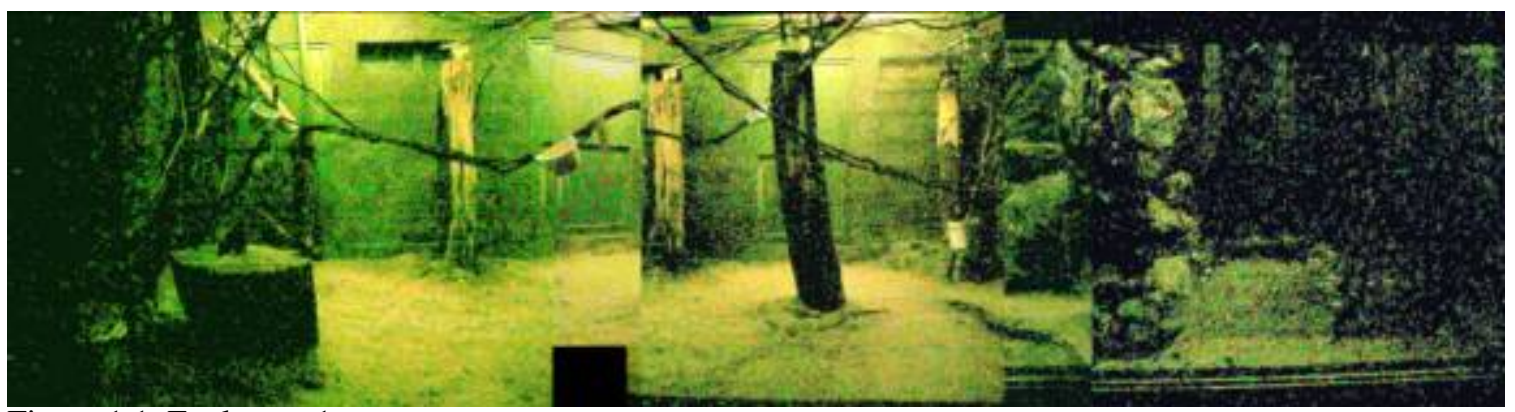

Figure 1.1. Enclosure 1.

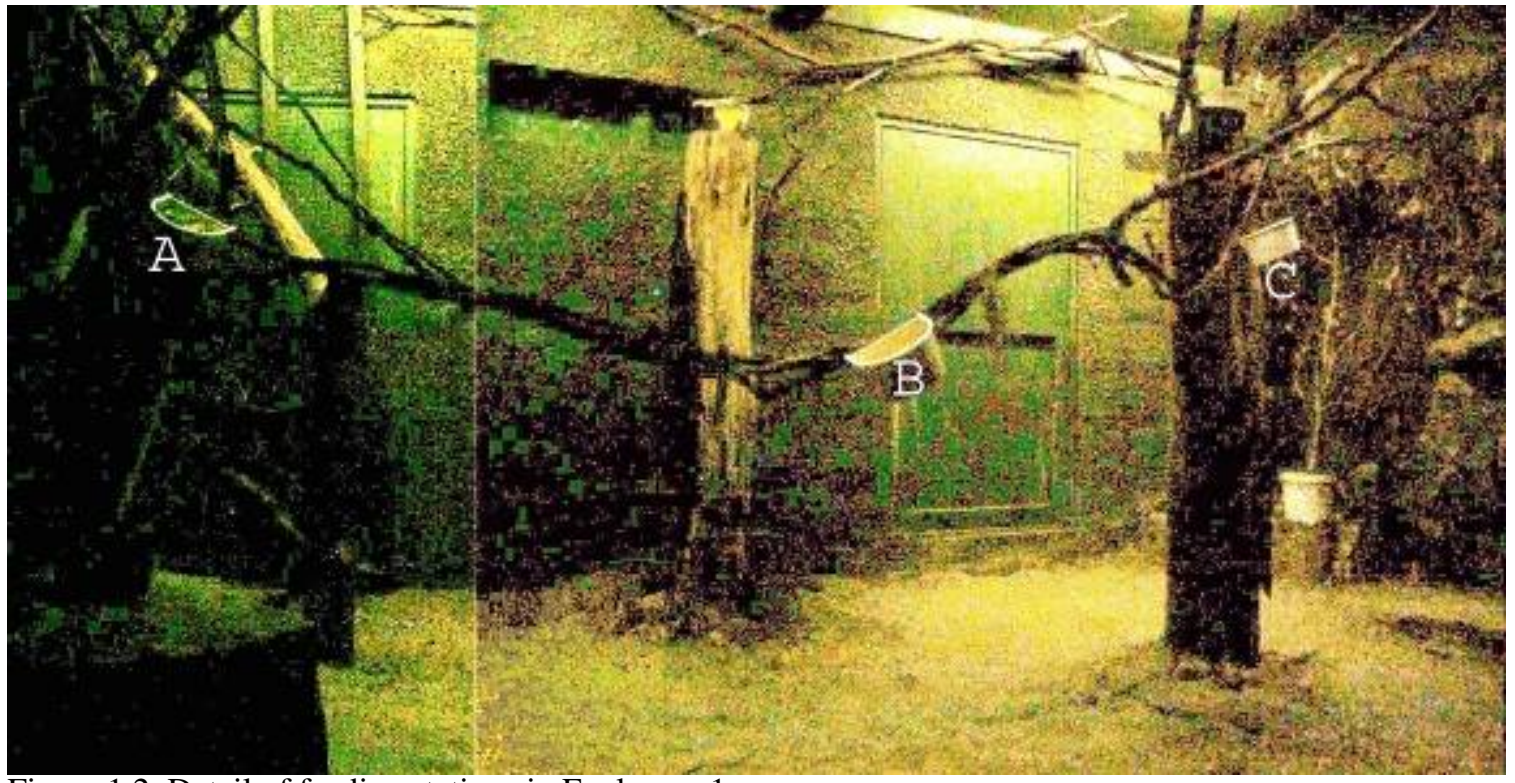

Figure 1.2. Detail of feeding stations in Enclosure 1.

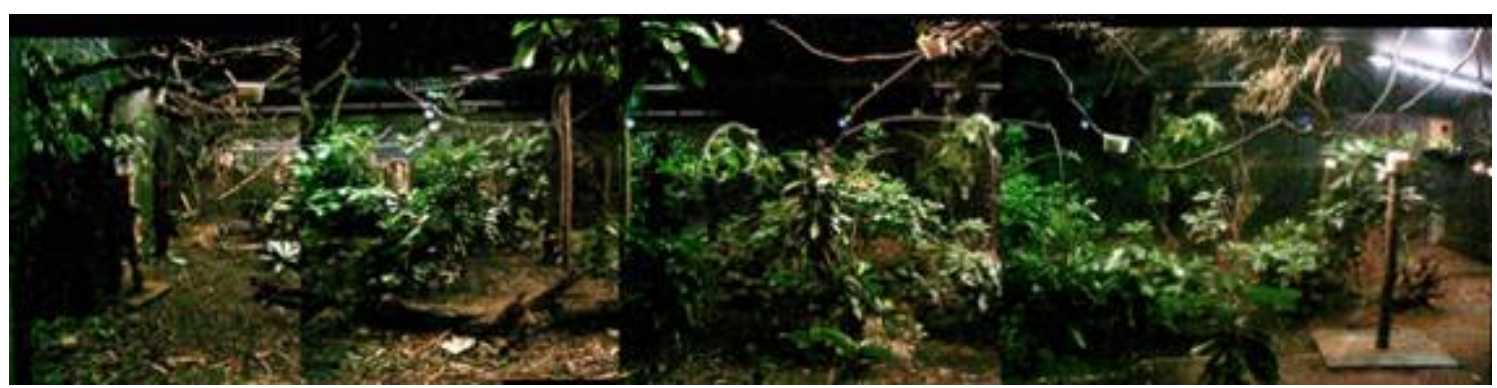

Figure 1.3. Enclosure 2.

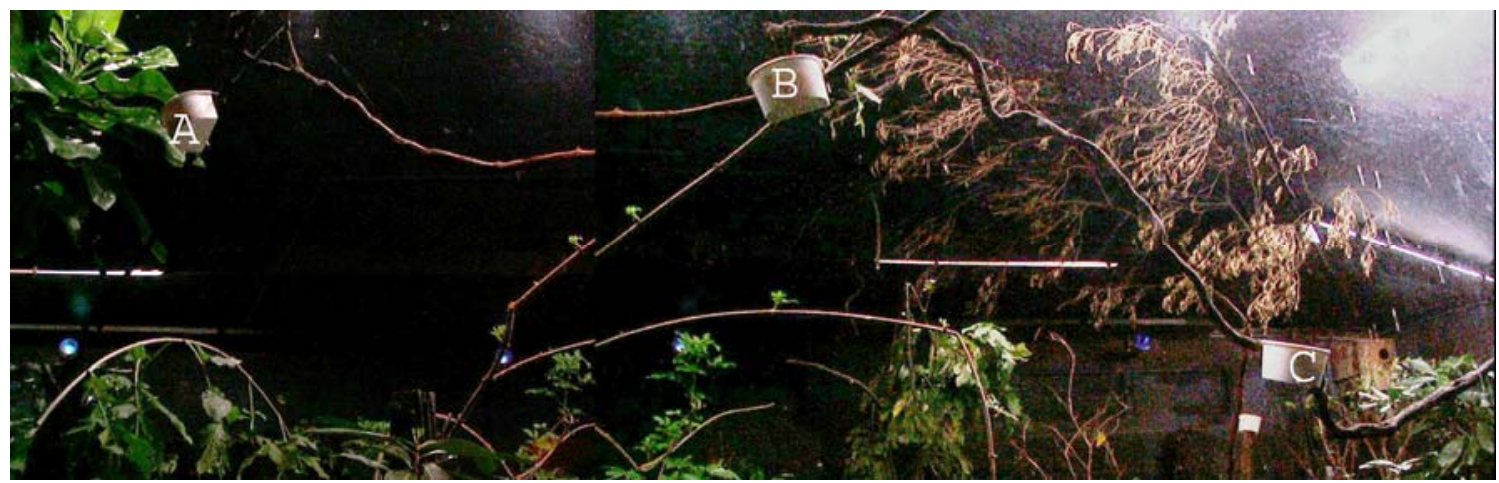

Figure 1.4. Detail of feeding stations in Enclosure 2. 
Table 2.1. Fruit and position schedule. Order indicates feeding station (ABC). $1=$ apple, $2=$ banana, $3=$ fig, 4 = grape, 5 = mandarin, 6 = mango, 7 = nectarine. Set 513 was moved from Week 3 Day 4 to Week 6 Day 3. Numbers in italics indicate that processed versions of the fruit were used. * indicates that only Group 2 was tested.

\begin{tabular}{|l|l|l|l|l|l|l|l|}
\hline \hline $\begin{array}{c}\text { Day } \\
\text { Week }\end{array}$ & 1 & 2 & 3 & 4 & 5 & 6 & 7 \\
\hline 1 & - & 157 & - & 632 & 471 & - & - \\
\hline 2 & 526 & 314 & - & 657 & 234 & - & - \\
\hline 3 & 125 & 467 & - & 513 & 742 & - & - \\
\hline 4 & 613 & $542 *$ & - & 763 & - & - & - \\
\hline 5 & 416 & 273 & - & 564 & 271 & - & - \\
\hline 6 & 345 & 126 & 513 & 735 & - & - & - \\
\hline
\end{tabular}

Table 2.3. BBS scores for fruit preference shown in Chart 2.2. "Combined" is calculated from the combined win-lose data of both groups.

\begin{tabular}{|c|c|c|c|}
\hline \hline & Group 1 & Group 2 & Combined \\
\hline Apple & -1.042 & -0.577 & -0.788 \\
\hline Banana & 0.672 & 0.901 & 0.786 \\
\hline Fig & -0.63 & -0.886 & -0.757 \\
\hline Dried Fig & 0.357 & -0.552 & -0.07 \\
\hline Grape & -0.133 & 0.645 & 0.254 \\
\hline Mandarin & 0.271 & -0.172 & 0.015 \\
\hline Mango & 0.186 & 0.168 & 0.163 \\
\hline $\begin{array}{c}\text { Canned } \\
\text { Mango }\end{array}$ & -0.393 & 0.407 & -0.014 \\
\hline Nectarine & 0.71 & 0.181 & 0.433 \\
\hline $\begin{array}{c}\text { Canned } \\
\text { Nectarine }\end{array}$ & -0.094 & -1.24 & -0.553 \\
\hline
\end{tabular}

Table 3.1. Summary of group composition and observation days.

\begin{tabular}{|c|c|c|c|}
\hline \hline & $\begin{array}{c}\text { Number } \\
\text { (Adult [M:F]; Juvenile [M:F]) }\end{array}$ & Days & Total Days \\
\hline \multirow{2}{*}{$\begin{array}{c}\text { Group } \\
1\end{array}$} & $7(6[1: 5] ; 1[0: 1])$ & $1-12$ & 12 \\
\cline { 2 - 4 } & $3(2[1: 1] ; 1[0: 1])$ & $14-15$ & 2 \\
\hline \multirow{2}{*}{$\begin{array}{c}\text { Group } \\
2\end{array}$} & $8(7[2: 5] ; 1[0: 1])$ & $16-22$ & 7 \\
\cline { 2 - 4 } & $7(8[4: 4] ; 3[2: 1])$ & $1-12$ & 12 \\
\hline
\end{tabular}


Table 3.2. Behaviours performed by Group 1 bats. Activities (average of all stations per hour) considered successful for seed dispersal are in bold; unsuccessful attempts to obtain food are in italics.

\begin{tabular}{|c|c|c|c|c|c|}
\hline $\begin{array}{l}\text { Raider } \\
\text { (BBS) }\end{array}$ & Avg/hour & Activity & $\begin{array}{l}\text { Raider } \\
\text { (BBS) }\end{array}$ & Avg/hour & Activity \\
\hline \multirow{9}{*}{$\begin{array}{c}\text { Blue } \\
(-0.202)\end{array}$} & 1.649 & Near & \multirow{9}{*}{$\begin{array}{c}\text { Gold } \\
(1.046)\end{array}$} & 0.860 & Near \\
\hline & $\mathbf{0}$ & Steal & & $\mathbf{0}$ & Steal \\
\hline & 0.0717 & No Food & & 0 & No Food \\
\hline & 0.0717 & Food & & $\mathbf{0}$ & Food \\
\hline & $\mathbf{0}$ & Ejected by other res. & & $\mathbf{0}$ & Ejected by other res. \\
\hline & 0 & Ejected by raider & & $\mathbf{0}$ & Ejected by raider \\
\hline & 0 & Distant Display & & 0 & Distant Display \\
\hline & 1.649 & Attempts/h & & 0 & Attempts/h \\
\hline & o & Success/h & & $\mathbf{0}$ & Success/h \\
\hline \multirow{9}{*}{$\begin{array}{c}\text { Green } \\
(-1.250)\end{array}$} & 1.577 & Near & \multirow{9}{*}{$\begin{array}{c}\text { Purple } \\
(0.696)\end{array}$} & 1.290 & Near \\
\hline & 0.860 & Steal & & 0.0717 & Steal \\
\hline & 2.222 & No Food & & 0 & No Food \\
\hline & 0.860 & Food & & 0.215 & Food \\
\hline & $\mathbf{0}$ & Ejected by other res. & & $\mathbf{0}$ & Ejected by other res. \\
\hline & $\mathbf{0}$ & Ejected by raider & & 0.0717 & Ejected by raider \\
\hline & 0 & Distant Display & & 0 & Distant Display \\
\hline & 3.943 & Attempts/h & & 0.358 & Attempts/h \\
\hline & 1.720 & Success/h & & 0.358 & Success/h \\
\hline \multirow{9}{*}{$\begin{array}{c}\text { Red } \\
(0.170)\end{array}$} & 0.789 & Near & \multirow{9}{*}{$\begin{array}{l}\text { Red \& } \\
\text { Silver } \\
(-0.592)\end{array}$} & 0.932 & Near \\
\hline & $\mathbf{0}$ & Steal & & $\mathbf{0}$ & Steal \\
\hline & 0.287 & No Food & & 0.573 & No Food \\
\hline & 0.215 & Food & & 0.143 & Food \\
\hline & $\mathbf{0}$ & Ejected by other res. & & $\mathbf{0}$ & Ejected by other res. \\
\hline & 0.358 & Ejected by raider & & $\mathbf{0}$ & Ejected by raider \\
\hline & 0 & Distant Display & & 0 & Distant Display \\
\hline & 0.860 & Attempts/h & & 0.717 & Attempts/h \\
\hline & 0.573 & Success/h & & 0.143 & Success/h \\
\hline \multirow{9}{*}{$\begin{array}{l}\text { Silver } \\
(1.316)\end{array}$} & 0.430 & Near & \multirow{9}{*}{ ? } & 0 & Near \\
\hline & 0 & Steal & & $\mathbf{0}$ & Steal \\
\hline & 0 & No Food & & 0.0717 & No Food \\
\hline & $\mathbf{0}$ & Food & & $\mathbf{0}$ & Food \\
\hline & $\mathbf{0}$ & Ejected by other res. & & $\mathbf{0}$ & Ejected by other res. \\
\hline & $\mathbf{0}$ & Ejected by raider & & $\mathbf{0}$ & Ejected by raider \\
\hline & 0 & Distant Display & & 0 & Distant Display \\
\hline & 0 & Attempts/h & & 0.0717 & Attempts/h \\
\hline & $\mathbf{0}$ & Success/h & & $\mathbf{0}$ & Success/h \\
\hline
\end{tabular}


Table 3.3. Behaviours performed by Group 2 bats.

\begin{tabular}{|c|c|c|c|c|c|}
\hline $\begin{array}{l}\text { Raider } \\
\text { (BBS) }\end{array}$ & Avg/hour & Activity & $\begin{array}{l}\text { Raider } \\
\text { (BBS) }\end{array}$ & Avg/hour & Activity \\
\hline \multirow{9}{*}{$\begin{array}{c}\text { Blue } \\
(0.518)\end{array}$} & 0.488 & Near & \multirow{9}{*}{$\begin{array}{c}\text { Gold } \\
(-0.395)\end{array}$} & 0.325 & Near \\
\hline & 0.0542 & Steal & & $\mathbf{0}$ & Steal \\
\hline & 1.192 & No Food & & 1.789 & No Food \\
\hline & 0.596 & Food & & 0.705 & Food \\
\hline & $\mathbf{0}$ & Ejected by other res. (Blue leaves) & & $\mathbf{0}$ & Ejected by other res. \\
\hline & $\mathbf{0}$ & Ejected by raider (Blue leaves) & & $\mathbf{0}$ & Ejected by raider \\
\hline & 0 & Distant Display (Blue deterred) & & 0.163 & Distant Display \\
\hline & 1.843 & Attempts/h & & 2.656 & Attempts/h \\
\hline & 0.650 & Success/h & & 0.705 & Success/h \\
\hline \multirow{9}{*}{$\begin{array}{c}\text { Green } \\
(0.427)\end{array}$} & 0.867 & Near & \multirow{9}{*}{$\begin{array}{c}\text { Purple } \\
\text { (1.311) }\end{array}$} & 0.434 & Near \\
\hline & $\mathbf{0}$ & Steal & & $\mathbf{0}$ & Steal \\
\hline & 0.650 & No Food & & 0.108 & No Food \\
\hline & 0.108 & Food & & $\mathbf{0}$ & Food \\
\hline & $\mathbf{0}$ & Ejected by other res. & & $\mathbf{0}$ & Ejected by other res. \\
\hline & $\mathbf{0}$ & Ejected by raider & & $\mathbf{0}$ & Ejected by raider \\
\hline & 0 & Distant Display & & 0 & Distant Display \\
\hline & 0.759 & Attempts/h & & 0.108 & Attempts/h \\
\hline & 0.108 & Success/h & & $\mathbf{0}$ & Success/h \\
\hline \multirow{9}{*}{$\begin{array}{c}\text { Red } \\
(-1.363)\end{array}$} & 0 & Near & \multirow{9}{*}{$\begin{array}{c}\text { Red \& } \\
\text { Green } \\
(-1.282)\end{array}$} & 0 & Near \\
\hline & $\mathbf{0}$ & Steal & & $\mathbf{0}$ & Steal \\
\hline & 0.488 & No Food & & 0.271 & No Food \\
\hline & $\mathbf{0}$ & Food & & $\mathbf{0}$ & Food \\
\hline & $\mathbf{0}$ & Ejected by other res. & & $\mathbf{0}$ & Ejected by other res. \\
\hline & $\mathbf{0}$ & Ejected by raider & & $\mathbf{0}$ & Ejected by raider \\
\hline & 0 & Distant Display & & 0 & Distant Display \\
\hline & 0.488 & Attempts/h & & 0.271 & Attempts/h \\
\hline & $\mathbf{0}$ & Success/h & & $\mathbf{0}$ & Success/h \\
\hline \multirow{9}{*}{$\begin{array}{c}\text { Red \& } \\
\text { Silver } \\
(-1.290)\end{array}$} & 0.0542 & Near & \multirow{9}{*}{$\begin{array}{l}\text { Silver } \\
(-0.202)\end{array}$} & 1.409 & Near \\
\hline & $\mathbf{0}$ & Steal & & $\mathbf{0}$ & Steal \\
\hline & 2.547 & No Food & & 0.434 & No Food \\
\hline & 0.759 & Food & & 0.488 & Food \\
\hline & $\mathbf{0}$ & Ejected by other res. & & $\mathbf{0}$ & Ejected by other res. \\
\hline & $\mathbf{0}$ & Ejected by raider & & $\mathbf{0}$ & Ejected by raider \\
\hline & 0.163 & Distant Display & & 0.271 & Distant Display \\
\hline & 3.469 & Attempts/h & & 1.192 & Attempts/h \\
\hline & 0.759 & Success/h & & 0.488 & Success/h \\
\hline \multirow{9}{*}{$\begin{array}{l}\text { Juv. } \\
\text { Gold }\end{array}$} & 0 & Near & \multirow{9}{*}{$\begin{array}{l}\text { Juv. } \\
\text { Red }\end{array}$} & 1.518 & Near \\
\hline & $\mathbf{0}$ & Steal & & 0.0542 & Steal \\
\hline & 0.217 & No Food & & 0.867 & No Food \\
\hline & 0.163 & Food & & 0.0542 & Food \\
\hline & $\mathbf{0}$ & Ejected by other res. & & $\mathbf{0}$ & Ejected by other res. \\
\hline & $\mathbf{0}$ & Ejected by raider & & $\mathbf{0}$ & Ejected by raider \\
\hline & 0 & Distant Display & & 0.108 & Distant Display \\
\hline & 0.379 & Attempts/h & & 1.084 & Attempts/h \\
\hline & 0.163 & Success/h & & 0.108 & Success/h \\
\hline
\end{tabular}




\begin{tabular}{|c|c|c|c|c|c|}
\hline \multirow{9}{*}{$\begin{array}{c}\text { Juv. } \\
\text { Silver } \\
(-1.376)\end{array}$} & 0.488 & Near & \multirow{9}{*}{ ? } & 0 & Near \\
\hline & 0.271 & Steal & & 0 & Steal \\
\hline & 4.824 & No Food & & 1.789 & No Food \\
\hline & 1.355 & Food & & 0.596 & Food \\
\hline & o & Ejected by other res. & & o & Ejected by other res. \\
\hline & $\mathbf{0}$ & Ejected by raider & & $\mathbf{0}$ & Ejected by raider \\
\hline & 0.271 & Distant Display & & 0.108 & Distant Display \\
\hline & 6.721 & Attempts/h & & 2.493 & Attempts/h \\
\hline & 1.626 & Success/h & & 0.596 & Success/h \\
\hline
\end{tabular}

Table 3.4. Percent of attempted and successful raids performed by individual Group 1 bats.

\begin{tabular}{|l|r|r|}
\hline \hline & Attempted & Successful \\
\hline Blue & 2.35 & 2.50 \\
\hline Gold & 0 & 0 \\
\hline Green & 64.71 & 60.00 \\
\hline Purple & 5.88 & 12.50 \\
\hline Red & 14.12 & 20.00 \\
\hline Red \& Silver & 11.76 & 5.00 \\
\hline Silver & 0 & 0 \\
\hline$?$ & 1.18 & 0 \\
\hline
\end{tabular}

Table 3.5. Percent of attempted and successful raids performed by individual Group 2 bats.

\begin{tabular}{|l|c|c|}
\hline \hline & Attempted & Successful \\
\hline Blue & 8.56 & 12.37 \\
\hline Gold & 12.34 & 13.40 \\
\hline Green & 3.53 & 2.06 \\
\hline Purple & 0.5 & 0 \\
\hline Red & 2.27 & 0 \\
\hline Red \& Green & 1.26 & 0 \\
\hline Red \& Silver & 16.12 & 14.43 \\
\hline Silver & 5.54 & 9.28 \\
\hline Juv. Gold & 1.76 & 3.09 \\
\hline Juv. Red & 5.04 & 2.06 \\
\hline Juv. Silver & 31.24 & 30.93 \\
\hline ? & 11.84 & 12.37 \\
\hline
\end{tabular}

Table 3.6. Results of $t$ tests comparing the rates of attempted raids/h and of attempted raids/h/extra bat in Group 1 when group size was changed. No comparisons were significant.

\begin{tabular}{|l|l|l|}
\hline \hline & Reduced $(N=3)$ & Augmented $(N=8)$ \\
\hline Baseline $(N=7)$ & $t(12)=1.73 \mathrm{NS}$ & $t(17)=1.44 \mathrm{NS}$ \\
\hline Reduced $(N=3)$ & - & $t(7)=1.69 \mathrm{NS}$ \\
\hline & Reduced $\left(N_{\text {extra }}=0\right)$ & Augmented $\left(N_{\text {extra }}=5\right)$ \\
\hline Baseline $\left(N_{\text {extra }}=4\right)$ & $t(12)=1.73 \mathrm{NS}$ & $t(17)=1.81 \mathrm{NS}$ \\
\hline Reduced $\left(N_{\text {extra }}=0\right)$ & - & $t(7)=1.69 \mathrm{NS}$ \\
\hline
\end{tabular}


Table 3.7. Group 1 ( $N=7$ ) event counts (events/hour) at each feeding station over 358 minutes.

\begin{tabular}{|c|c|c|c|l|}
\hline \hline A & B & C & Average & Event \\
\hline $68(11.4)$ & $194(32.5)$ & $94(15.8)$ & $118.6(19.9)$ & No Bat \\
\hline $210(35.2)$ & $148(24.8)$ & $195(32.7)$ & $184.3(30.9)$ & Resident Only \\
\hline $72(12.1)$ & $12(2.0)$ & $23(3.9)$ & $35.6(6.0)$ & Near \\
\hline $\mathbf{3 ( 0 . 5 )}$ & $\mathbf{0 ( 0 )}$ & $\mathbf{1 0 ( 1 . 7 )}$ & $\mathbf{4 . 3 ( 0 . 7 )}$ & Steal \\
\hline $21(3.5)$ & $3(0.5)$ & $22(3.7)$ & $15.3(2.6)$ & Ejected (no food) \\
\hline $\mathbf{4 ( 0 . 7 )}$ & $\mathbf{1 ( 0 . 2 )}$ & $\mathbf{1 6 ( 2 . 7 )}$ & $\mathbf{7 . 0 ( 1 . 2 )}$ & Ejected (food) \\
\hline $\mathbf{1 ( 0 . 2 )}$ & $\mathbf{0 ( 0 )}$ & $\mathbf{4 ( 0 . 7 )}$ & $\mathbf{1 . 7 ( 0 . 3 )}$ & Resident Ejected (by raider) \\
\hline $\mathbf{1 ( 0 . 2}$ & $\mathbf{0 ( 0 )}$ & $\mathbf{0 ( 0 )}$ & $\mathbf{0 . 3 ( 0 . 0 6 )}$ & Resident Ejected (by resident) \\
\hline $0(0)$ & $0(0)$ & $0(0)$ & $0(0)$ & Distant Display \\
\hline $\mathbf{0 ( 0 )}$ & $\mathbf{0 ( 0 )}$ & $\mathbf{0 ( 0 )}$ & $\mathbf{0 ( 0 )}$ & Mobbing x 2 \\
\hline $21(3.5)$ & $3(0.5)$ & $22(3.7)$ & $15.3(2.6)$ & Non-successful Attempts \\
\hline $\mathbf{9 ( 1 . 5 )}$ & $\mathbf{1 ( 0 . 2 )}$ & $\mathbf{3 0 ( 5 . 0 )}$ & $\mathbf{1 3 . 3 ( 2 . 2 )}$ & Successful Attempts \\
\hline $30.0 \%$ & $25.0 \%$ & $57.7 \%$ & $46.5 \%$ & \% Success \\
\hline
\end{tabular}

Table 3.8. Group $1(N=3)$ event counts (events/hour) at each feeding station over 62 minutes.

\begin{tabular}{|c|c|c|c|l|}
\hline A & B & C & Average & Event \\
\hline $39(37.7)$ & $62(60.0)$ & $56(54.2)$ & $52.3(50.6)$ & No Bat \\
\hline $19(18.4)$ & $0(0)$ & $6(5.8)$ & $8.3(8.1)$ & Resident Only \\
\hline $4(3.9)$ & $0(0)$ & $0(0)$ & $0(0)$ & Near \\
\hline $\mathbf{0}(\mathbf{0})$ & $\mathbf{0 ( 0 )}$ & $\mathbf{0 ( 0 )}$ & $\mathbf{0 ( 0 )}$ & Steal \\
\hline $0(0)$ & $0(0)$ & $0(0)$ & $0(0)$ & Ejected (no food) \\
\hline $\mathbf{0 ( 0 )}$ & $\mathbf{0 ( 0 )}$ & $\mathbf{0 ( 0 )}$ & $\mathbf{0 ( 0 )}$ & Ejected (food) \\
\hline $\mathbf{0}(\mathbf{0})$ & $\mathbf{0 ( 0 )}$ & $\mathbf{0 ( 0 )}$ & $\mathbf{0 ( 0 )}$ & Resident Ejected (by raider) \\
\hline $\mathbf{0 ( 0 )}$ & $\mathbf{0 ( 0 )}$ & $\mathbf{0 ( 0 )}$ & $\mathbf{0 ( 0 )}$ & Resident Ejected (by resident) \\
\hline $0(0)$ & $0(0)$ & $0(0)$ & $0(0)$ & Distant Display \\
\hline $\mathbf{0 ( 0 )}$ & $\mathbf{0 ( 0 )}$ & $\mathbf{0 ( 0 )}$ & $\mathbf{0 ( 0 )}$ & Mobbing x 2 \\
\hline $0(0)$ & $0(0)$ & $0(0)$ & $0(0)$ & Non-successful Attempts \\
\hline $\mathbf{0 ( 0 )}$ & $\mathbf{0 ( 0 )}$ & $\mathbf{0 ( 0 )}$ & $\mathbf{0 ( 0 )}$ & Successful Attempts \\
\hline $0.0 \%$ & $0.0 \%$ & $0.0 \%$ & $0.0 \%$ & \% Success \\
\hline & & & &
\end{tabular}

Table 3.9. Group $1(N=8)$ event counts (events/hour) at each feeding station over 213 minutes.

\begin{tabular}{|c|c|c|c|l|}
\hline \hline A & B & C & Average & Event \\
\hline $45(12.7)$ & $177(49.9)$ & $107(30.1)$ & $109.7(30.9)$ & No Bat \\
\hline $109(30.7)$ & $33(9.3)$ & $76(21.4)$ & $72.7(20.5)$ & Resident Only \\
\hline $71(20.0)$ & $6(1.7)$ & $28(7.9)$ & $35.0(9.9)$ & Near \\
\hline $\mathbf{1 ( 0 . 3 )}$ & $\mathbf{0 ( 0 . 0 )}$ & $\mathbf{0 ( 0 . 0 )}$ & $\mathbf{0 . 3 ( 0 . 0 9 )}$ & Steal \\
\hline $7(2.0)$ & $0(0.0)$ & $4(1.1)$ & $3.7(1.0)$ & Ejected (no food) \\
\hline $\mathbf{2 ( 0 . 6 )}$ & $\mathbf{1 ( 0 . 3 )}$ & $\mathbf{1 ( 0 . 3 )}$ & $\mathbf{1 . 3 ( 0 . 4 )}$ & Ejected (food) \\
\hline $\mathbf{4 ( 1 . 1 )}$ & $\mathbf{0 ( 0 . 0 )}$ & $\mathbf{1 ( 0 . 3 )}$ & $\mathbf{1 . 7 ( 0 . 5 )}$ & Resident Ejected (by raider) \\
\hline $\mathbf{5 ( 1 . 4 )}$ & $\mathbf{0 ( 0 . 0 )}$ & $\mathbf{0 ( 0 . 0 )}$ & $\mathbf{1 . 7 ( 0 . 5 )}$ & Resident Ejected (by resident) \\
\hline $0(0.0)$ & $0(0.0)$ & $1(0.3)$ & $0.3(0.9)$ & Distant Display \\
\hline $\mathbf{0 ( 0 . 0 )}$ & $\mathbf{0 ( 0 . 0 )}$ & $\mathbf{0 ( 0 . 0 )}$ & $\mathbf{0 ( 0 )}$ & Mobbing x 2 \\
\hline $7(2.0)$ & $0(0.0)$ & $5(1.4)$ & $4.0(1.1)$ & Non-successful Attempts \\
\hline $\mathbf{1 2 ( 3 . 4 )}$ & $\mathbf{1 ( 0 . 3 )}$ & $\mathbf{2 ( 0 . 6 )}$ & $\mathbf{5 . 0 ( 1 . 4 )}$ & Successful Attempts \\
\hline $63.2 \%$ & $100.0 \%$ & $28.6 \%$ & $55.5 \%$ & \% Success \\
\hline
\end{tabular}


Table 3.10. Group $2(N=11)$ event counts (events/hour) at each feeding station over 369 minutes.

\begin{tabular}{|c|c|c|c|l|}
\hline \hline A & B & C & Average & Event \\
\hline $29(4.7)$ & $77(12.5)$ & $26(4.2)$ & $44.0(7.2)$ & No Bat \\
\hline $148(24.1)$ & $156(25.4)$ & $239(38.9)$ & $181.0(29.4)$ & Resident Only \\
\hline $17(2.8)$ & $43(7.0)$ & $38(6.2)$ & $32.7(5.3)$ & Near \\
\hline $\mathbf{5 ( 0 . 8 )}$ & $\mathbf{0 ( 0 . 0 )}$ & $\mathbf{3 ( 0 . 5 )}$ & $\mathbf{2 . 6 ( 0 . 4 )}$ & Steal \\
\hline $137(22.3)$ & $95(14.4)$ & $51(8.3)$ & $94.3(15.3)$ & Ejected (no food) \\
\hline $\mathbf{6 8 ( 1 1 . 1 )}$ & $\mathbf{1 2 ( 2 . 0 )}$ & $\mathbf{9 ( 1 . 5 )}$ & $\mathbf{2 9 . 7 ( 4 . 8 )}$ & Ejected (food) \\
\hline $\mathbf{1 1 ~ ( 1 . 8 )}$ & $\mathbf{7 ( 1 . 1 )}$ & $\mathbf{1 ( 0 . 2 )}$ & $\mathbf{6 . 3 ( 1 . 0 )}$ & Resident Ejected (by raider) \\
\hline $\mathbf{2 ( 0 . 3 )}$ & $\mathbf{0 ( 0 . 0 )}$ & $\mathbf{3 ( 0 . 5 )}$ & $\mathbf{1 . 7 ( 0 . 3 )}$ & Resident Ejected (by resident) \\
\hline $7(1.1)$ & $6(1.0)$ & $7(1.1)$ & $6.7(1.1)$ & Distant Display \\
\hline $\mathbf{2 ( 0 . 3 )}$ & $\mathbf{8 ( 1 . 3 )}$ & $\mathbf{0 ( 0 . 0 )}$ & $\mathbf{3 . 3 ( 0 . 5 )}$ & Mobbing x 2 \\
\hline $144(23.4)$ & $101(16.4)$ & $58(9.4)$ & $101(16.4)$ & Non-successful Attempts \\
\hline $\mathbf{8 8 ( 1 4 . 3 )}$ & $\mathbf{2 7 ( 4 . 4 )}$ & $\mathbf{1 6 ( 2 . 6 )}$ & $\mathbf{4 3 . 7 ( 7 . 1 )}$ & Successful Attempts \\
\hline $37.9 \%$ & $21.1 \%$ & $21.6 \%$ & $30.2 \%$ & \% Success \\
\hline
\end{tabular}

Table 3.11. Group 2 ( $N=7$ ) event counts (events/hour) at each feeding station over 279 minutes.

\begin{tabular}{|c|c|c|c|l|}
\hline \hline A & B & C & Average & Event \\
\hline $37(8.0)$ & $47(10.1)$ & $86(18.5)$ & $56.7(12.2)$ & No Bat \\
\hline $128(27.5)$ & $97(20.9)$ & $126(27.1)$ & $117.0(25.2)$ & Resident Only \\
\hline $3(0.6)$ & $80(17.2)$ & $25(5.4)$ & $36.0(7.7)$ & Near \\
\hline $\mathbf{1 2 ( 1 . 6 )}$ & $\mathbf{3 ( 0 . 6 )}$ & $\mathbf{7 ( 1 . 5 )}$ & $\mathbf{7 . 3 ( 1 . 6 )}$ & Steal \\
\hline $79(17.0)$ & $72(15.5)$ & $25(5.4)$ & $58.7(12.6)$ & Ejected (no food) \\
\hline $\mathbf{4 2 ( 9 . 0 )}$ & $\mathbf{9 ( 1 . 9 )}$ & $\mathbf{9 ( 1 . 9 )}$ & $\mathbf{2 0 . 0 ( 4 . 3 )}$ & Ejected (food) \\
\hline $\mathbf{1 ( 0 . 2 )}$ & $\mathbf{1 1 ( 2 . 4 )}$ & $\mathbf{8 ( 1 . 7 )}$ & $\mathbf{6 . 7 ( 1 . 4 )}$ & Resident Ejected (by raider) \\
\hline $\mathbf{0 ( 0 . 0 )}$ & $\mathbf{2 ( 0 . 4 )}$ & $\mathbf{0 ( 0 . 0 )}$ & $\mathbf{0 . 7 ( 0 . 1 )}$ & Resident Ejected (by resident) \\
\hline $10(2.2)$ & $4(0.9)$ & $5(1.1)$ & $6.3(1.4)$ & Distant Display \\
\hline $\mathbf{0 ( 0 . 0 )}$ & $\mathbf{0 ( 0 . 0 )}$ & $\mathbf{0 ( 0 . 0 )}$ & $\mathbf{0 ( 0 . 0 )}$ & Mobbing x 2 \\
\hline $89(19.1)$ & $76(14.3)$ & $30(6.5)$ & $65.0(14.0)$ & Non-successful Attempts \\
\hline $\mathbf{5 5 ( 1 1 . 8 )}$ & $\mathbf{2 5 ( 5 . 4 )}$ & $\mathbf{2 4 ( 5 . 2 )}$ & $\mathbf{3 4 . 7 ( 7 . 5 )}$ & Successful Attempts \\
\hline $38.2 \%$ & $24.8 \%$ & $44.4 \%$ & $34.8 \%$ & \% Success \\
\hline
\end{tabular}

Table 4.1. Interaction outcomes in Group 2. Outcomes to the right and below of the dotted lines were not included in analysis for Chart 4.2.

\begin{tabular}{|c|c|c|c|c|c|c|c|c|c|c|c|c|c|}
\hline \multirow[b]{2}{*}{ Winner } & \multicolumn{12}{|c|}{ Loser } & \multirow{2}{*}{$\begin{array}{l}\text { Total } \\
\text { Wins }\end{array}$} \\
\hline & Purple & Blue & Green & Silver & Gold & $\begin{array}{l}\text { Red \& } \\
\text { Green }\end{array}$ & $\begin{array}{l}\text { Red \& } \\
\text { Silver }\end{array}$ & Red & \begin{tabular}{|c|} 
Juv. \\
Silver
\end{tabular} & \begin{tabular}{|l} 
Juv. \\
Red
\end{tabular} & \begin{tabular}{|l} 
Juv. \\
Gold
\end{tabular} & ID? & \\
\hline Purple & - & 32 & 15 & 14 & 32 & 2 & 32 & 4 & 54 & 18 & 6 & 9 & 218 \\
\hline Blue & 3 & - & 9 & 5 & 17 & 3 & 12 & 2 & 23 & 2 & 0 & 11 & 87 \\
\hline Green & 1 & 8 & - & 4 & 7 & 0 & 16 & 4 & 13 & 3 & 0 & 14 & 70 \\
\hline Silver & 0 & 0 & 0 & - & 0 & 0 & 3 & 1 & 21 & 1 & 0 & 3 & 29 \\
\hline Gold & 0 & 0 & 2 & 2 & - & 0 & 8 & 1 & 30 & 1 & 2 & 15 & 61 \\
\hline Red \& Green & 0 & 0 & 0 & 0 & 0 & - & 0 & 0 & 0 & 0 & 0 & 1 & 1 \\
\hline Red \& Silver & 0 & 0 & 0 & 0 & 0 & 0 & - & 0 & 0 & 0 & 0 & 0 & 0 \\
\hline Red & 0 & 0 & 0 & 0 & 0 & 0 & 1 & - & 1 & 0 & 0 & 0 & 2 \\
\hline Juv. Silver & 0 & 0 & 0 & 0 & 0 & 0 & 1 & 0 & - & 0 & 0 & 0 & 1 \\
\hline Juv. Red & 0 & 6 & 0 & 1 & 2 & 0 & 15 & 2 & 5 & - & 0 & 6 & 36 \\
\hline Juv. Gold & 0 & 0 & 0 & 0 & 0 & 0 & 0 & 0 & 0 & 0 & - & 0 & 0 \\
\hline ID? & 0 & 0 & 0 & 0 & 0 & 0 & 0 & 0 & 0 & 0 & 0 & - & 0 \\
\hline Total Losses & 4 & 46 & 26 & 26 & 58 & 5 & 88 & 13 & 147 & 25 & 8 & 59 & \\
\hline
\end{tabular}


Table 4.2. Interaction outcomes in Group 1.

\begin{tabular}{|c|c|c|c|c|c|c|c|c|}
\hline \hline \multirow{2}{*}{ Winner } & \multicolumn{7}{|c|}{ Loser } & Total \\
\cline { 2 - 9 } & Silver & Gold & Purple & Red & Blue & $\begin{array}{c}\text { Red \& } \\
\text { Silver }\end{array}$ & Green & Wins \\
\hline Silver & - & 0 & 3 & 7 & 0 & 7 & 19 & 36 \\
\hline Gold & 0 & - & 1 & 2 & 2 & 3 & 14 & 22 \\
\hline Purple & 0 & 1 & - & 2 & 0 & 0 & 9 & 12 \\
\hline Red & 0 & 0 & 0 & - & 2 & 3 & 12 & 17 \\
\hline Blue & 0 & 0 & 0 & 0 & - & 0 & 5 & 5 \\
\hline $\begin{array}{c}\text { Red \& } \\
\text { Silver }\end{array}$ & 0 & 0 & 0 & 1 & 0 & - & 2 & 3 \\
\hline Green & 0 & 0 & 0 & 0 & 0 & 0 & - & 0 \\
\hline $\begin{array}{c}\text { Total } \\
\text { Losses }\end{array}$ & 0 & 1 & 4 & 12 & 4 & 13 & 61 & \\
\hline
\end{tabular}

